\title{
Persistence behavior of chronic low back pain patients : a medical psychological study
}

Citation for published version (APA):

Schmidt, A. J. M. (1986). Persistence behavior of chronic low back pain patients : a medical psychological study. [Doctoral Thesis, Maastricht University]. Rijksuniversiteit Limburg. https://doi.org/10.26481/dis.19861114as

Document status and date:

Published: 01/01/1986

DOI:

10.26481/dis.19861114as

Document Version:

Publisher's PDF, also known as Version of record

\section{Please check the document version of this publication:}

- A submitted manuscript is the version of the article upon submission and before peer-review. There can be important differences between the submitted version and the official published version of record. People interested in the research are advised to contact the author for the final version of the publication, or visit the DOI to the publisher's website.

- The final author version and the galley proof are versions of the publication after peer review.

- The final published version features the final layout of the paper including the volume, issue and page numbers.

Link to publication

\footnotetext{
General rights rights.

- You may freely distribute the URL identifying the publication in the public portal. please follow below link for the End User Agreement:

www.umlib.nl/taverne-license

Take down policy

If you believe that this document breaches copyright please contact us at:

repository@maastrichtuniversity.nl

providing details and we will investigate your claim.
}

Copyright and moral rights for the publications made accessible in the public portal are retained by the authors and/or other copyright owners and it is a condition of accessing publications that users recognise and abide by the legal requirements associated with these

- Users may download and print one copy of any publication from the public portal for the purpose of private study or research.

- You may not further distribute the material or use it for any profit-making activity or commercial gain

If the publication is distributed under the terms of Article $25 \mathrm{fa}$ of the Dutch Copyright Act, indicated by the "Taverne" license above, 


\title{
PERSISTENCE BEHAVIOR OF CHRONIC LOW BACK PAIN PATIENTS
}

\section{A Medical Psychological Study}

\begin{abstract}
PRDEF SCHR IF T
ter verkrijging wan de grasd van doctor in de geneeskunde

aen de Rijksuniversiteit Limburg te Masstricht, op gezag van de Rector Magnificus, Prof. Dr. F.I.M. Bonke, valgens het besluit van het College van Dekanen, in het openbaar te verdedigen op wrijdag 14 november 1986 , des namiddags om 16.00 uur
\end{abstract}

door

Antonius Johannes Martinus Schmidt

geboren te 's Gravenhage in 1946 
PERSISTENCE BEHAVIOR OF

CHRONIC LOW BACK PAIN PATIENTS

A Medical Psychological Study 

Promotor: Prof. Dr. J.J.C.B. Bremer

Referenten: Prof. Dr. A.J. van der Linden

Prof. Dr. L.J. Menges

Prof. Dr. R.S. Reneman 
Manuscript: Isel van Noppen

Ontwerp omslag: Hanny Keljsers

Druk: Ben Meersted 
1. Introduction 3

1.1. Benign chronic low back pain 3

1.2. The concept of chranicity 4

1.3. Chronic pain vs acute pain 5

2. Some epidemiological aspects of CLBP 9

2.1. Prevention and course 9

2. 2. Risk factors 10

3. Psychollogy and CLBP 13

3.1. Intraduction 13

3.2. The psychological assessment of the CLBP-patient 13

3.3. Psychological theories concerning CLBP 16

3.3.1. The operant approach to chronic pain 17

3.3.2. The cognitive approach to chronic pain 19

4. Summary and conclusions 35

4.1. Summary 35

4.2. Conclusions 37

5. Statement of the problem 41

6. Cognitive factors in the performance level of chronic low back pain patients

7. Performance level of chronic low back pain patienta in different treadmill test conditions

8. Persistence behavior of chronic low back pain patienta in treadmill test conditions with false and adequate feedback 
9.1. Persistence behavior of chronic low back pain patients in an acute pain situation

9.2. Persistence behavior of chronic low back pain patients in a non-pain eliciting test situation

10. General conclusions

11. Diagnostic and therapeutic consequences

Summary

Samenvatting

References

Acknowledgements

Curriculum Vitae 


\section{INTRODUCTION}

\subsection{Benign chronic low back pein}

This study deals with chronic low back pain (CLBP) which is also called lumbosacral pain and is localized in the center of the back in the region of the lumbal spine, the os sacrum and the gluteus musculature. These pain complaints can occur with or without a clear somatio etiology. The following are considered to fall under the heading of somatic etiology: "ankylosing spondylitis, cancer and spinal infections, as well as referred pain from the urinary tract and intestine and pelvic argans. Such conditions are comparatively rare and their exclusion can usually be made by a careful history and clinical examination" (Anderson, 1981).

This study is limited to the so-called benign chronic low back pain syndrome. Within this syndrome a distinction is made between the severity of the objective, somatic findings and the severity of the complaints: the somatic explanation of the alinical picture must be qualified as inadequate (Nachemson, 1979). Possibly somatic deviations cannot be demonstrated. Because of this somatic obscurity, CLBP is seen as a symptom of many different illnesses (Flor and Turk, 1984):

- degenerative disorders: spondylosis (progressive degeneration of the intervertebral disc), osteoarthritis (degenerative disease of the spinal joint cartilage), aacralization or lumbalization (abnormal fusion of vertebrae) and spondylolisthesis (forward shift of one vertebra on another).

- structural abnormalities: congenital or acquired, including traumatic injury and occupational factors.

- muscular and ligamentous dysfunctions: fibrositis (inflammation of paravertebral muscle tissue) or 1igamentous ruptures; muscle spasms of underexercised muscles and muscular atrophy and degeneration of muscle fibers in hypertenaive trepezius muscles.

- traumatic injury and occupational factors.

After reviewing the scientific research, Flor and Turk concluded, however, that no direct causal relationghips can be made between the aforementioned illnesses and the prevention of CLBP. In support of 
this assertion they present the following arguments:

- If a specific somatic illness coincides with CLBP in only a small percentage of the patients, this 11 lness cannot be considered to be the cause.

- If no difference in the incidence of a particular somatic deviation can be demongtrated between a CLBP group and a non-CLBP control group, this deviation cannot be considered to be the cause of CLBP.

- If several studies disagree with respect to the relation between a certain somatic illness and CLBP, no causal relationship can be infered.

- The conclusion that causal relationships exist can never be based on studies that are hampered by methodological problems.

In full agreement with him, Flor and Turk quote the following strong statement by Nachemson (1979): "Having been engaged in research in this field for nearly 25 years and having been clincially engaged in back problems for nearly the same period of time, and as a member and scientific adviser to severel internationel beck essociations, I can only state that for the majority of our patients, the true cause of low back pain is unknown."

It appears from a recent study by Vällfors (1985) that despite a very carefully described and standardized clinical examination, no objective findings were found for $70 \%$ of a group of ClBP patients $(N=70)$. It is therefore not surprising that the diagnosis made for 50-90\% of the CLBP patients is not explanatory, but a description of symptoms (Benn * Wood, 1975).

\subsection{The concept of chroniclty}

In the literature on pain, chronicity is usually defined in terms of the duration of the complaints. In genera1, a period of at least six months is used. Exceptions to the six month criterion are, however, regularly found. In a study by Carron et al. (1985), a lower limit of three months was used, while he sti1l speaks of CLBP. White (1966) even used period of six weeks. Anderson et al. (1984), on the other hand, used a period of at least one year as a criterion for chronic pain. It can be stated that the lower limit of six months is rather 
arbitrary and that it has not been establighed in the literature on pain. Chronicity refers to a more or less stabilized or crystallized situation. It is assumed that in the case of CLBP this situation is reached in the sixth month of the history of the illness. - It is not evident, however, to what extent the complaints had not stabilized a few months earlier as the researchers who use the three month criterion apparently assume.

Research data on this point are also lacking. In fact, the observed spread in the determination of a lower limit for chronicity reflects the lack of knowledge that exists with respect to the transition between acute and chronic. The category "subacute" which was introduced to define the transition between acute and chronic (Wril, 1979; Vallfors, 1985) is a term which indicates mothing more than the absence of a clear acute or chronic pain situation.

An extra difficulty with respect to the chronicity criterion is the fact that a retrospective determination of the start of the histary of the $i \mathbb{l l n}$ ess cannot be made in all cases. Of the CLBP patients $(N=101)$ participating in the studies described in this dissertation, approximately 40\% stated that the complaints began suddenly; approximately $60 \%$. Indicated thet the pattern of complaints emerged gradually and eventually crystallized into the CLBP syndrome.

\subsection{Chronic pein vs acute pain}

In addition to the time oriterion, there is algo a more essentiel difference between chronic pain and the typical acute pain atage. This is discussed further in the article: "Persistence behevior af chromic low back pain patients in an acute pain situation" that is included in this dissertation. Acute pain is primarily seen as a sensory phenomenon, closely related to tissue damage. Pain onset is recent and specific autonomic nervous system activity is present. There is no relationship with specific personality characteristics. Adequate amelioration of pain can often be obtained as function of purely somatogenic treatment (Schmidt, 1986). As Fordyce et al. (1973) stated: "acute pain is a symptom which occurs as an automatic or reflex response to afferent stimulus produced by some pethogenic factor." That this 
response, however, is not as reflexive as fordyce assumes becomes clear in observations where the stress of environmental factors is such that a pain response is strongly suppressed or is not manifested at 11 , for example, with frontline soldiers with bullet wounds (Beecher, 1956$)$.

In the chronic benign pain syndrome there is no clear relationsthip with tissue damage; pain related autonomic nervous system activity is not present. The relationship between chronic pain and personality has been extensively investigated, but a specific back-pain personality has not emerged from these studies. In his study of the epidemiology of low back pain, Haanen (1984) reviewed the literature on the relationship between low back pain and personality structure. Low back pain was found to be related to fear, neuroticism, introversion, depression, guilt and self-esteem (E1ten et al., 1978; Armentrout, 1979). Deviant MMPI personality profiles were also mentioned (Freeman et a1., 1976). Chronic pain complaints appeared largely resistent to monodisciplinary, somatic treatment. This last statement is in fact a teutology *

Although theoretically there is a great deal that is unclear about the concepts acute and chronic and expecially the transition between them, practically, this problem is of little lmportance in research on pain and the treatment of CLBP patients. The average duration of the complaints of the CLBP patients involved in our studies was 8.5 years. Several (therapy evaluation) studies also mention a pain anamnesis of a number of years (see Table 1). In other words: because of the especilally long duration of pain complaints in chronic pain (treatment) research, the problems of the distinction and the transistion from acute to chronic is avoided. 
Table 1. Average duration of pain complaints in different studies on the treatment of chronic pain

\begin{tabular}{|c|c|c|c|}
\hline & & & - \\
\hline Author & Patients & N & $\begin{array}{l}\text { X duration of } \\
\text { complaints }\end{array}$ \\
\hline
\end{tabular}

\begin{tabular}{|c|c|c|c|c|c|c|}
\hline Block et al. & $(1980)$ & Mixed chronic pain & 20 & & 10 & years \\
\hline Carlsson & $(1984)$ & $\begin{array}{l}\text { Chronic pain of } \\
\text { non-malign origin }\end{array}$ & 58 & & 6.4 & years \\
\hline Carron et al. & $(1985)$ & CLBP & 198 & \pm & 3 & years \\
\hline Chapman et al. & $(1979)$ & Mixed chronic pain & 400 & \pm & 5.5 & years \\
\hline Fordyce et al. & $(1973)$ & Mixed chronic pain & 36 & & 8 & years \\
\hline Gottlieb et al. & (1977) & CLBP & 72 & & 3.6 & years \\
\hline Hemborg et al. & (1985) & CLBP & 20 & & 5.5 & years \\
\hline Lankhorst et al. & (1985) & CLBP & 43 & \pm & 5.5 & years \\
\hline McCreary et al. & $(1984)$ & CLBP & 59 & & 3 & years \\
\hline McCreary et al. & $(1981)$ & CLBP & 102 & & 3 & years \\
\hline Naliboff et al. & $(1982)$ & CLBP & 74 & & 11.5 & years \\
\hline Price et al. & $(1983)$ & $\begin{array}{l}\text { Back and shoulder } \\
\text { pain }\end{array}$ & 30 & & 3.5 & years \\
\hline Prieto et al. & $(1980)$ & CLBP & 198 & & 7.2 & years \\
\hline Pilowski et al. & (1976) & Mixed chronic pain & 100 & & 7.4 & years \\
\hline Rybstein-Blinchik & $(1979)$ & Mixed chronic pain & 44 & & 5 & years \\
\hline Rosenstiel & (1983) & CLBP & 61 & & 6.4 & years \\
\hline Schmidt & (1985) & CLBP & 39 & & 8.7 & years \\
\hline Swanson et al. & $(1979)$ & Mixed chronic pain & 200 & & 7 & years \\
\hline Skevington & $(1983)$ & CLBP & 25 & & 12 & years \\
\hline Seres et al. & $(1976)$ & CLBP & 100 & & 5.7 & years \\
\hline Swanson et al. & $(1976)$ & Mixed chronic pain & 50 & & 7.2 & years \\
\hline Toomey et al. & $(1983)$ & Mixed chronic pain & 92 & & 4.1 & years \\
\hline
\end{tabular}


$-8-$ 


\section{SOME EPIDEMIOLOGICAL ASPECTS OF CLBP}

\subsection{Prevention and course}

Back pain is a common complaint in our society. Recent epidemiolagical. data concerning CLBP in the Dutch situation are mentioned in Haanen (1984): "An epidemiological survey on low back pain". From this and other publications (Hult, 1954; Valkenburg en Maanen, 1982; Flor and Turk, 1984) it appears that $80 \%$ of the population in industrialized countries will at some time suffer from back pain. In Haanen's review of the literature, the incidence (=number of new cases per year) of low back complaints is estimeted at 2-5\%, an estimate supported by his own findings. He also refers to a study by Benn en Woad (1975) who with the help of British sickness and injury benefit statistics calculated the course of the averagle acute LBP attack and found an average of 18-20 workdeys missed due to illness. This average is specified as follows:

length of spells $<2$ weeks

- in 50\% of the cases

length of spells between 2 and 8 weeks : in 45\% of the cases

length of spells between 2 and 6 months: in $4.5 \%$ of the cases

length of spells $<6$ months

: in $0.5 \%$ of the cases

These results pertain to the (non-Dutch) prafessional population. McGill (1968) and Cailliet (1981), among others, calculated that the chance of resuming work after an uninterrupted aick leave of six months because of LBP is $50 \%$; this chance drops to $25 \%$ in the case of an absence of one year and to almost zero in the event of a two-year absence. Furthermore, it becomes clear from the literature. (Haanen, 1984; Flor and Turk, 1984; Nachemson, 1975; Vallfors, 1985) that the chance of recidivism after the first LBP attack is very high, namely 80-90\%. Haanen even uses the slogan, "Once LBP, always LBP." It also appears that each successive attack lasta longer than the one before. The general consensus of the epldemiological studies that the LBP complaints decrease after the age of $65 \mathrm{is}$ noteworthy. Given the abovementioned epidemiological resulto, it would be reasonable to change the time criterion for CLBP from six montha to 2 months. After this period $95 \%$ of the acute LBP patients are cured. The 
other 5\% appears to have a high risk with reapect to the development of work disability.

Such an advancenent of the chronicity criterion could be advantageous for the study of the paychological and social mechanisms that lead to prolonged chronicity which in turn could result in a policy more directed towards prevention.

\section{2. Risk factors}

Prolonged (heavy) physical activity, whether in the form of work or not, is Identifled as a 'common-sense' risk factor leading to CLBP. The results of research, however, do not allow such a simple conclusion to be drawn. In their review, Flor en Turk (1984) concluded that these fectors "may contribute to back pain, but they do not seem to be sufficient causes for most cases of chronic back pain. "Haanen concurs with this conclusion: "In the EPOZ investigation we could not demonstrate a relationship between the type of work and the prevention of LBP and with the help of the AI (activity index) and the PI (passivity index) no relationship between physical activity and LBP could be demonstrated. This can mean that these indexes do not discriminate well, but it is believed that LBP complaints occur as frequently among passive as among active persons."

In the discugsion of risk factors and CLBP, the role of the psychologl.cal variables mentioned earlier needs to be considered. The nature of the research on the prevention of these factors does not allow us to infer cause and effect relationships. In other words, it is not clear if depression, for example, should be considered as an effect of CLBP, or as a riak factor for its development, ar whether both - depression and CLBP - are caused by an even more fundamental 111 ness. Clearly, studies addressing these questions are needed since the only data currently available in the literature is from part of Haanen's study (1984). He calculated the chance of having an acute LBP attack for people with a high score on the IN scale of the NPV compared to those with a low score on this scale. The IN scale measures 'inadequacy': the degree of tension and depression felt. Heanen concludes: "The 
relative risk of having $\angle B P$ within one year was four times higher for people with the 20\% highest scores an the IN scale of the NPV who had never had LBP than for those with the 20\% lowest scores."

Thus it seems that a high IN score on the NPV is a risk factor for the develapment of LBP and therefore indirectly for the development of CLBP. It is, however, a risk of limited significance, for from the same study it also appears that the chance of getting LBP after having had LBP (in the past) is thirty-five times as great as the chance of getting LBP having never had it (in the past). 
$-12-$ 


\section{PSYCHOLOGY AND CLBP}

\subsection{Intraduction}

Because of the great limitations of somatic treatment of chronic LBP, these complaints have increasingly become the subject of study in psychology, psychosomatics and psychiatry. From the polint of view of the patient, this fact is not always easy to accept. By pointing out the importance of these fields of study, the medical specialist raises doubts in the patient who feels he is being asked to wonder whether he is 'faking' or 'crazy.' It should be stated that the medical specialist is also not explicitly trained in the psychalogical frame of reference and that his diagnosis of 'psychogenic' pein often means little more then the observation of the absence - or insufficient presence - of a somatic etiology.

Several major themes can be found in psychological knowledge with respect to CLBP:

1. The relationship between CLBP and the personality of the patient: the psychodiagnostics of the CLBP patients.

2. The psychological theories of chronic pain and the psychological treatment methods derived from them.

From an empirical point of view two approaches can be discussed:

a. the operant approach to chronic pain

b. the cognitive approach to chronic pain.

Each of the above mentioned themes w111 be dealt with in the following sections.

\subsection{The psychological assessment of the CLBP patient}

One of the first questions asked by psychologists when examining a somatic clincial profile is about the specific personality. A cllear example of this is the description of the so-called A-type in studies of risk factors for the occurrence of heart attack (Haynes et al., 1980; Appels, 1985).

Specific personality variables of chronic LBP patienta were aloo investigated. Inttilly, Engel (1955) described the "pain prone per- 
sonality" as having the following characteristics:

- a prominence of guilt feelings

- measochiam

- a strong aggressive drive which is not fulfilled

- development of pain upon a losis or a threatened loss.

Leter it was redefined (Blumer et al., 1982; Bouchoms et al., 1985; Bouchoms, 1985) and it should be regarded as a "descriptive category of chronic pain characterized by a denial of affect, particularly anger, with peradoxical intense drive to overcome any challenge. Unrealistic, idealized expectations of family, caregivers and oneself are characteristic. Depressive symptoms are present, although dismissed by the patient in a cursory manner." (Bouchoms, 1985).

Bouchoms himgelf questions the usefulness of this clinicel description because of his finding that more than $50 \%$ of his chronic pain patients did not satisfy the criteria for the pein-prone disorder.

The Minnesota Multiphasic Personality Inventory (MMPI) is frequently used in personality research with CLBP patients. The following has been repeatedily found:

- the conversion V: high hysteria and hypochondria scores, combined with a low depression score (Henvik, 1951; Pilowski, 1967; Freeman et al., 1976; Murray, 1982).

- the neurotic triad: high scores on the hysteria-, hypochondria- and depreasion scales (Sternbach et al., 1973(I); Sternbach et al., 1973 (II); Leavitt et al., 1980 ).

Murray (1982) focused on the high degree of heterogeneity of CLBP patients' MMPI scores and warned against drawing conclusions in indiwidulal ceses. For example: "high neuratic triad scores accurred also in subjects who had many somatic disturbances." Moreover he stated that: "Discrimination between 'organic' and 'functional' low back pain patients by means of MMPI profiles proved to be difficult. The overlap between the MMPI profiles of Punctional and orgenic subjects averlapped too much to permit satisfactory individual diagnosis."

In addition to the MMPI, neuroticism-, depression- or self-conceptquestionnaires are also regularly used in psychometric research with CLBP patients (Sternbach et a1., 1973; Maruta et al., 1976; Elton et 
al., 1978; Armentrout, 1979; Blumer, et al, 1981; Swenson, 1981; Schmidt, 1985). On these, CLBP patients as group always score paychologically poorly. The following personality disorders reported for CLBP patients: acute and chronic fear (Brown et al., 1954; Duckro et al., 1985), psychosis in 7\% (Pichogt et l., 1972), emotional disorders in 37\% (Leavitt et al., 1978), psychiatric disorders in 35\% (Lloyd et al., 1979), the inability to express anger (Garron et al*, 1979), feelings of inadequacy, affection disorders (Pongratz, 1980) and feelings of impotence and grief (Verkes et al., 1985). This 11 ist is far from complete. Completing it would only increase the heterogenity. One can conclude, as Neliboff et al. (1982) did, that: "The (MMPI) data do not support attempts at defining a low back pain or chronic pain personality profile apart from the emotional disturbance associated with chronic limitation and disruption of activity." Moreover, a cause-effect relationship has still not been established between psychometric variables and CLBP complaints.

In the literature, personality variables are frequently related to therapy-outcome variables. The question then is if or to whet extent psychological test results can predict the effect of a perticular treatment on chronic low back pain patients. In studies of this type, MMPI data are frequently used. Nine of the thirteen investigations referred to by Oostdam (1982) in his literature study demonstrated a relationship between psychological tests and the effect of treatment. The deviant scores on the MMPI scales in thig case concerned: Mf (masculinity/feminity scale), $\mathrm{R}$ (repression), Hs (hypochondria), Hy (hysteria), D (depression), Pd (psychopathy), Pa (paranoia) and Es (ego strength). The results do not lend themselves to a clear interpretation. Although percentages of approximately go\% correct predictions have been found for the passibilitiea "guccessful" va "uribuccessful" (Blumetti et al., 1976; Maruta, 1979), these findinga can hardly be generalized. Sometimes the group to which the data relate are not clearly describer, especially with respect to chronicity. Moreover, the predictive power only applies to one specific there peutic intervention or particuler therapeutic program. It is solentifically unjustifiable to generalize the psychological predictors found to all forms of (psychologically-oriented) pain treatment programs. 
Finally, percentage of BO\% correct predictions means less the more successful (or less successfull) the therapy is. A therapy which is consildered successful in 4 out of 5 cases will result in a predictability of 80\% if eriori positive therapeutic outcone is predicted for all patients. Thu the correct prediction of the minority group is especially important. The power of paychological predictors should be denonstrated by:

1. high degree of correctness in the prediction of unsuccessful treatment for treatments which are normally considered successful.

2. high degree of correctness in the prediction of success for treatments which are nomally regarded as unsuccegsful.

3. a high degree of correctness in the prediction of treatment results for those treatments which normally are successful in 50\% of the cases.

If these requirements are satisfied, as they are in the study by Maruta et al. (1979), for example, one can speak of a useful clinical selection instrument, but even then only for that situation in which this instrument was tegted. This position advocated by Maruta et al. is, however, challenged by Dostdam with respect to the indications to operate: "The goal of pre-operative psychological research is not to decide if an operation makes sense or is necessary" (0ostdam, 1982).

\subsection{Paychologicel theories concerning CLBP}

Two empirioal psychological theories emerge from the literature on back pain: the operant paradigm and the cognitive paradign. Therapeutic models for the treatment of chronic pain have been developed from each of these theories. These treatments are often complex, intensive and multidisciplinary. Sternbach (1983) points out the disadvantage: "These approaches all have adherents and evidence to support their effectiveness. But it should be pointed out here that virtually all clinical pain treatment programs offer a variety of therapies to their pain patients, and it is most difficult, therefore, to evaluate the contribution of each component." So one could speak of the 'buckshot' therapies.

The psychological theories mentioned with respect to chronic low back 
pain have more general character from two points of wew:

- the development of psychological theory relates to chronic pain in general and not to CLBP in particular.

- it is, in fact, a more general psychological theory which is applied in a special field, in this case chronic pain complaints.

Approaches which are less based on empirical research will not be considered in this study. What is meent in particular is the paychoanalytic approach and the family system theory of chronic back pain. See Turk and Flor (1984) for a discussion of these two approaches.

\subsubsection{The operant approach to chronic pain}

The basic assumption of the operant learning principle is that behavior is influenced by reward or punlahment (Skinner, 1930). Behavior, followed immediately by positive relinforcement, will increase in frequency, while behavior that is not rewarded - or is followed by punishment - will decrease in frequency (extinction). It is prinoipally fordyce $(1973,1976,1981,1982,1984,1985)$ who has applied this learning principle to chronic pain behaviar. By chronic pain behavior is meant pain related behavior which can be observed and quantified, such as non-verbal behavior (moaning and groaning, certain postures or facial expressions), resting or lying down, quantifiable physical activities (wolking speed, maximum walking distance), passivity or avoidance behavior, medical consumption and verbal complaint behavior. The operant principle states that if thege forms of illneas behavior receive positive reinforcement in the acute gtage, the result will be chronic pain behevior or the maintenence of chronic pain behavior already present. The increasing stream of researoh date showa the usefulness of this theory. Cairns et al. (1977) showed that verbal reinforcement for activity (well behavior) and a lack of attention to peil behavior in hospitalized patients who were idlagnosed as suffering chronic organic and nonorganic low back pain led to an increase in well behavior. In an interview situation Block et al (1980) denonstrated the role of the observing partner of the pein patient. When the observer was solicitous spouse, the patient reported higher pain levels as compared to neutral observer condition. However, when the 
spouse was non-solicitous, the patient reported lower pain levels as compared to a neutral observer condition. Applying the operant principle, Fordyce (1973) demonstrated increasing activity levels and decreasing medication use. White et al. (1985) showed the positive effecto on self-reported pain and mood levela of time-contingent medication delivery as compared to pein-contingent medication delivery. In the literature the usefulness of the operant principle applied to chrondic pain is further ghown by a large number of therepy evaluation studies presented in a review article by Turner and Chapman (1982). In these therapies pain behavior, as operationalized above, is modified by the application of the operant paradign. In general, an increase in the level of activity and a decrease in medication dependency is pursued. The pain itself - as a sensation - is not treated directly, although a long-term decrease is sometimes subjectively reported (Anderson et al., 1977; Roberts et al., 1980). Operant pain therapists refer to the large discrepancy between subjective reports of pain intensity and actual pain behavior. Fordyce (1985), for example, came to the conclusion that subjective reports of pain "had wirtually no relationship to patients' reported accounts of health care utilization; pain related medication consumption; hours spent sitting, standing, walking, or reclining; or frequency of engaging in set of common place activities during the preceding week."

The therapeutic results of operant conditioning approaches have been demonatreted repeatedly. Both Flor and Turk (1984) and Turner and Chapman (1982) conoluded that "the operant approach has shown remarkable improvements in patients, especially with regard to increased physical activity levels and decreased medication use."

Some important methodolagical prablems, however, require that caution be exercised when avaluating the role of operant factors in chronic pain:

- in general, patient selection procedures for operant chronic pain programs are very strict.

- the operant treatment itself is almost always embedded in a multidisciplinary approach ('buckshot'-therapy), which can consist of biofeedback, relexation training, hypnosis, group therapy, transcutaneous neural stimulators, nerve blocks, vocational counseling, 
marital therapy, occupational therapy, and physical therapy, to mention the ones that occur most frequently. The exact contribution of the operant conditioning procedure is therefore sometimes difficult to determine. It is moreover very doubtful whether "pure" aperant programs can exist in practice and in theory.

- "strictly speaking, it is not necessary to assume that pain behavior is learned or acquired in the first place, merely because it can be modified subsequently" (Sternbach, 1983).

- operant treatment programs are not designed to treat or influence pain "but are intended to treat excess disability and expressions of suffering" (Fordyce, 1985). This, in fact, means that no judgements about the influence of operant factors on the development and maintenance of chronic pain as such can be made on the basic of operant treatment. It nevertheless appears that pain intensity - as a subjective given - can, as stated before, be influenced by operant programs. Theoretically little is known about this interaction.

\subsubsection{The cognitive approach to chronic pain}

In this section special reference is made to reviews by Turner and Chapman (1982), Turk and Flor (1984) and Tan (1982), and to a recent handbook by Turk, Meichenbaum and Genest (1983): "Pain and Behavioral Medicine, a cognitive-behavioral perspective". Turner and Chapman describe the cognitive point of view: "a basic assumption is that the cognitions (attitudes, beliefs and expectations) people maintain in certain situations can determine their emotional and behavioral reactions to those situations. As cognitive (e.g. diatraction, significance of the pain for the individual) and emotional variableg (e.g. anxiety) influence the experience of pain, it seemg logical that the modification of cognitions could be used to alter the pain experience."

Tan concurs: "Cognitive methods are those which attempt directly. to modify thought processes in order to olternate pain. The underlying essumption of these approsches is that a person's "cognitions" or appraisals of his environment are critical determinanta of his experiences and emotions. In other words, our expectations and ideas can 
influence what we see or feel. Hence faulty 'cognitions' lead to negative experiences, including exacerbation of anxiety, depression and peitin."

Turk et al. express it in a somewhat more complicated mannex: "Cognitive-behavioral models have generally adopted a view of change that Bandura has temed reciprocal determinism." This view holds that behavioral change is a reflection of the intimate interrelationships among the patients cognitive structures (schemata, beliefs), cognitive processes (automatic thoughts, internal dialogue, images), interpersonal behavior and resulting intrapersonal and interpersonal consequences."

In aumriary: according to the cognitive approach, cognitions not only influence overt pain behavior, but also the pain experience itself. With respect to chronic pein behavior this meens that this behavior is also directed by the way one interprets certain situations with respect to one's own coping possibilities. In regard to the pain es such this means that the way pain is thought about affects the pain sensation. These points of view have been investigated in several empirical studies.

Tan used the follawing classification in his review:

1. Studies of the effect of information preceding an impending event which may be discomforting or painful:

a. With respect to experimental pain

b. with respect to clinical pain.

2. Studies of the influence of cognitive coping skills on pain:

a. With respect to experimental pain

bi with reapect to clinical pain.

Ad la. Studies on the influence of giving advance information on pain, when administering an experimental pain stimulus

According to Tan, two main types of preparatory information can be distinguished: "procedural information about the objective aspects of the upcoming event" and "sensory information about specific sensations an individual is likely to experience during such an event." Tan notes that the material studied by him does not lead to clear 
conclusions. The findings of Staub and Kelle (1972) that only the combination of both procedural and sensory information was effective for increasing pain tolerance is not supported by replication of the research (Avia and Kanfer, 1980).

Preceding radiant-heat pain tolerance test or the pressure-algometer pain tolerance test, Bobey and Davidson (1970) used four kinds of instruction tapes: the control tape contalined irrelevant information; the 'relaxation' tape contained relaxation instruction which followed Wolpe's procedure; the 'anxiety' tape consisted of an edited version of various cries, screams and moans produced by women in the latter stages of labour and during childbirth; the 'cognitive rehearsal' teape was specially prepared with detailed descriptions of the procedurea of the session. Results showed that cognitive rehearsa 1: was an effective method of raising pain tolerance, but only with the heat measures and anly with a male experimenter. Relaxation proved the most effective in all the conditions investigated.

Neufeld and Davidson (1971) had their subjects observe others being tested befare they thenselves participated in the radiant-heat pain tolerance test.

A second group received a precise, audiotaped description of the procedure and the pain sensations evoked by $i$ t. They found that subjects rehearsing the pain were no more tolerant of it than those in the control group.

Johnson (1973) manipulated expectations by giving male subjects a description of the sensations to be expected from ischemic pain or a control message which described the procedure used to produce ischemic pain. He concluded that "subjecta who received a description of the sensations frequently experienced had more accurate expectations about and reported lower distress during the painful experisence than those who received a description of the procedure". However "the different information did not significantly affect perceptions of the intensity of the physical sensations."

Summarizing, the data from the literature are still too fragmentary to draw clear conclusions. 
Ad 1b: Studies on the influence of advence information on the pain in a clinical treatment

In theae studies one cannot speak of pain or pain behavior following a palnful medical operation or a painful medical examation, but rather recovery behevior of which the pain behavior is a part. A general connection between this recovery behevior and the supplying of information has not been shown. Móre specific links have been claimed, however.

Auerbach et al. (1976) evaluated the effects of two typies of preparatory information (general and apecific) given prior to dental surgery. They found that subjects with an internal lacus of control orientation viewing the specific information tape showed better adjustment during surgery than internals who viewed the general tape. The conwerse was true of external subjects, who responded more favorably to the general information.

The concept locus of control refers to the way in which people percelve themselves as having personal control over the reinforcement they obtain as a consequence of their behavior. 'Externals' have, according to the definition, a low level of personal control and ascribe success or failure experiences to external factors such as coincidence or bad luck. 'Internals', on the contrary, start with a strong personal control over success and failure experience (Rotter, 1966. Helfens, 1985).

Johnsan and Leventhal (1974) claim "to have made a substantial contribution to practice by showing that specific types of information can be used to reduce patients' aversive responses and to strengthen effective coping responses to the endoscopic examination." The type of specific information they mean is sensory description information and behevioral instructions. The dependent wariables were gagging and time for tube passage. Pain or pain behavior were not studied directly. Besides the lack of information on this point, Tan (1982) rightly observes that the influence of pre-operative information on the postoperative process is too dependent on the kind of operation, the type of information, personality variables and coping style to make a general assessment of the influence of advance information. 
Ad 2a. Studies on the influence of coping styles on pain in an expeximental setting

Relatively speaking, there are many studies on the influence of coping styles on the pain-threshold or pain tolerance. Blitz and Dinnerstein (1968), using electric shock as the pain stimulus, found that different pre-test instructions resulted in differences in pain thresholds, drug request points and maximum pain toleranoe. The purpose of this research was "to demonstrate the potential 'analgesic-1ike' effects of instructions which encourage their reinterpretation of ambigous somesthet ic experience."

In a comparable experiment Blitz and Dinnerstein (1971) used the cold pressor test as noxious stimulus. Again, cognitive relabeling of the pain stimulus - focussing on cold or interpreting it as pleasant showed significant elevation in pain threshold, but not in pain tolerance, in both instruction groups as compared to control group. Spanos et al. (1975) used a cognitive relabeling strategy vs. - what Spanos called - irrelevant coping strategy, which; in fact, is comparable to a superficial distraction strategy. With the cold-pressor test his conclusion regarding the pain-perception threshold is that: "The use of strategies (relevant or irrelevant) did not alter the pain thresholds for subjects with low pretest thresholds. Among those subjects with high pretest thresholda, use of a relevant atrategy led to a greater increase in threshold than an irrelevent strategy, which, in turn led to a greater increase than the control condition. Subjecte who were highly involved in their imagininge showed greater increases in pain threshold than those who were not."

In a later study $5 p a n o s$ et al. (1984) used a suggestion (imagining the hand as numb and insensitive) va. a distrection strategy and found that the suggestion condition lowered the aubjective pain ratings during a one minute immersion period in the cold pressor test. How ever, this lowering was only present in subjects high in hypnotic susceptibility and was not found in subjects law in hypnotic susceptibility. In the distraction condition, lowered pain-ratings were found in both subgroups.

Farthing's findings (1984) correspond with these. For high hypnotic 
susceptible subjects he found a reduction of perceived pain during a 50-second immersion period in the cold pressor test as a result of the following coping-strategies:

- anelgesira suggestion,

- verbal distraction strategy and

- combination of both suggestion and distraction.

This last combination was no more effective than was either of the single treatments alone in reducing pain. Among law hypnotizables, only the distraction treatment was effective.

Rosenbaum (1980) also used the cold pressor test, but was specifically interested in the effects of cognitive control on the maximum pain tolerance time. He felt that his most important finding was that high self-contral subjects across the various treatment conditions consigtently tolerated the cold pressor-test longer than low self-control subjecta. To measure self-control Rosenbaum used a self-report instrument, covering the following content areas:

- use of cognitive and 'self-statements" to contral emotional and physiological responses;

- application of problem-solving strategies (e.g., planning, problem definition, evaluating alternatives, anticipation of consequences);

- ability to delay immediate gratification; and

- perceived self-efficacy.

Horan et al. (1977) evaluated parts of the stress-inoculation paradigm of Meichenbeum and Turk (1976). This program trains skills specifically to the sensory-discriminative, the motivational-affective and the cognitive-evaluative dimensions of pain. The cognitive components relate to the training of distraction, somatization, in vivo emotive limagery, imaginative transformation of pain and imaginative transformation of context. This coping skills training resulted in significant improvement in the cold pressor test for pain threshold, pain tolerance and self-reported discomfort. The results could not be generalized to pressure-algoneter task.

Kanfer and Seidner (1973) also found an effect of the distraction strategy on cold pressor tolerance. They specify this general effect: "subjects who could advance slides of travel pictures at their own rate tolerated ice water immersion of the hand longer than yoked sub- 
jects whose slides were changed by the experimenter." So the principle of self-control appears to play a role in the application of the distraction strategy.

Jarenko (1978) investigated the effect of four cognitive strategies on pain tolerance using the cold pressor test. The strategies were:

- rationalization (concentrating on the reason for participating in the test);

- relabeling (cold is pleasant and refreshing);

- irrelevant thinking;

- no strategy.

The relabeling and rationalization strategies were the most effective. All groups tolerated more pain than the control group; that is, control Ss. removed their hands sooner.

McCaul and Haugtiedt (1982) compared the effects of distracting oneself from versus attending to the sensations produced by cold-pressor. stimulation. They showed that distrection is a better coping strategy than attention to sensations when Ss. are asked to report pain threshold and tolerance.

However, when asked to report their subjective distress during 4minute cold-pressor trial, distraction reduced distress early in the trial, but attention to sensations proved to be superior strategy for the last 2 minutes of the trial.

Chaves and Berber (1974) conducted a 2 minute pain test with a pressure pain stimulus on the middle phalanx of the gubjects index finger. Immediately after the stimulation, Ss. were arked to rate the average amount of pain they had felt during the first minute and during the second minute on a ten-point scale. Ag could be expected, both cognitive strategies investigated - distraction and relabeling - - ignificantly reduced pain as compared to the control treatment.

Af ter the cold pressor test Schmidt and Brands (1986) asked their subjects if they could describe the cognitive strategy they used during imnersion. A higher pain tolerance was measured for the group who said they mainly used diatraction techniques than for the group who said they mainly concentrated on the pain.

Beers and Karoly (1979) used the cold-pressor teat to investigate the effect on pain threshold and pain tolerance of some coping-strategies: 
- rational thinking in which "subjects made positive self-statements and task relevant atatements designed to emphasize the positive, and minimize the unpleasant aspects of the cold-pressor experlence";

- compatible inagery which entailed imaining a pleasant but coldrelated (winter) scene";

- incompetible imagery, which required imegining a pleasant, warm scene;

- task irrelevant cognition, which entailed counting backward from 1000 by threes.

The results suggest that "cognitive instructional strategies are effective pain endurance mechaniams as indexed by increases in cold pressar tolerance and in the latency to the self-reported pain." Pasitive expectancy (via a statement that the second cold pressor trial. would be experienced as less aversive and easier to withstand) had no influence on dependent variables.

A variant of this kind of study was conducted by Craig et al. (1974). Here the stimulus was an electric current, which was in fact of a constant, low amperage intensity that uaually is accepted without expressions of discomfort. Exposure to a model expressing disconfort and pain strongly influenced subjects to describe the normally nonaversive shocks as progressively more distressing and ultimately painfull. In 96 series, 75 series were described as painful when the model expressed obvious pain behavior. In the model-inactive group only 7 of the 96 serles were described as painful.

In $\operatorname{Tan}^{\prime}(1982)$ survey of the relation between cognitive coping skills and experimental pain Turk's (1992) classification of cognitive coping skillo is cited. He distinguished 6 categories:

1. Imaginative inattention: ignoring the pain by engaging in imagery which is incompatible with the experience of pain.

2. Imaginative transformation of pain acknowledging the noxious sangations but interpreting them as something other than pain, or minimizing them as trivial or unreal.

3. Imaginative transformation of context: acknowledging the noxious sensations, but transforming or changing their setting or context, for example, picturing oneself as 'James Bond', etc. 
4. Attention - diversion (external): focussing attention on physical cheracteristics of the environment.

5. Attention - diversion (internal): focussing attention on selfgenerated (non-imagery produced) thoughts, for example, doing mental arithmetic or making a list of the words of popular sangs.

6. Somatization: focussing on the part of the body receiving the intense stimulation but in a detached manner, for example, analysing the intense stimulation and sensations as if preparing to write a biology report.

The evaluation of the relationship between cognitive coping strategies and expermimental pain is not easy. Tan notes the obvious shortcom ings: the differences between the tests being used (cold pressor test, radiant heat test, etc.) and the difference in procedures within every test. The dependent variables alsio often differ: pain intensity (meesured in different ways), pain perception threshold, pain tollerance threshold, average pain level over a certain period during the experiment, physiological measures (especially heart frequency and GSR). For that reason, the various studies are difficult to compare. Nevertheless, the general conclusion that cognitive behavior influences pain perception and pain tolerance is sclentifically sound. This is in accord with Tan's conclusion: "While pain tolerance and to a lesser extent pain threshold, can be significantly enhanced by a variety of cognitive strategies, subjective pain intensity ratings and physiological indices are less susceptible to such cognitive influence."

Ad $2 \mathrm{~b}$. Studies on the influence of cognitive coping ski11s on clinical pain

Studies on the influence of cognitive coping akille on clinical pain can be characterized as therapy outcome research when the training of cognitive coping skills is considered a therapy for the treatment of chronic pain complaints. The training of certain coping strategies has also been investigeted in relation to the undergoing of medical or surgical operations which are known to be painful. In this case, pain behavior - for example, pain medication administered upon request - is considered part of operative recovery. 
Cohen and Lazarus (1973) diegnosed 3 groups of surgical petients (for hernia, gall bledder and thyroid conditions), on the basis of different styles of coping behavior:

a. the avoldence group

b. the vigilence group, and

c. the mixed group.

The avoldance group was characterized as showing "avoidance or denial of emotional or threatening aspects of the upcoming medical experience, as indicated by restriction of knowledge or awareness about the medical condition for which surgery was recommended, the nature of the surgery and the post surglcal outlook and by unwillingness to discuss thoughta gbout the operation."

In the vigilance group, patients were "overly alert to emotional or threatening aspects of the upcoming medical experience, as indicated by the seeking out of knowledge about the medical condition, the nature of the surgery and the post surgical outlook, and by the readinegs to discusis thoughts about the operation."

In the mixed group were those who gave evidence of both avoidant and vigilant models of coping. The results showed that the avoident group recovered faster than did the vigilant group on 2 recovery variables: days in hospital and minor complications. (Pain medication - analgesics and sedatives - did not differ between both groups.)

Holroyd et a1. (1977) compared the effectiveness of stress-coping tralning and blofeedback training with chronic tension headache patients, using a waiting-list contral group. It was concluded that "a stress-coping training procedure deslgned to enable individuals to identify cognitive responses to stress and to employ effective cognitive coping akllis provided an effective treatment for tension headache." Effects were demonstrated with respect to headache frequency, headache duration and headache intensity. EMG biofeedback training led to a significant reduction in frontalis electromyographic activity, but did not influence the headache pain pattern. The usefulness of the coping skills training program for other chronic pain syndroms is only suggested, since this procedure was not tallored specifically to tension headaches, but focussed on providing general skills for coping with psychological stress. 
Rybstein-Blinchik and Grzesiak (1979) tested the effectiveness of cognitive treatment of clinical pain in preliminary study with 5 patients with pain complaints that persisted despite appropriate medical treatment. A stress inoculation training program resulted in decreasing scores in "pain rating" and 'number of ward chosen" indices (McGill Pain Questionnaire) from pre-treatment to post-treatment and follow-up.

There was a reduction of pain behavior indices and nursing notations from pre-treatment to follow-up. It should be noted that the stressinoculation training not only invalves cognitive coping akills training, but also other techniques, e.g. relaxation-training (Meichenbaum, 1976).

In another study Rybstein-Blinchik (1978) examined the influence of three types of cognitive strategies: reinterpreting the pain stimuli, diverting one's attention from it and concentrating on the sensation itself. Ss. were patients with a hiatory of persistent pain complainta despite appropriate medical treatment; the average duration of pain was 5 years. The results indicated the potential effectiveness of cognitive strategy procedures, as measured by the McGill Pain Questionneire and systematic observation of palin behavior.

The reinterpreting technique was found to be superior; the distraction strategy also effected changes in McGill scores. Only the reinterpreting strategy was related to changes in pain behaviors. Follow-up results are not available.

The general tendency noted in the studies discusaed above was not confirmed in a recent study by Rosenstiel and Keef (1983). In an analysis of questionnaires completed by CLBP patients the following three factors expleined a large proportion of the variance in the responses to the questionnaire:

1. Cognitive coping and suppression: this factor consists mainly of reinterpreting pain sensations, coping self-gtatements (telling oneself that one must cope with the pain, no matter how bad it gets) and ignoring pain sensations;

2. Helplessness: this factor is associated with frequent use of catastrophizing (negative self statements), rare condosement of items on the increasing activity level subscale and low ratings of coping strategy efficacy; 
3. diverting attention and praying: coping with pain by focussing on things perceived to be external.

It was found that the reported use of these coping strategies was related to adjustment to chronic pain problem. High scores on the coping and suppression factor were related to more functional impairment, 1.e. pain interfered more with their daily activities. Patients high on the helplessness factor were more depressed and more anxious. Patienta high on the diverting attention and praying factor reported more pain and more functional impairment. So the results of this study do not support findings from previous studies on experimental pain (see 2a).

In his review, Tan (1982) is rather optimistic about the cognitive therapeutic possibilities for chronic pain patients. Given the research available, however, restraint must be exercised. There are some specific shortcomings which affect the generalizability of the resulta:

- The large difference in dependent variables: surgical recovery, behavior-observation variables, pain intensity scores, questionnaire responses, physiological measures, the pain pattern, functional impairment, anxiety, depression, etc. This is a consequence of the variability of cognitive starting points for any treatment. In contrast to the clear definitions of the dependent variables in the operant model - namely observable and quantifiable pain behavior the cognitive approach has 3 pointa of view. The first point of view relates to the effect of cognitive technique on the pain itself. The second emphasizes the fatalistic or negative thinking habits of pain patients by which they limit their behavioral possibilities in pain relevant situations (for example, the walking of CLBP patients). Lastly, the third point of view starts from a more general inadequate cognitive stress-coping, of which pain is the consequence and so the treatment emphesizes the training of adequate coping with general stress.

- The large difference in independent variables. Although the classification of specific coping techniques is comprehensible, it is scientifically confusing. The distinction between imaginative inattention and external attention-diversion (Turk, 1982), for instance, 
is arbitrary: the categories are not mutually exclusive.

- Many cognitive coping programs are part of a more comprehensive treatment program. This is also true of the stress inoculation program. Because of that, the study does not elucidate the specific effect of the cognitive influence. The question is if in practice this specilfic effect can be demonstrated in treatment setting.

- Control groups (placebo effect) and follow-up studies are often lacking.

- The heterogenity of the subjects: sometimes the group investigated is more homogeneous (for example CLBP, tension headache) sometimes less (for example post-operative patients).

- The mutually contradictory findings of the cognitive therapies.

- Not considering the subjects' own 'spontaneous' coping behavior. This problem is related to the fact that cognitive coping strategies cannot be directly observed by the experimenter or therapist. To be able to judge the effeot of a particular coping atrategy, it is necessary to be certain that the trained skill is used in the relevant clinical situation and is properly applied in a complete and motivated fashion. No single study can offer assurances that this was the case.

Finally, there are some basic arguments which cast doubt on the therapeutic usefulness of cognitive techniques alone to combat chronic pain. These are derived from the implicitly used mechanistic vision and are associated with the paradox inherent in these therapies. This mechanistic vision can be presented as follows:

Every pain expert knows that the object of thought can influence pain. It is impossible to even speak of pain when cognitions are not associated with it. In this connection Beecher (1956) showed that the sensation of pain is completely absent when attention, and as a reault: one's immediate thoughts, are completely occupied by the influence of very powerful stressors, as is known from warfront situations. An unnatural restriction of attention, through hypnosis for example, can, if fully realized, lso result in pain insensitivity (Hilgerd, 1975). Pain is suppressed from consciousness and as a result there is no longer any sensation of pain. In these cases, there is always an ex- 
ceptional altuation (atress, the narrowing of consciousness), coupled with a (temparary) diminution of sensitivity to pain. The training of cognitive coping techniques used with chronic pain patients is based on this repression principle, but there is no traumatic stress situation, nor it is the intention to bring the patient in a situation of reduced consciourness. Nothing more can be expected from the selfinduced cognitive techniques than some temporary relief from the actual pain sensation. One could speak of a 'cognitive aspirin." It therefore cannot be made immediately plausible that with the help of circumscript, cognitive coping techniques a substantial improvement can be expected in chronic pain pattern, neither with respect to the - average - pain Intensity nor the frequency of the average duration of the pain attacks.

Additionally, the use of cognitive coping techniques can be paradoxical, the ultimate goal is to effect a decrease in pain and to see that the chronic pain patient does not remain a chronic pain patient. It is possible, that cognitive pein coping could lead to the replacement of one form of chronic pain behavior, i.e. complaints, low level of activities, misuse of medicines, etc. - by another form of chronic pain behavior, i.e. relaxing, imagining oneself in pain incompatible situations or relabeling pain as a numb sensation. This perhaps somewhat absolutely steted presentation demands that attention be paid to two aspects:

1. cognitive pain coping a a technique applied and directly intended to reduce pain will rarely be related to and certainly not be incorporated in the patient's dally life; this is also not the goal of the treatments.

2. the cognitive coping techniques should not be dissociated from the behavioral consequences; the distraction technique will in any case work better when the pain patient not only thinks of other things, but also does other things; in other words, not only thinks of some diversion, but also looks for diversion. This means, however, that any possible effects of thinking and doing intermingle.

Summarizing: the direct effects of cognitive pain coping techniques on pain can only be demonstrated convincingly by research in which og- 
nitive treatment group and contral group follow identical programs. The cognitive coping training of the experimental group must not include behavior exercises. Finally, after laboratory training, the task of applying what is learned in practice should demonstrate the effect of the training, namely reduction of pain. During this stage, the level of activities of the experimental and the control group has to be controlled, because the explanation: cognitive coping training $\rightarrow$ increase in level of ectivities $\rightarrow$ decrease of pain has to be excluded. 
$-34-$ 


\section{SUMMARY AND CONCLUSIONS}

\section{1. Summary}

It is difficult for the somatic health care services to treat CLBP successfully since there is either a complete lack of somatic etiology or what is present is inadequete to explain the complaints. A lower limit for chronicity for CLBP is generally six months, although there are epidemiological arguments for a lower limit of two months. A lower limit is also argued for from the point of view of prevention: indications are that $10 \%$ of the group of LBP patients with complaints lasting two months become CLBP patients when the six month criterion is applied. Epidemiological research also shows that long lasting and/ or heavy physical activity, whether in the form of work or not, is not a risk factor for the development of CLBP. Furthermore, no psychological. risk factor has been demonstrated yet. With a few exceptions, prospective studies on this are lacking.

Medical psychology has been concerned with several aspects of CLBP. In the first place the concern has been the relationship between CLBP patients and personality characteristics. Many researchers have used personality queationnaires and in particular the MMPI. With some degree of regularity the presence is reported of the so-called neurotic triad (high scores on hysteria, hypochondria and depression scales) and to a lesser extent the so-celled conversion $V$ (high scores on hysteril and hypochondria scales combined with a low depression core). CLBP is also sometimes regarded as masked depression, the pain keeping the depression in the background. On the other hand, a high depression score is also connected with CLBP the pain is then defined as a symptan of the depression. The lack of coherence in the personality profile of CLBP patients is emphasized even more by studies that used other data collection techniques. Within psychodynamic thought, for example, various personality disturbances have been introduced. No conclusions with respect to the existence of a back pain personality can be drewn.

In the second place, psychology has been concerned with the search for explanatory theories of CLBP as well as more general psychological 
theories which can also be applied to pain.

The operant approach to chronic pain, the foundation of which was laid by Fordyce, emanates from the idea that abservable pain behavior is a function of the consequent positive or negative reinforcenent of this buehavior.

The extent to which the diliy environment of the pain patient reacts positively to pain behavior, will be reflected in the increase of this pain behavior. Experimental abservations have demonstrated thet the reactions of the surroundings can indeed influence the nature and degree of the pain behevior. In therapy research in which the operant paradigm is used as a starting point for the treatment program, it has been repeatedly demonstrated thet these progrems bring about an increase in the level of activities as well as a decrease of medication dependency of the CLBP patient.

The cagnitive approach, adwocated by Meichenbaum and Turk, emanates from the idea that incorrect, negative and fatalistic thinking habits can be the cause of the maintenance of the pain behavior and pain itself. Changing these thinking habits is coupled with changes in the experience of pain. Research into this relationship has different emphases. Research results with respect to the influence of advance information on the pain threshold or pain tolerance with experimental pain are still not very consistent. There seems to be a difference between procedural information and sensoric information. Sensoric information refers to information that informs the patients about the physical sensations to be expected.

In the clinical situation, the relationahip between information and pain is often studied with surgical patients or with patients who have to endure a diagnostic investigation known to be troublesome. Because the dependent research variables are also often described as recovery behavior and pain behavior is only one part of this, no clear conelusions can be drawn here as well.

There are indications that information can have a different effect on persons with an 'internal locus of control' and persons with an 'external locus of cantrol."

The effect of cognitive coping (dealing with pain or pain situation differently in imagination) has been investigated in experimental and 
clinical situations. In experimental situations clear relationships have been found between certain cognitive coping techniques (relabelling, distraction) and an increase of the pain threshold and pain tolerance. With reapect to the clinical situation, however, it cannot yet be concluded that cognitive pain coping techniques can have a therapeutic effect on pain behavior or the pain report of chronio pain patients.

\section{2. Conclusions}

The general conclusion to be drawn from the foregoing can be nothing other than that specific psychological theorizing with respect to CLBP is still not very advanced in terms of breadth and depth. As stated before, it pertains to existing, general psychological theories meant to explain learned behavior, whether deviant or not, which are primarily applied to chronic pain behavior and only secondarily to CLBP. One consequence of this is that little specific CLBP knowledge develops from these frames of reference. The fallowing comparison can be made: Assume that the CLBP problems can be compared to a box of marbles of different sizes. The goal is to know more about this box of marbles. For this a well-known and often used grate (the operant model) is put over the bax of marbles and the box is turned over. Some marbles fall through the grate to the ground, others stay in the box. When the box is turned over again, some marbles are left on the ground. What knowledge can these sifted marbles give us about the original contents of the box? In the first place, it is now known that these marbles came out of the box; in other words, there are aspects of the CLBP problem which are under operant influence. This conclusion is rather trivial because the question is not whether behavior can be influenced operantly, but rather to what extent operant factors can influence spocific CLBP behaviors. Moreover, perhaps there are still more little marbles left in the box because the big marbles blocked the holes in the grill; in other worda, one can still say little about the latitude

of the operant behavior. Further, the marbles on the ground provide information about the grate, namely about the size of the openinge it contains! In other words, operant behavior teaches us something about 
the usefulness of the operant peradigm. Unfortunately, few conclusions can be drawn about the original contents of the box of marbles on the basis of the sifted marbles.

The lack of more specific psychological knowledge with respect to CLBP is expressed at several levele:

1. there is no psychodiagnostic know-how with respect to the transition from acute backpain complaints and CLBP,

2. there is a lack of internel coherence between many reported personality characteristics, whether pathological or not, of CLBP patients,

3. It is still not clear what the cause-effect relationship is between assumed personality complaints of CLBP patients and pain complaints,

4. there is a lack of psychological insight into the complaint sustaining factors of CLBP; this is especially true of the way the CLBP patient deals with or reacts to his own pain complaints,

5. the great degree of heterogenity within the CLBP population has as yet hardly been investigated in hypothesis testing research,

6. it is still not clear what the relationship is between cognitive and operant chronic pain theory. It may be assumed that, as stated in the operant theory, pain behavior will increase in frequency when reinfarced. It is also likely that reinforcement is only reinforcement if it is experienced as such. The relationship between both thearles with respect to CLBP has not been worker out. It is conceivable that operant and cognitive factors have a different influence and importance in different stages of LBP,

7. the status of the cognitive approach for CLBP is at 11 not clear. Should cognitive treatment be directed at adequate stress coping in general sense, or at mare specific pain-coping or at coping in a more specific pain-situation? Here the problem that cognitive coping techniques have not been developed from CLBP, but from a cognitive-oriented psychology in general presenta itself clearly,

8. a consequence of the lack of specific psychological knowledge with respect to CLBP is that on an individual level the effects of psychological interventions are unpredictable, 
9. If psychological mechanisms are responsible for the maintenance of CLBP, are these mechanisms then also responsible for its development?

It is of course not possible in a study such as this to answer the above questions or fill in the gaps that were observed. It should be stated, however, that by accumulating specific psychological knowledge in the field of CLBP, a contribution towards answering the abovenentioned questions can be made.

The use of existing paychological diagnostic instruments holds little promise, given the above arguments and the literature referred to. Therefore the design chosen for this study was to study the behavior of CLBP patients in speciflc backpain situations under atandardized conditions. 
$-40-$ 


\section{STATEMENT OF THE PROBLEM}

In his article: "The behavioral management to chronic pain: a response to critics" Fordyce summarized common criticiams of operant programs for chronic pain (Fordyce, 1985). After responding to these criticisms, he cestated his position clearly:

"Pain behavior resulting from prolonged disuse or overguarding may also be modified by behavioral methods (the operant paradigm). In these instances, it is reasonable to consider that increases in activity level and reduction in overguarding probably lead directly to diminished pain, though it is not necessary to so conclude in order to justify use of the methods. Pain behaviors which have come under virtual tatal control of environmental contingencies, when modified presumably change with little or no relevance to the issue of nociception in the sense of that which is assumed to have existed at time of onset and though healing time."

CLBP is a chronic pain situation of which, according to fordyce, it may be assumed that the pain behavior may have come under virtual total control of environmental contingencies.

This position assumes that by removing these contingencies which reward pain behavior or are experienced as rewarding, pain behavior will be extinguished. Fordyce (1985) describes $₫$ very interesting experiment in this connection.

A group of chronic pain patients participated in an exertion test under instructions to stop when pain, weakness or fatigue became too mulch for them to handle. Care was toiken to ensure that all performance feedback during the exercise was withheld. Thus no control of environmental contingencies was possible. It can also be asaumed that the participating subjects, given that they did not know the experimental practice situation, could not attune their performance to earlier experiences in physically taxing situations. Theoretically, the expectation is that if chronic pain behavior is under virtual control of environmental contingencies, the removal of these contingencies will mean that the pain behavior cannot bie observed.

Pain behavior in this experimentel setting wes operationalized as persistence behavior, referring to how long a gubject will voluntarily 
endure atressful, physically taxing situation before he terminates the atreasor. And indeed, when chronic pain patients who were not yet in treatment were compared with non-patient controls, it showed "that the patients and the controls performed almost identically and that both groups increased the amount done across 4 sessions of working to tolerance at virtually identical rates." In other words: in this experimental setting the pain behavior had disappeared completely! In 3 aut of the 5 investigations described in this study, namely those investigations related to the treadmill-tests, an attempt was made to replicate and to extend this spectacular finding for CLBP patients. One of the most important aspects of CLBP pain behavior consists of the poor performance - possibly even avoidance - in back stressing situations. CLBP patients complain about restriction of movement, not walking the stairs well, trembling, not working well above the head, bending or exertions. Therefore the persistence behavior of CLBP patients in back atressing conditions was chosen as the most representative and clinically most relevant operationalization of pain behavior with CLBP patients. In Chapter 6 and 7 of this study the more general term "performance behavlor' was used. However, as the study progressed the term 'persistence behavior' was preferred, because it expresses more precisely what is meant.

An immediate extension of this is the choice of the treadmill test to study this persistence behevior:

- walking speed and the alope of the treadmill can be set without atairg;

- back atregs cen be minimized as well as maximized;

- treadnill protocols can be standardized very well;

- the protocols, although very pain relevent, are not considered by the subjects to be very comparable with their daily experiences;

- feedback on the performance during the test can be minimized simply;

- the dependent performance variables can be observed, so they are to a great degree objective.

Originally the research queation was limited, i.e. does the removal of environmental contingencies in back stressing situation mean that the persistence behavior of CLBP patients does not differ from the 
persistence behavior of a control group of non-CLBP patients. A positive answer to this question is a strong indication thet the pein behavior of CLBP patients is under virtual control of environmental contingencies.

In the studies described in Chapters 7 and 8 this first ressearch question was extended. This was done on the basis of the research findings discussed earlier which indicate that creating certain expectations by offering information in edvance can influence the persistance behavior of healthy subjects who have been given an experimental pain stimulus (Johnson, 1973). For CLBP patients this can be operationalized by studying the effect of anticipated fallure or success on pain reports or persistence behavior on the treadmill-test.

Because the treadmill is excellently suited to dose or manipulate infornation or feedback, it was used to investigate the following questions:

- What is the effect of creating a high level of expectation (which in fact induces a failure experience) on persistence behavior, reported pain intensity and physiological and subjective exhaustion levels of CLBP patients in a back-stressing situation? (Chapter 7)

- What is the effect of creating a low level of expectation (which in fact induces a success experience) on persistence behavior, reported pain intensity and physiological and subjective exhaustion levels of CLBP patients in a back-stresaing situation? (Chapter 8)

- What is the effect of supplying adequate feedback and information on persistence behavior, reported pain intensity and physiological and subjective exhaustion levels of CLBP patients in a back-stressing situation? (Chapter 8 )

In contrast to the findings of Fordyce discussed earliter, a clear difference in performance between the CLBP group and the control group in the no-performance - feedback condition was taken into account preceding the first treadilil test.

To obtain more insight into why a CLBP group performance would possibly be worse, the following extra information was collected:

- biographic information: personal information, factual information concerning pain-anamesis, etc. 
- aubjective information: psychological questionnaires, pain and fatigue scores, etc.

- objective, physiological informetion: heart-beat frequency, lactate, etc.

Beceuse the study is presented in several papers, some overlap in the introductory sections of Chapters 6,7 and 8 will be inevitable. 


\title{
6. COGNITIVE FACTORS IN THE PERFORMANCE LEVEL OF CHRONIC LOW BACK PAIN PATIENTS
}

\author{
ANTon J. M. Schmidt * \\ (Received 7 Febrwary 1984; accepted in revised form 12 Seprember 1984)
}

\begin{abstract}
An experimental group of 39 chronic low back pain (CLBP) patients and an equall number of controls, matched for age and sex, completed questionnaires of self-concept and performance motivation. SS were also tested on a standardized biack-stress physical test carried out with how external information and feedlback. The results revealed a strong tendency for CLBP patients to have a negative self-concept, confirming the findings of previous research. Poorer performance of the CLBP patients on the physical test measure of behavioural persistence and on physiological measures were unrelated to reported pain level or to poor physical condition. Compared to the controls, the chronic low back pain group was less able to estimate their physiological level of exertion, being inclined to overrate their act tall individual effort. The interaction of a negative self-concept and negative expectations is discussed.
\end{abstract}

\section{INTRODUCTION}

RECENT studies have shown that chronic low back pain (CLBP) can be influenced by operant conditioning programmes and by cognitive-behavioural interventions [ $1-5]$. The operant paradigm suggests that verbal and non-verbal pain betiaviours of CLBP patients are sustanned by systematic positive reinforcement. An operant conditioning programme results in the reduction of complaints, improvement of mood, lower medication dependence and increased physical activity, through the restructuring of behaviourall consequences [6-10].

Negative self-cognitions have been reported in CLBP patients [11]. A cognitivebehavioural intervention model assumes that changing negative self-cognitions to more neutral or more positive labeling of the pain-eliciting situations, or of the pain itself, leads to reduction of pain [12]. Examples of this kind of intervention have been to supply information to surgical patients [13》 and to teach cognitive copingskills such as 'Attention Switching' and 'Relabeling' [10, 14-16]. The influence of cognitive strategies on pain thresholds has also been established in the laboratory [17-24].

One problem with the operant treatment of pain is that the perradigm cannot be applied in a pure form. Cairns and Pasino [25] compared a number of different reinforcers and found verbal reinforcement of goal-directed behaviour to be the most effective in increasing activity level. This raises the question of whether pure operant conditioning is directly responsible for the therapeutic results. Verbal reinforcers affect CLBP patients' negative self-concept, which, in turn, may influence behaviour in a positive way. Cognitive restructuring may therefore be implicit within the framework of an operant treatment programme. Verbal reinforcement may even be the most effective technique, because it directly influences the pattient ${ }^{\text {s }}$ s self-concept.

Despite a growing consensus of the importance of cognitive factors in CLBP it is still unclear how CLBP behaviour is affected by them [26]. The relationship belween cognitions, especially expectations, and subsequent performance has been extensively

\footnotetext{
"Requests for reprimts: Drs. A. J. M. Schmidt, Medical Psychology, University of Limburg. P.O. Box
} 6I16, Masstricht, The Netherlands. 
studied in the social-psychological literature. Weiner $[27,28]$ has postulated in his achievernent-motivation theory that expectation of future performance is determized by attributions made about previous experiences of success or fallure. These attributions are formulated on two dimensions: "internal vs external locus of control' and 'stlability vs instability". Attributions responsible for success or failure are characterized by "ability" (internal-stable), "effort" (internal-unstable), "task difficulty" (external-stable) and 'luck' (external-unstable) [29]. Expectations are most resistant to change when atributions involve stable factors. Negative expectations are particularly difficult to change if earlier experiences of failure are attributed to stable factors [33]. Andrews et al. [30] showed that such negative expectations had a negative influence on subsequent behaviour.

On the basis of this achievement-motivation model, the following inferences about CLRP patients can be made:

-CLBP patients have a negative expectation about their ability on certain motor skills-such as mounting stairs, walking, lifting things, physical exercise, and capacity to function without medicines-which are attributed to a stable factor (the chronic pain) and to an external locus of control (the back pain, which can only be influenced marginally). According to Weiner's theory this combination of attributive dimensions will cause these patients to label physical efforts as too difficult or too pain-prowoking.

- This negative expectation causes poor performance, reduces persistence behaviours or may lead to avoidance [30, 32-34].

On the basis of these findings this study seeks to answer the following questions:

1. Can previous findings that CLBP patients have a negative self-concept be replicated?

2. Can differences in physical performance between CLBP patients and a control group be established by means of a standardized, back-st ressing exercise?

3. Can these differences in physical performance be explained by increased pain?

4. It is possible to trace cognitive factors causing lower performance levels in CLBP patients?

\section{Subjects:}

\section{METHOD}

Thirty-nine CLBP patients and 39 heal thy controls participated in the study. Patiens: were referted by the orthopatic clinic of the medical center. Selection criterian includted:

-age bet wen 25 - 55 .

-low back pain for ail least 6 months.

- somatic findings not corresponding wh sewerity of complaints: no major pathological findings and adequate back functions in an orthopaedie examination.

- not suffering from cardiovaseular disease, in wiew of the physical exercise involwed in the research protocol.

- no distinct limilations of motor performance or disturbance of walk, due to disease or surgery.

All subjects were wolunteerg. It was made clear that the study bore go relation to their medical treatment and that thiter participation was for research purposes only.

The CLBP patients were elinically diagnosed as hawing low back pain, a degenerative back-complaint. spondylosis, spondylarthrosis or chronic anydgia. None of the patients who were asked to participate refused. Forty CLBP patients were seen and only one did not complete the study. The 49 controls were recrulted by letuer from the general population of Maastricht, and were matched for sex and age before being seen; the response tate was bout 10\%, Only two wolunteers did not complete the research studiy.

\section{Mexisuries}

Subjects performed a treadmill-exercise. Treading speed was maintained at $5 \mathrm{~km} / \mathrm{hr}$ and grade at 5\% for the first minute, increasing by I 
subjects. Subjects were instructed to continue walking on the treaduill until neding to stop due tio pain or fargue. When they were to give a signal, the procedure was ended immediately. No verbal or non-verbal information was giver to subjects during the exereise and any recording equipment which miny have given them feedback about their performance was placed outside their field of vision. Stubject: therefore had to make the decision to stop without recourse to external reference aids.

The following biographic, psychological and somatic dsta was collected for each subject:

- Personal data: biographic questionnaire pain anamnesis (CLBP patients only) physical screening including $E C G$, pre-test pain level (CLBP patients only), self-esteem questionnujre, N.P. W. (Neuroticism questionnaire), P. M.T. (achicwement-motivation questionnaire) [46, 47]|.

-Treadmill recordings: $E C G$, heart frequency, respiratory quotient.

- Measurements immediately after the test: maximum heart rate, maximum respixatory quoticnt, batate (mmoles/1), post-test exhaustion level, post-test pain level (CLBP patients only) and total treading time.

Pre- and post-test pain levels, as well as post-test exthaustion levels were measured using the visuall Analogue Scale technique $[3.5-40]$.

\section{RESULTS}

CLBP patients and controls were compared on the biographic and psychological variables using $t$-tests and these results are shown in Table $I$. The average duration of back complaints was over $8.5 \mathrm{yr}$, ranging from 6 months to $25 \mathrm{yr}$.

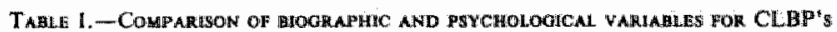
AND CONTROLS

\begin{tabular}{|c|c|c|c|c|c|}
\hline \multirow[b]{2}{*}{ Variables } & \multicolumn{2}{|c|}{$\begin{array}{l}\text { CLEPP } \\
n=319\end{array}$} & \multicolumn{2}{|c|}{$\begin{array}{c}\text { Controls } \\
n=\mathbf{3 8}\end{array}$} & \multirow[b]{2}{*}{$p$} \\
\hline & $x$ & $s$ & $x$ & $s$ & \\
\hline \multicolumn{6}{|l|}{ Biographic } \\
\hline age & $4 \|$ & 9 & 41 & 8 & NS \\
\hline weight & 78 & 12 & 76 & 7 & NS \\
\hline height & 174 & 8 & 1.77 & 6 & NS \\
\hline duration complaints (anih) & 104 & 85 & & & \\
\hline Psyehological & & & & & - \\
\hline \multicolumn{5}{|l|}{ P.M.T. } & 0.0002 \\
\hline $\mathbf{P}$ & $2 \| .2$ & 7.1 & 23.6 & 7.4 & NS \\
\hline F- & 15.0 & 10,2 & 7.6 & 5.3 & 0.0002 \\
\hline$F *$ & 7.3 & 5.0 & 11.7 & 4.4 & 0.0001 \\
\hline \multicolumn{6}{|l|}{ N.P.V. } \\
\hline IN & 17.2 & 11.3 & B. 3 & 8.6 & 0,0002 \\
\hline SI & 131.8 & 13.6 & 9.1 & 7.9 & NS \\
\hline$V E$ & 25.5 & 6.8 & 19.2 & 6.5 & 0.0001 \\
\hline $\mathrm{RG}$ & 32.4 & 9.0 & 28.6 & 7.6 & 0.05 \\
\hline $\mathrm{ZE}$ & 16.5 & 5.8 & 12.9 & 4.8 & 0.004 \\
\hline$Z W$ & 25,9 & 7.9 & 29.4 & 7.4 & 0,05 \\
\hline
\end{tabular}

None of the biographic variables were significantly different between the two groups, nor did they differ in social or marital status. CLBP patients showed significantly lower self-esteem (S.E.) than eontrols. On the achievement-motivation test (P.M.T.) they scored significantly higher on negative fear of failure (F-) and significantly lower on positive fear of failure ( $F+)$ than the controls. It has been reported that high scorers on negative fear of failure perform relatively poorly in an unstructured setting in which expectations are not made clear, while high scorers on positive fear of failure perform better in such situations [47]. 
On the Dutch Personality Questionnaire (NPV), CLBP patients differed significantly from controls on 5 subscales: they consider themselves less adequate and more often troubled by wague physical complaints, depressed moods, nonspecific anxieties and feelings of inadequacy (IN). They are more critical and distrustful of others (VE) and have more rigid personalities (RG): They are less influenced by external factors (ZE) and have lower self-esteem ( $Z W)$.

This data confirmed the results of previous research with CLBP patients [41, 42]. However, negative self-concept was mot related to the duration of back pain (see discussion). The treadmill test data and 1 -test results comparing the two groups are summarized in Table II.

\begin{tabular}{|c|c|c|c|c|c|}
\hline \multirow{2}{*}{ Variable } & \multicolumn{2}{|c|}{$\begin{array}{l}\text { CLAP } \\
n=39\end{array}$} & \multicolumn{2}{|c|}{$\begin{array}{c}\text { Controls } \\
n=38\end{array}$} & \multirow[b]{2}{*}{$p$} \\
\hline & $x$ & $s$ & $x$ & $s$ & \\
\hline Total time on mill & $100^{\circ} 40^{\circ}$ & $5^{\circ} 29^{*}$ & $14^{\prime} 42^{\circ}$ & $440^{\prime \prime}$ & 0,0011 \\
\hline Max, heart rate & 1,59 & 22 & 170 & 20 & 0,02 \\
\hline Max, resp quot & 0.98 & 0.09 & 1.04 & 0.08 & 0.04 \\
\hline Max. lavetate & 4.86 & 2.37 & 5.87 & 2.75 & NS \\
\hline Pre-test pain lewel & 47 & 28 & & & \\
\hline Poss-test pain llevel & 53 & 30 & & & NS \\
\hline Posit-1est level of exteruion & 55 & 19 & 54 & 21 & NS \\
\hline
\end{tabular}

$* n=25$ for both groups.

As hypothesized, Table II shows that, on average, the controls stayed on the treadmill longer than CLBP patients and this was associated with higher scores on the physiological measures. CLBP patients pre- and post-test pain levels, however were not significantly different. Therefore, CLBP patients cannot have performed more poorly because of increasing pain. Premature stopping due to increasing pain rather than exhaustion, would imply a negative correlation between post-test pain level and degree of physical effort achieved. This relationship was not found as the following correlations demonstrate:

-post-test level $x$ heart rate $=0.16$ (NS).

-post-test pain level $\times$ respiratory-quotient $=-0.03$ (NS).

-post-test pain level $\times$ lactate $=-0.03$ (NS).

- post-test pain level $\times$ total treading time $=-0.17$ (NS).

Both groups showed equivalent subjective levels of exertion, but physiologically exerted themselves to different degrees. The CLBP patients overestimated the physiological level of exertion or exhaustion. This is shown in Table III.

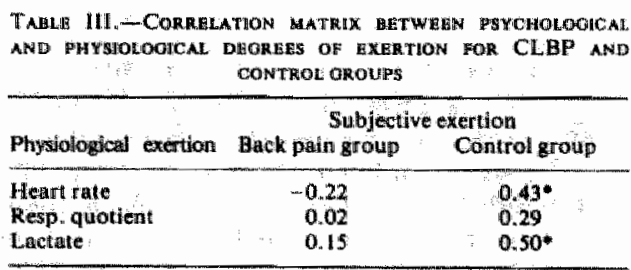

$p<0.01$. 
DISCUSSION

This study attempted to confirm the presence of a negatiwe self-concept in CLBP patients and to determine the role of cognitive factors in accounting for the difference in performance between CLBP patient group and a control group. The results suggest the following conclusions:

1. Chronic low back pain patients hawe a low self-concept, which is not correlated with the duration of their complaints.

It may be assumed that these negative self-cognitions affect the physical performance of CLBP patients. A vicious circle could develop from the interaction of continual low performance and a negative self-concept [44]. Recently, Skevington demowstrated that a non-organic chronic pain group had a "greater awareness of the importance of rest" than an organic pain group and that the resulting decreased activity level of the former was, amongst other factors, linked to their "strong (beliefs in) disease conviction" [45].

2. It seems that the poorer physical performance of the back pain group, as measured by a shorter average time on the treadmill cannot be attributed to an increase of pain to an unbearable level. Strikingly, this group reported that pain only slightly increased as a result of the treadmill test even though this test was selected for its backstressing capacity. At the end of the test, several CLBP patients reported that they stopped so that they would not be troubled by pain later that day or the next. The impression was obtained that CLBP patients were poorer at discriminating between chronic back complaint and muscular pain resulting from the intensive exercise of infrequently used muscles, which may therefore lead to mislabeling and avoidance behaviour.

3. The poorer physical performance of CLBP patients on the treadmill test cannot be explained by their poorer physical condition. If the treading time for the two groups is equalised by taking the scores of the control group after $75 \%$ of their total average treading time (i.e. at $10,40 \mathrm{hr}$ ), the groups showed similar scores on the heart rate and respiratory measures:

CLBP group: respiratory quotient $=0.98$; heart rate $=159$.

Control group: respiratory quotient $=0.96$; heart rate $=155$.

The physical condition of CLBP patients was therefore not significantly different to that of the controls and cannot account for the difference in average total treading time between the two groups.

4. The CLBP patients, in contrast to the controls, subjectively misevaluated their exhaustion from proprioceptive exertion signals. This inability might be explained in two ways:

-organic pathology may occur within the proprioceptive system. The literature, however, reveals no evidence for this supposition.

-proprioceptive signals are cognitively misinterpreted and therefore causing the performance difference.

In the experimental setting, exlernal feedback or an external frame of reference was awoided whenver possible. CLBP patients were therefore guided solely by their own internal signal and motivational cognitions. As the proprioceptive signals of exhaustion were not interpreted properly, the decision to stop or to continue on the treadmill was likely to have been substantially influenced by motivational factors. It seems obvious that the negative self-concept or the negative pain 
expectations influenced the process leading to this decision. Negative cognitive structures, rather than the physical limitations or pain, may explain the decreased performance level in CLEP patients in this experimental setting, which lacked feedback and information. This is in agreement with the high $F$-scores for the CLBP group which are associated with low performance level in relatively unstructured situations. Further research is now being conducted on the influence of more explicit external information and feedback on the endurance performance of CLBP patients in an experimental setting similar to that described in this study. There are two remaining questions about the specificity of the results:

1. Are the results specific to the setting in which the research was carried out or would the reduced persistence-behaviour in CLBP patients also be present in a performance setting that is not considered to provoke back pain, e.g. a psychomotor task?

2. "To what extent are the research findings specific to CLBP patients? Would they also apply to other categories of chronic pain patients, e.g. chronic headache patients or a chronic organic pain group?

Further research is being carried out to answer these questions.

Acknowledgements - The author acknowledges the asisistance of the following people: R. Gierlings, or her essential organizational support" the staff of the laboratory for exercise physiology of the Uniwersity of Limburis particularly P. Geurten. H. Kuipers and F. Verstappen; the staff of the orthopaedical department of Animadal Hospital at Maastrichi, under the direction of $\mathrm{A}_{\mathrm{A}} \mathrm{V}_{\mathrm{a}} \mathrm{d}$. Linden; $\mathrm{S}$. Wijnen fior his assistance in the treadmill tests; J. Bremer, M. de Vries and M. v.d. Hout, for their valluable criticisms: and all others who contributed to this research project.

\section{REFERENCES}

1. TuRnar JA, CHaPMaN CR. Psychological inventions for chronir pain: a critical review-II. Operant conditioning, hypnosis and cognitive-behavioral therapy. Pain 1982; 12:23-46.

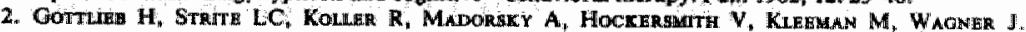
Comprehensive rehabilitation of patients having chronic low back pain. Arch Phys Rehabil 1977; 58: $399-408$.

3. SWANSON DW, SWENSon WM, ManUTA T, MCPHEE MC. Program for managing chronic pain-1. Program descriptions and characteristics of patients, Moyo Clinic Proceiedings $1976 ;$ 51: 401-408.

4 SWhison DW, FLoREzN AC, SWENson WM. Program for managing chronic pain-11. Short-iterm reswits Moyo Clinis Proceedimgs 1976: $511: 409-411$.

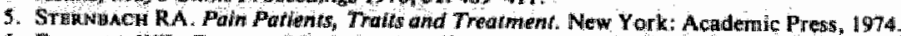

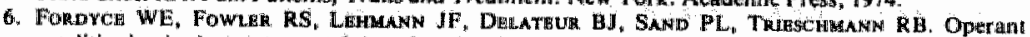
conditioning in the treatment of chronte paifi. Arch Phws Med Rehabil $1973 ; 34 ; 399408$.

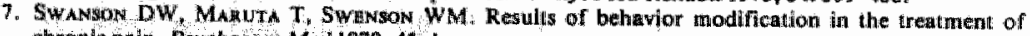
thronic pain. Psychosom Med 1979; 41 1. 1 .

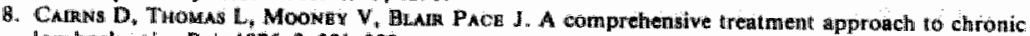
low back pain. Poin 1976; 2: 301-308.

9. Fonbyce WE. Dehawioral Methodis for Chronic Pain and Whess. St. Louris: Mosby, 1976.

10. CAUrala JR. The use of covert condlioning in modirying pain behavior. Behav Ther Exp Psychiar $1977 ; 4: 45-52$.

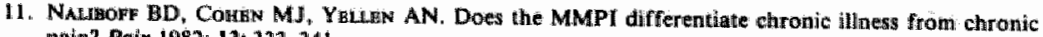
pain? Poin 1982; 13:333-341.

12. Duvioson PO (Ed The Bethavioral Momogement of Antieties, Depression and Pain New York: Brunmer/Mazel, 1976.

13. ANDKew IM. Recovery from surgery, with and without preparatory insuruction, for three copping styles. JPerson Soc Psychol 1970, 15: 223-226.

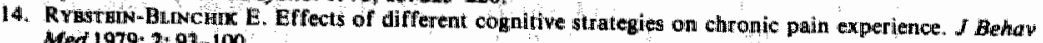
Med 1979, 2: 93 100 .

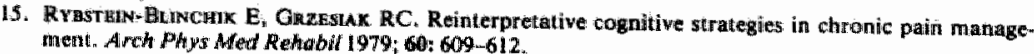


16. TAN SX, Cognitive and cognitive-behavioral methods for pain control selective rewiew. Pain 1982; 12: 201-208.

17. MCCAUL KD, Hatugrvedt C. Attention, distrastion and cold-pressor pain. I Person Soc Psychol 1982; $43: 154-162$.

18. BEERs TM, Karoly P. Cognuttive strategies, expectancy and coping style. I Congult Chin Psychol 1979; $47: 179-160$.

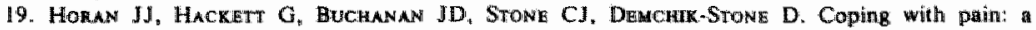
component analysis of stress inccculation. Cogmitive Therapy Res 1978: 1:211-221.

20. JAREwKo ME. Cognitive strategies in the control of pain tolerance. I Bhehow Ther Exp Pspehiat 1978; 9. 239-244.

21. KANFER $\mathrm{FH}_{4}$ Seldenen ML. Self-control: factors enhancing tolerance of moxious stimulation. J Person Soc Psychol 1973; $25: 381 \cdots 389$.

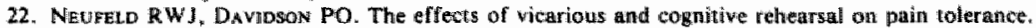

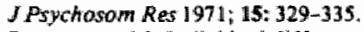

23. ROSENRAum $M$. Individual differences in self-control behawiors and tolerance of painful stimulation. J A briorm Psychol 19:80; 89:581-590.

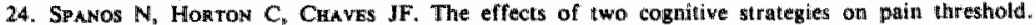
$J$ Abuorm Psychol 11975; 84: 677-681.

25. CAIELS D, PASINO JA. Comparison of verbal reinforcement and leedback in the operemit Ireatment of disability due to chronic low back pain. Bethawior Therapy 1977: 18: 621-630.

26. Marantura JS. Cognitive therapy and behavioral practice. Behaw Res Ther 1980; 18 : 249-258.

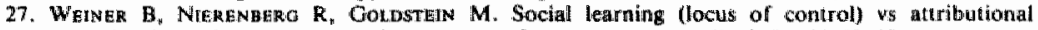
(causal stability) interpretations of expectancy of success. I Personality 1976; 44:52-68.

28. Weinge B. Achievement motivation and altribution theory. New Jersey, Morristowa: General Learaing Press, 1974.

29. Rurmer BS. Infuence of causal beliefs on the alfect and expectancy. I Person Soc Psychol 1975. $31 \div 1163-1167$.

30. ANDREws GR. DEats RL. Persistence and causal perception af failure: modifying ognitive altributions. I Educat Psychol 1978; 70: 154-166.

31. SKevington SM. Chronic pain and depression: universal or personal helplessness? Pain 1983; 15: 309-317.

32. METTEE DR. Rejection of unexpected success as a function of the negative consequences of aceepting success. J Person Sac Psychol 1071: 17:" 332-341.

33. MCCAUGans. Stabillity/instability and change of expectancy a test for cognitive dieterminants of psychomotor performance. Percepr Motor Skills 1978; 46: 219-225.

34. FEATHER NT, SAWLLE MR. Effeets of amount of prior suceess and failure on expectations of success and subsequent task pertiormance. J Persom Soc Psychol 1967; 5: 226-232.

35. Carlsgon AH. Assessment of chronic pain-1. Aspects of the reliability and validity of the visual anallogte scale. Pain 1983; 16:87-101.

36. ArtKen RCB. Measurement of feelings using Visual Analogue Scales. Proc $R$ Soc Med 1969; 62: 989-993.

37. Husxassion EC. Measurement of pain. Loncet 1974; 9: 1127-1131.

38. JoYce CRB Z ZUSH DW, HRupes V. MASON RM. Comparison of tixed interval and visual analogue scales for rating chronic pain. Journal unknown 1975.

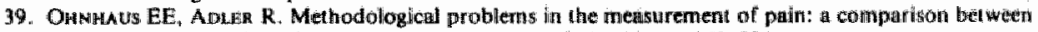
the verbal rating scate and the wisual anatogue scalle, Pain 1975; 1: 379-384.

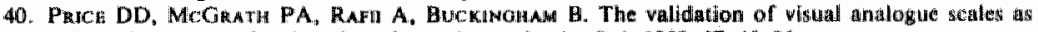
ratio sciale measures for chronic and experimental pain. Pain $1983 ; 17 ; 45-56$.

41. ARmENTrout DP. The impact of chronic pain on the self-concept. I Crinical psychol 1979; 35: $517-521$.

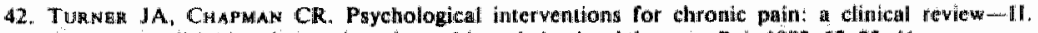
Operant conditioning, hypnosis and cognitiwe-behavioral therapy, Pain 1982;12:23 44 .

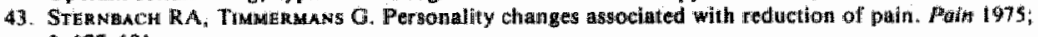
1. $177-181$.

44. CoLuwowooo TR. The effects of physical training upon behavior and selfartitudes, $J$ climical Psychol 1972; 28: $983-585$.

45. SKevinoron SM. Activities as indices of illmess behawiout in chronic pain. Pain 1918; 15:295-307.

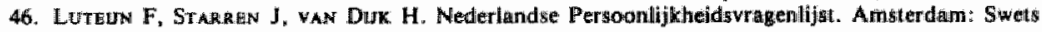
\& Zeirlinger B.V., 1974 .

47. Hermans HJM. Handleiding bij de Prestatie Motivatie Test (PMT). Amsterdam: Swet: en Zieitinger. 1968. 
$-52-$ 


\title{
7. PERFORMANCE LEVEL OF CHRONIC LOW BACK PAIN PATIENTS IN DIFFERENT TREADMILL TEST CONDITIONS
}

\author{
ANTON J. M. SCHMTI
}

(Received 22 January 1985; accepred in revised form 15 March 1989)

\begin{abstract}
An experimental group of 39 chronic low tack pain (CLBP) patients and an equall number of control subjects matched for age and sex were tested with a stamdardited back stress physical hest. The subjects were given no indication of the perfiormance expected and no feedback was given during the thest. The test was repeated with a high frame of reference and feedback offered to the subjects. In the latider condition the control group improwed their performance in contrast to the CLBP group. The poorer performance of the CLDP patients in botth conditions was umelated to pain increase, posth mest pain level or poor plyysical condition. Howewer, there is a clear relationship between performance and prentest pain level, especially in the feedback condition. In this condition, it also seems that increasing pain level during the test is used as a "rationalization" for the builtin fallure experience. Compared to the control group the CLBP patienis were less able to estinute their physiological level of exertion and were inelined io overrate their actual effort.
\end{abstract}

\section{INTRODUCTION}

IN A RECENT review of etiological theories and treatiments for chronic back pain Fllor and Turk [1] enumerate some impressive facts. Ninety percent of acute backsyndromes improwe within 2 months, but the recurrence rate is very high $(90 \%)$, with each recurrence becoming more severe and more lasting. Moreover, only $50 \%$ of the patients who have back pain for more than 6 months return to work. For 50-90\% of chronic back pain patients the diagnosis is not explanatory but is a description of symptoms, since little is known about the etiology of chronic back pain.

No single physical illness can adequately account for the problem of chronic back pain which means that the medical treatment is predominantly symptomatic. Flor and Turk come to the grave conclusion that 'lack of efficacy of the traditional medical treatment approaches has forced many patients into a 'low back loser'-career with changing physicians, growing medical records, disability, depression and overutilization of the health care system without appropriate relief".

There is a little more optimism regarding the effectiveness of psychological interventions [2-5]. Unfortunately the psychological models on which they are based 'are not yet well elaborated and also lack rmpirical evidence' [2], It therefore seems important to study the behaviour of chronic low back pain (CLBP) patients in a controlled experimental setting.

In an earlier study $[6]$ the persistence behaviour of a CLBP group on a treadmill test was compared with the performance of a control group. The standardized backstress physical test was carried out without stating explicitly beforehand what the expected performance was. During the test no qualitative or quantitative feedback was given.

The results can be summarized as follows:

- The CLBP group performed poorer on the treadmill test as measured by total treading-time and physiological measures.

Requests for reprints: Dr. A. S. M. Schmidt, Depl of Medical Psyelioliogy, Liniwersity of Limburg, P.O. Box 616, 6200 MD Maastricht, The Netherlands. 
- This difference was not related to a poorer physical condition of the CLBP group compared to the control group.

-This difference was unrelated to pain, because, for the CLBP group, reported back pain levels did not increase during the test.

-In the control group there was a significant positive correlation between the physiological exertion measures and the subjective feeling of exertion immediately after the treadmill test. However, the CLBP patients were not able to correctly estimate their level of physiological exhaustion and were inclined to overrate their actual individual effort.

These results point to the existence of large discrepancies between subjective back pain complaints and objective obserwable behaviour in this test situation which was characterized by a lack of frames of reference. The subjects were given no information about their performance, so a success or failure experience was avoided. it is assumed, however, that CLBP patients experience many physical failures in daily life, resulting in a negative attitude concerning their ability to perform physically. It is further assumed that this negative wiew has a negative influence on their behavior [7]. It is therefore important to investigate the persistence behavior of CLBP patients during conditions of failure. For that reason a second treadmill test was conducted which included telling the subjects the expected treading time beforehand.

The treading time chosen was one that in practice none of the subjects could obtain. Because of this manipulation a 'built-in' failure experience was added to this test condition. The question investigated was whether this would cause behavioral changes in the CLBP group and the control group in comparison to their first treadmill test.

\section{METHOD}

\section{Subjects}

Thirty-nine CL BP patients and 38 healthy control subjects participated in the study. Patients wete referred by the orthopaedic clinic of the medical center or responded 10 an announcement in a local newspaper. Selection criteria included:

age between $25-55$;

low back pain for at least 6 months:

somatic firdings not correspording with severity of complaints; no major pathological fundings and. adequate back thinctions in an orthopacdic examination;

not suffering from cardiovascular disense, in wiew of the physigal exercise involved an the research protocol:

aro distinet hanital ions of motor performance or disturbance of wallk dwe to disease or surgery. All CLBP patients were wolunters. If was made clear that the study bore no relation to their medical treatment and that their partiefpation was for tesearch purposes only.

The CLBP patients were clinically diagnoged as having low back pain, degenerative back-disease. spondylosis, spondylariturcsis or chronic myatgia. None of the patients who were asked to participate refulsed. Forty CLBP patients were and only one did not complete the protocol. The 40 malle cantrol subjects were recruited by letter from the genieral population of Masstricht and were matched for age before being. seen: the tesponse ratio was about 10\%, Only two volunters did not omplete the research protocol.

\section{Procedure anid design}

Figure \describes the design of the study. Subjects performed treadmillmexercises. Treading speed was maint at ned at $5 \mathrm{~km} / \mathrm{h}$ and grade at $5 \%$ for the first minute, ingreasing by $1 \%$ at one minnte untervals. These changes were not defected by the subjects. Subjects were to stop due to pain or fatigue. When they gawe signal, the procedure was ended lmmediately?

In condition I, the basic condition for all subjects, no verbal or non-werbal information was given to subjects on expected or actual performance. Any recording equipment which may have given thern feedbacik was placed ouside their field of wision. Subjeets therefore had to make the decision to stop without recourse to external reference aids: 


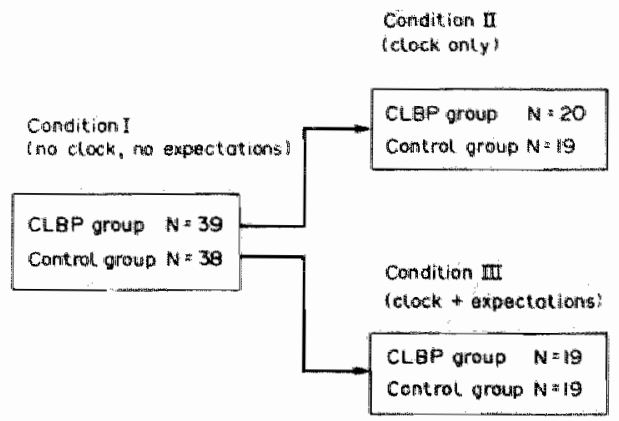

Fiva, 1.

Arourd three weeks later half of each group participated in condition the the other half in condition III (random assignment). Condition II was identical to condition 1 , the only difference being that a clock was placed in front of the subjects which was started at the beginuing of the treadmill exercise. Condition III was likewise a second test with a clock in front of the subjects, In this condition, however, a frame of reference was offered to the subjects. Just before the treadmill test began the subjects werc told the expected treading time. The time was suggested to be an average time for a CLBP group for for a control group), but in fact the time presented was the time as measured in condition if for this subjest $+30 \%$. Only after condition II and III the perfomances were discussed with the subjests.

\section{Mearures:}

The following biographic, psychological and somatic data was collected for each subject:

Personal datz: biographic questionmaire, pain anamnesis (CLBP patients only), physicall screenimg (including ECG), pre-test pain levell (CLBP patients only), self-esteem questonnaire, N,P.V. (neuroticism questionnaire, 18 ]), P.M.T. (achievement motivation questionnaire, [9]).

Treadmill recordings: ECG, heart rate, respiratory quotient.

Post-test recordings. maximum heart rate, maximum respixat ory quotient, lactate (minoles/1), post-test exhaustion levell, post test pain level (CLAP patients only) and total treading thrte.

Pre- and post-test pain levels, as well as post-test exhaustion levels were measured using the Visual Analogue Scale technique $[10-12]$.

\section{RESULTS}

The results of the treadmill test for the different conditions are summarized in Table 1. For all dependant wariables and within both groups no significant differences were found between conditions I and II ( $t$-tests), meaning that no training-effects could be found.

The first two columns of Table ${ }_{1}$, relating to the measurements in condition $I$, hawe already been discussed in another study which was summarized above [6]. Comparing conditions II and III, changes in dependant measures were analysed by a 2 (condition III and III) $\times 2$ (groups) analysis of variance (ANOVA). This analysis showed a significant group effect for treading time $(F=17.25 ; p=0.0001)$, lactate $\left(F=10.0 \mathrm{~B}_{;}\right.$ $p=0.002)$, respiratory quotient $(F=4.75 ; p=0.03)$ and heart rate $(F=11.51$; $p=0.001)$. ANOVA showed a significant condition effect for lactate $(F=12.43$; $p=0.0007)$ and respiratory quotient $(F=4.78 ; p=0.03)$. T-tests were used to compare different performances within both groups in condition II and III.

The introduction of a high frame of reference to the control group produced a tendency toward somewhat better physical performance. The performance of the 


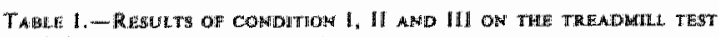

\begin{tabular}{|c|c|c|c|c|c|c|c|c|}
\hline & \multicolumn{2}{|c|}{ Conditton I } & \multicolumn{2}{|c|}{ Condtion II } & \multicolumn{2}{|c|}{ Condition III } & \multicolumn{2}{|c|}{$\begin{array}{c}\text { Cond } \\
\text { III } \\
(i-\operatorname{tes} t)\end{array}$} \\
\hline & $\begin{array}{l}\text { CLBP } \\
\text { group } \\
n \rightarrow 39\end{array}$ & $\begin{array}{c}\text { Control } \\
\text { group } \\
\text { in } 38\end{array}$ & $\begin{array}{l}\text { CLBP } \\
\text { group } \\
n=20\end{array}$ & $\begin{array}{l}\text { Contri. } \\
n=19\end{array}$ & $\begin{array}{l}\text { CLEP } \\
\text { G'DuP } \\
n=19\end{array}$ & $\begin{array}{l}\text { Control- } \\
\text { group } \\
n=19\end{array}$ & $\begin{array}{l}\text { CLBP- } \\
\text { group }\end{array}$ & $\begin{array}{l}\text { Control- } \\
\text { group }\end{array}$ \\
\hline Time & $100^{\prime} 40^{\circ}$ & $14^{x}+42: 4$ & $1102^{N}$ & $15^{\prime} 55^{\prime}$ & $110^{4} 28^{n}$ & $162^{\prime 2}$ & NS & $\mathrm{NS}$ \\
\hline Heart-rate & 159 & 170 & 159 & 175 & 159 & 175 & NS & NS \\
\hline Latate & 4.86 & 5.87 & 4.31 & 6.04 & 6.54 & 9.24 & $<0.05$ & $<0.001$ \\
\hline Preventest pain & $47+\cdots$ & & $52+$ & & $34+4$ & & $<0.05$ & \\
\hline Post-test pain & 331 & & 631 & & 491 & & $\mathrm{Nis}$ & \\
\hline Post-lest exertiol & 55 & 54 & 64 & 64 & 64 & 64 & NS & NS \\
\hline Resp. quouticul & 0.98 & 104 & 1.01 & 1.07 & 0.98 & 1.02 & $\mathbb{N S}$ & NS \\
\hline
\end{tabular}

CLBP group remained on the same level. In condition II and in condition III the CLBP group had a post-test exertion lewel equal to the control group at objectively clearly different levels of performance. Finally, it seems that for CLBP patients, condition III is asssociated with statements of increased subjective pain.

Subjective and objective variables were correlated to determine whether this increase in pain corresponded to the worse performance level of the CLBP group in this condition. The results are summarized in Table II. From this table it appears that for the CLBP group the pain level preceding the treadmill test is related to the performance level. This holds for condition I, but to an even greater extent for the condition in which the high frame of reference was offered. Neither the pain level at the moment the test is stopped nor the exertion levell then present influence the

\begin{tabular}{|c|c|c|c|}
\hline $\begin{array}{l}\text { Condition I: }=39 \\
\text { Condtion II: } n=20 \\
\text { Condtution It: } n=19\end{array}$ & Heart rate & Lactate & Tine \\
\hline \multicolumn{4}{|l|}{ pre-iest pan } \\
\hline condition I & $-0.43^{*}$ & $-0.46^{*}$ & $-0.51 *$ \\
\hline condition II & $-0,07$ & -0.10 & -0.35 \\
\hline condition III & $-0.72^{*}$ & $=0.67^{\circ}$ & -0.74 \\
\hline \multicolumn{4}{|l|}{ posl-test pain } \\
\hline condlition & $-0,20$ & 0.19 & -0.02 \\
\hline condition ll & 0.07 & 0.02 & -0.24 \\
\hline condition III & -0.34 & -0.14 & -0.33 \\
\hline \multicolumn{4}{|l|}{ post-test exertion } \\
\hline condition I & $\therefore 0.00$ & 0.13 & -0.16 \\
\hline condition & 0.17 & $-0,08$ & 0.07 \\
\hline contidition dII & 0.13 & 0.24 & 0.10 \\
\hline
\end{tabular}

$\$ 0 ;<0,01$. 
performance level of the CLBP group on the treadmill test. The increase of pain (post test pain level minus pre-test pain level) also does not seem to influence performance as the following results show:

condition I $:(r, \Delta$ pain:time $)=0.19 \mathrm{NS}$.

condition II $:(r, \Delta$ pain:time $)=0.12$ NS.

condition III: $(r, \Delta$ pain:time $)=0.36$ NS.

The correlation between performance levell and subjective fatigue is presented in Table III. This table shows a significant correlation between the subjective and objective performance level in condition I for the control group but not for the CLBP group. However, when external information (clock or clock plus high frame of reference) is added, this relationship is no longer observed for the control group.

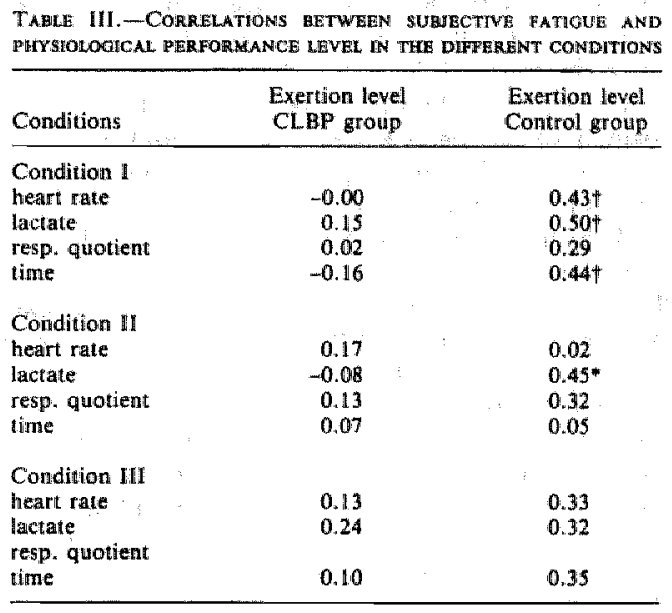

$p<0.05 . \quad+p<0.01$

\section{DISCUSSION}

There are very few studies in which the pain behavior of CLBP patients has been studied in a controlled situation to obtain more knowledge of the psychology of chronic pain. In the study described here it was possible to investigate the behavior of CLBP patients under different back-stressing conditions and to compare this with the behavior of healthy subjects. In all the conditions investigated the CLBP group performed less well than the control group. It has been shown that this lower performance level was not related to pain level or the increase of pain. In two conditions no significant pain increase could be found. Only in one condition (in which a high frame of reference was offered), a significant increase of pain could be obserwed. Two points are of interest here. Firstly, the increase of pain in this condition did not so much consist of a high increase of the pain level in comparison to the two other conditions, but of a combination of a relatively low pre-test level and an average post-test level. Secondlly, it should be noted that the group that participated in condition III had already participated in condition I and that in this 
condition there was no significant increase of pain although the performance was the same.

From this it may be concluded that statements about the increase of pain in condition III have more to do with the specificity of this condition than with the back-stressing character of the treadmill test. The specificity of condition III consisted of the creation of an expectation level which was experienced as too high during the treadmill test. It thus seems that the experience of failure which was the result of this was 'rationallied' by reports of pain increase.

Table II shows that in no single condition the performance level of CLBP patients correlates with the pain level at the moment the test was stopped. However in combination with the absence of information, preceding or during the treadmill test, pre-test pain level seems to have a predictive value for the performance level of the CLBP group on this test. In combination with a built-in failure experience this relationship is even closer $(r=0.74)$. This means that CLBP patients will have a great deal of difficulty increasing their level of activities because new physically-imposing behavior will not be regulated by the physical signals that are raised by it, but by the preceding pain. This endangers a conservative attitude in the CLBP patient: "If $I$ feel well I can do a lot; if I do not feel well I can do nothing. This point of wiew needs further experimental study. Moreower, the cognitive-behavioral approach to chronic low back pain managenent assumes a comparable starting point. The corresponding cognitive or operant treatments seem to produce hopeful results [2].

Table III shows that in condition I the control group behaves according to expectations: Ss. who stop relatively early generally report a lower level of tiredness than Ss. who continue for a longer time. Such relationship is not found in the other conditions. For condition III especially, this result is quite understandable. Creating a high expectation for the physical performance of healthy people resuits in a higher level of performance.. In sports it is assumed that physical condition is only one factor influencing performance and that fatigue and pain thresholds must be crossed to reach optimal performances [13]. In any case, for the group investigated, consisting of untrained though healthy Ss., it can be stated that the introduction of external and stimulating information results in slightly better performance and a disruption of the relationship with subjective fatigue.

For the CLBP group in mone of the conditions investigated a relationship is found between performance level and feelings of fatigue. Because the consistently poorer performing CLBP group reports a fatigue level equal to the control group, it may be suggested that the CLBP patients regularly overestimate their exertion levels.

It was demonstrated that pre-test pain levels, expecially in combination with a high frame of reference can to large extent determine the performance level of CLBP patients in back-stressing situations. The experimental setting is also suited to the investigation of the effects of a low frame of reference in which the now built-in failure experience can be changed to a success experience. More study is needed to obtain information on the behavior of CLBP patients in this condition.

Alenowledgemenw The atuthor acknowledges the assistance of the following people: $R$. Gierlings and J. Wan Houtem for thitir essential organizational and statistical supports: the staff of the sport-laboratory of the University of Limburg, particularly $P$. Guerten, $H$. Kuipers and $F$. Verstappen; the staff of the orthopaedical deparument of Annadal Hospital at Maistricht, under the direction of A. v.d. Linden; $S$. Winnen for his assistance in treadmill iests; J. Bremer and $M$. v.d. Hout for their waluable criticisms;
and all others who contributed 10 this tesearch project. 


\section{REFERENCES}

1. FLom $H_{\text {* TUR }}$ DC. Etiological theories and treaments for chronic back pain. 1 . Somatic models and interventions. Puin 1984; 19: 105-121.

2. Tukax DC, FLOR H. Etiological theones and ureatments for chronic back pain. II. Psychological models and interventions. Pain 1984; 19: 209-233.

3. TAN S-Y. Cognitive and cognitive-behavioral methods for pain control: a selectiwe rewiew Pain 1982: 12: $201-228$.

4. Turner JA, Chapman CR. Psycholagical interventions for chronic pain: a critical rewiew . Relaxation: training and biofeedback. Pain 1982; 12: 1-21.

5. TURNER. IA "ChApwan CR. Psychologieal interventions for chronic pain: a critical rewiew; II. Operant conditioning, hypnosis, and cognitive-behavioral therapy. Poin 1982; 12: 23-46.

6. Scrmid AJM. Cognitive factors in the performance level of chronic low back pain pat ients, $f$ Psychosom Res, 1985: 29: 18.5-189,

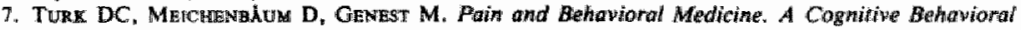
Perspecriwe. New York: Guillord Press 1983.

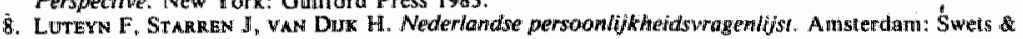
Zeitlinger B.Y. 1974 .

9. HeRmans HJM. Hamdleiding bif de Prestavie Motinatie Test (PMT) Amsterdam: Swets d Zeitlinger D., 1968 .

10. Carnsson AH. Assessment of chronic pain I. Aspects of the reliability and validity of the visual analogue scale. Paim 1983; 16:87-101.

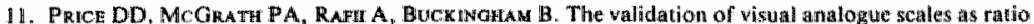
scale measures for chronic and experimental pain. Poin $1983 ; 17 ; 45-56$.

12. WALSA TD, LEBER B. Measuremient of chronic pain: Visual Analog Sates and Mcoill Melzack paili Questionnaire Compared. In Adyances in Paint Reseanch and Theropy. Vol. Sitedited by John J. Bontica et al. New' York: Raven Press, 1983.

13. Moronin WP, Honstiman DH, Crmeram A, Stokes J. Facilitation of physical performance by means of a cognitive strategy, Cognitive Theropy Res, 1983; 7: 251-264. 
$-601-$ 
8. PERSISTENCE BEHAVIOR OF CHRONIC LOW BACK PAIN PATIENTS IN TREADMILL TEST CONDITIONS WITH FALSE AND ADEQUATE FEEDBACK

Anton 3.M. Schmidt

Abstract

In order to study the persistence behavior of chronic low back pain (CLBP) patients in different conditions, an experimental group of 41 . male patients and a matched control group of 39 heal thy subjects performed standardized treadmill tests. The subjects were given no indication of the performence expected and no feedback was given during the test. Three weeks later the test was repeated. In experiment I a low frame of reference and continuous time feedback was then offered to the subjects; thus creating a success experience. In experiment II an adequate frame of reference and continuous time feedback was offered. Results show that in all conditions the performance behavior of CLBP patients is somewhat poorer than the behavior of the contral subjects but that (poorer) performance is unrelated to pain or pain increase.

It also appears that, compared with healthy subjects, CLBP patients' subjective reports regarding the degree of physlological exertion or fatigue are disturbed. These findings correspond to those of earlier research in which the persistence behevior of CLBP patients in failure-conditions was studied.

\section{Introduction}

It is beconing increasingly evident that the behevior of chronic low back pain patients (CLPB patients) is not just a function of pain and that the pain is not just a function of the objective findings or physical stress. In a recent study of a group of acute, subacute and chiconic CLBP patients $(N=170)$, Vellforg (1) observed that 49\% had objective findings. For the CLBP patients $(N=70)$ this was only $30 \%$, meaning that $70 \%$ had "normal movenent ability, normal nusculature, no signs of neurologic involvement, negative SLR, no fixxed peinful position and no pain during palpation or percussion." The presence of 
objective findings does not, however, mean thet causal relationship exists. This is especially true for radiological changes, which have been shown to occur more frequently with increasing age, but are not necessarily assoclated with pain complaints $(2,3)$.

It therefore appears that the puzzle of pain (4) becomes more complicated when CLBP patienta are considered to be physically ill. At the same time there is a growing tendency to regard chronic pain as the result of an inadequate interaction between the person and his environment (5). Regarding this matter, two points of view can be distinguished. The first emphasizes a faulty appraisall of the outside world and the subsequent inadequate reaction to this outside world. Describing chronic pain patients, Turk et al. (6) stated that the internal dialogue was disturbed, meaning "patients thought about being hopelegsily 111 , that therapy will be ineffective and that roads to change are non-existent or totally blocked." In this view the behavior of CLBP patients is related more to their subjective appraisal of the behavior possible for them in pain-related siturtions than to the actual possibilities themselves. This view, which is supported by relatively successful therapeutic applications $(7,8,9)$, is called the cognitive behavioral appraach.

The second approach, operant conditioning, places the accent on the direct and observable interaction between the person and his environment (9). Fordyce (10-13) stressed the fact that the general rule that reinforced behavior increases in frequency is also valid for the pain behavior of CLBP patients. In the therapeutic setting this proposition hes appeared to be a powerful therapeutio expedilent.

The usefulness of both these orientations has been demonstrated in a therapeutic setting. Nevertheless, the inability to predict the treatment reaults of individual CLBP patients indicates that the underlying psychological theories are still too global (7). To refine these theories, it will be necessary to study the behavior of CLBP patients in interaction with their environment in more controlled and standerdized circumstances.

This research is closely related to earlier studies of the persistence behavior of CLBP patients (14, 15). In these studies a standardized treadmill test was carried out with CLBP patients and control group, while no qualitative or quantitative feedback was given. Ss. walked to 
- subjective - exhaustion or to maximum pain threshold. The results of these studies can be summarized as follows:

- The CLBP group performed poorer on the treadmill test as measured by total treading-time and physiological measures compared to a control group.

- This difference was not related to poorer physical condition or pain increase during the test.

- In the control group there was a significant positive correlation between physiological exertion measures and the subjective feeling of exertion immediately after the treadmill test. However, the CLBP patients were not able to correctly estimate their level of physiological exhaustion and were inclined to overrate their actual individual effort.

When the test was repeated with a high reference time and time-feedback offered to the subjects - thus inducing a failure experience the control group improved their perfarmance in contrast to the CLBP group. In this condition previous findings were reconfirmed. In oddition, a very cliear relationship $(0.67<\mathrm{r}<0.74)$ was found between physiological performance measures and pre-teat pain level. In other words: in failure conditions - but also to a somewhat lesser extent in the no feedback condition - the physically imposing persistence behavior of CLBP patients will not be regulated by the pain that is produced by it, but by the preceding pain.

Finally, it could be demonstrated that, also in this condition, pain increase was related to the fallure-inducing qualities and not to the back-stressing qualities of the test.

The purpose of this study was to test the above-mentioned findings in manipulated success and adequate feedback conditions. By having the subjects participate in two standardized treadmill testa, it was possible to study the effect of a manipulated expectation pattern on the persistence behavior of the second test on the basis of the results of the first test. 


\section{Method}

Subjects

Forty-one male CLBP petients and 39 healthy control subjects participated in the study.

Patients responded to an announcement in local newspaper. Selection criteria included:

- Low back pain for at least 6 months;

- somatic findings not corresponding with severity of complaints; no major pathological findings and adequate back functions in an orthopaedic examination;

- not suffering from cardiovascular disease, in view of the physical exercise involved in the research protocol;

- no diatinct limitations of motor performance or disturbance of walking ability due to disease or surgery.

The selection procedure was carried out by a general practitioner. It was made clear in advance that the study bore no relation to their medical treatment and that their participation was for research purposes only. The CLBP patients were clinically diagnosed as having low back pain, a degenerative back-disease, spondylasis, spondylarthrosis of chronic myalgia.

The male control subjects were recruited by letter from the general population of Maastricht and were matohed for age before being seen. The response ratio was about 10\%. The selection procedure was carried out by a general practitioner. Selection criteria included:

- absence of acute or chronic pain;

- absence of cardiovascular disease;

- no distinct limitations of motor performance or disturbance of walking ability.

All subjects were peid volunteers. 
Procedure and design

Figure 1 describes the design of the study.

Figure 1. Design

\begin{tabular}{|c|c|c|c|}
\hline EXP. I. & $\begin{array}{l}\text { Basic condition } \\
\text { CLBP } N=20 \\
\text { Control Sa. } N=19\end{array}$ & 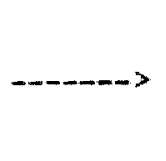 & $\begin{array}{l}\text { Success condition } \\
\text { CLBP } N=20 \\
\text { Control Ss. } N=19\end{array}$ \\
\hline & time $=0$ & & time $=0+3$ weeks \\
\hline EXP. II. & $\begin{array}{l}\text { Besic condition } \\
\text { CLBP } N=21 \\
\text { Contral Ss. } N=20\end{array}$ & $-\infty-\infty>>$ & $\begin{array}{l}\text { Adequate feedback condition } \\
\text { CLBP } N=21 \\
\text { Control Ss. } N=20\end{array}$ \\
\hline & time $=0$ & & time $=0+3$ werelks \\
\hline
\end{tabular}

Subjects performed treadmill exercises. Treading speed was maintained at $5 \mathrm{~km} / \mathrm{h}$ and grade at $5 \mathrm{~s}$ for the first minute, increasing by $1 \mathrm{y}$ at one minute intervals. These changes were below detection-threshold. Subjects were instructed to continue walking on the treadmill until $1 t$ was necessary to stop due to pain or fatigue. When they gave a signal, the procedure was ended immediately.

In the basic condition, which wes the same for all subjects, no verbal or non-verbal information was given to subjects on expected or actual performance. Any recording equipment which may have given them feedback was placed outside their field of vision. Subjects therefore had to make the decision to stop without recourse to external reference aids.

In the success condition, a clock was placed in front of the aubjects, which was started at the beginning of the treadmill-exercise. Furthermore, in this condition a frame of reference was offered to the sub- 
jects. Juat before the treadmill-test began the subjects were told the expected treading time. This time was suggested to be an average time for a CLBP group (or for a healthy group with the control subjecte), but in fact the time presented was the time measured in the basic condition for this subject minus $30 \%$.

The procedure in the adequate feedback condition was the same as in the success condition. However, in this condition the expected treading time suggested was in fact the exact time measured in the basic condition for this subject.

Only ofter completing the experiment were the performances discussed with the subjects.

\section{Measures}

The following biographic, paychological and samatic data was collected for each subject:

- Personal data: biographic questionnaire, pain anamesis (CLBP patients only), physical screening (including ECG), pre-test pain level (CLBP patients only), self-esteem questionnaire, N.P.V. (Dutch neuraticism questionnaire (16)), P.M.T. (achievement motivation questionnaire (17)).

- Treadmill recordings: ECG, heart rate, reapiratory quotient.

- Poot-teat recordings: max. heart rate, max. respiratory quotient, lactate (moles/1), post-test exhaustion level, post-test pain level (CLBP patients only) and total treading time.

Pre- and post-test pain levels, as well as post-test exhaustion levels were measured using the Visual Analogue Scale technique $(18,19)$.

\section{Rersults}

Descriptive variables are summarized in Table 1. 
Table 1. Some biographical variables for the CLBP group and control group in both experiments.

EXP. I.

EXP. II.

\begin{tabular}{|l|c|c|c|c|} 
& CLBP group & Control group & CLBP group & Control group \\
Mean age & $43(7)$ & $43(7)$ & $40(10)$ & $40(10)$ \\
Min. age & 31 & 32 & 26 & 26 \\
Max. age & 52 & 52 & 56 & 56 \\
Mean duration & & & $125(100)$ & - \\
of pain (months) & $138(109)$ & - & 8 & \\
Min. duration & & & & \\
of pain (months) & 14 & - & 360 & \\
Max. duration & & &
\end{tabular}

( ): s.d.

In the success condition, the success manipulation was adequate: all CLBP patients and all contral subjects performed better than the reference time offered. The results of the treadmill test for the different conditions are summarized in Table 2 .

Table 2. Results of different conditions on the treadmill test in experiment 1

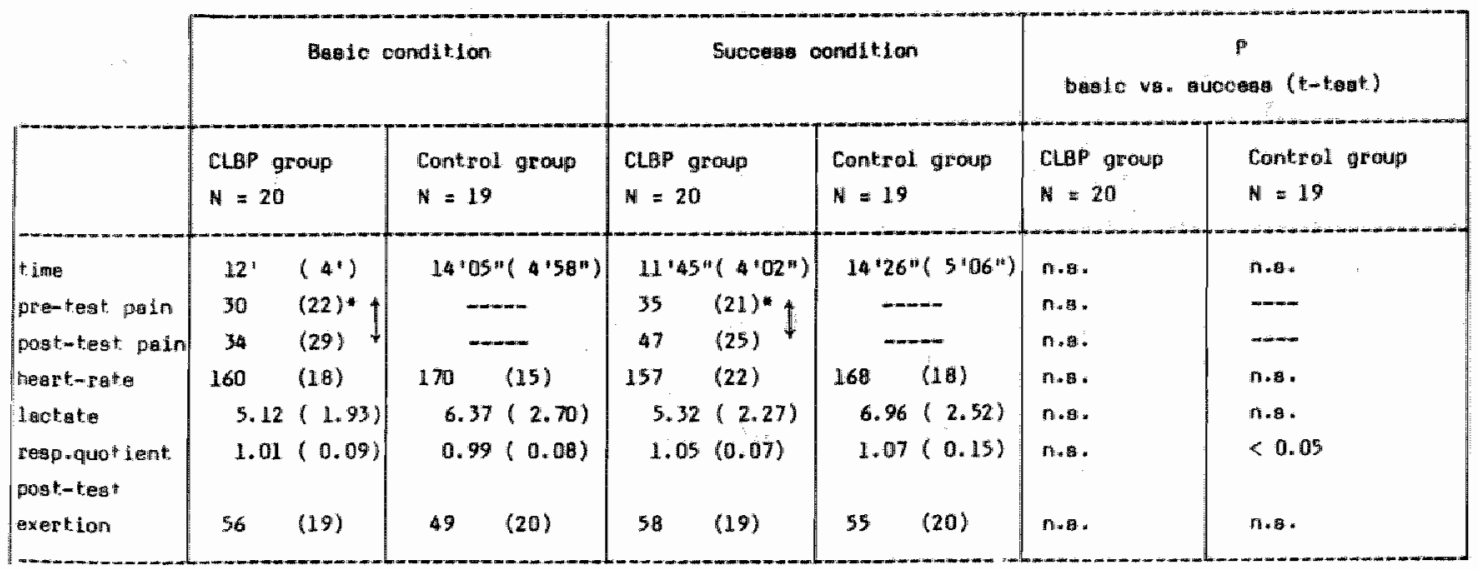


Experiment I: the success condition, compared to the basic condition. Chenges in dependent measurea were analysed by a 2 (basic vs. success condition) $\times 2$ (groups) analysis of variance for repeated measures (ANOVA). This analysis showed a significant group effect for lactate $(F=3.98 ; p=0.05)$ and significant condition effects for respiratory quotient $(F=5.90 ; p=0.02)$ and post-test pain $(F=8.32 ; p=0.01)$. T-tests were ured to compare performances within both groups in the basic and success condition. Comparing both conditions in general, the dependent variables within each group hardly changed.

In both conditions the CLBP group has a subjective post-test exertion lavel at least equal to the control group.

For CLBP patients the treadmill teat was not associated with significantly increased subjective pein. Pain increase (or decreese) - posttest pain minus pre-test pain - did not significantly influence treading time:

$\mathrm{r}(\Delta$ pain-time; besic condition) $=-0.06$ (n.s.)

$r(\Delta$ pain-time; success condition) $=-0.18(n .8$.$) .$

In order to test the findings of the earlier research summarized above, subjective and objective variables were correlated. The results are summarized in Table 3 .

Table 3. Results of different conditions on the treadmill test in experiment $\mathbb{I}$

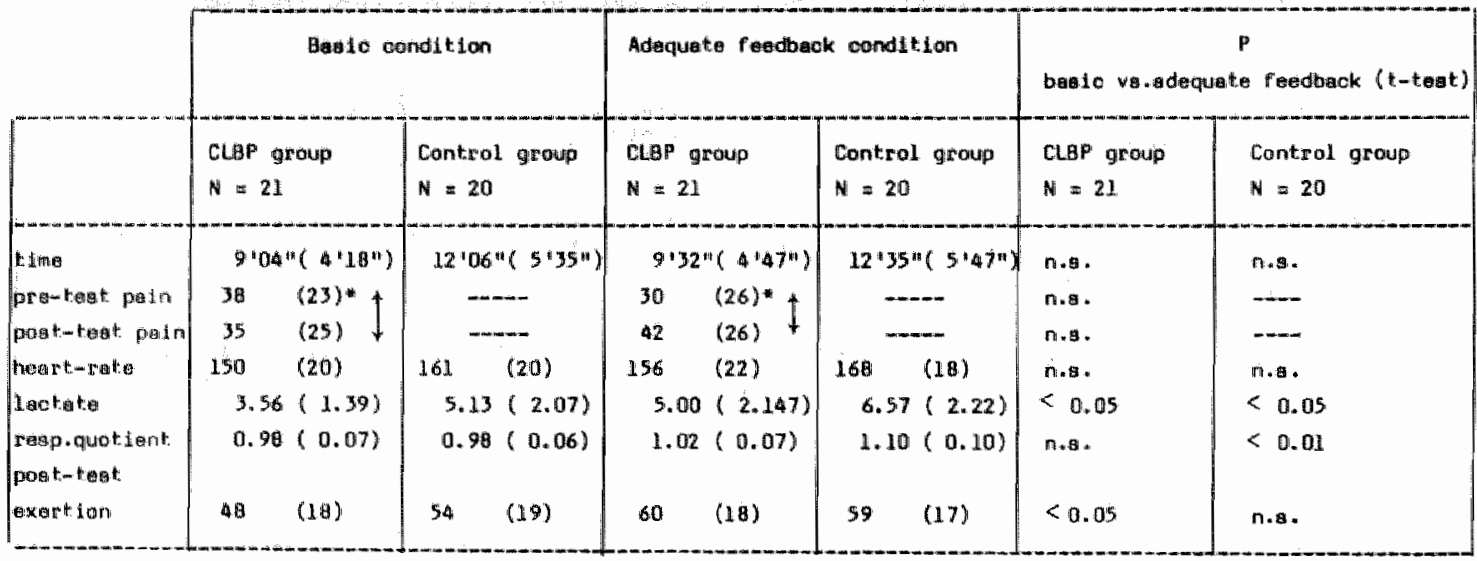


From this table it could be derived that pre-test pain has distinct predictive value for lactate in the basic condition and heart-rate in the success condition. Both for the CLBP group and the control group correlations between subjective and objective exertion levels are low and statistically not significant as is shown in Table 4.

Table 4. Correlation-matrix between subjective and objective variables in the basic and success condition

\begin{tabular}{|c|c|c|c|c|c|c|}
\hline & & & & & & \\
\hline & & & heart rate & lactate & time & resp.q. \\
\hline \multirow{6}{*}{$\begin{array}{l}\text { CLBP } \\
\text { group }\end{array}$} & \multirow{2}{*}{$\begin{array}{l}\text { pre-test } \\
\text { pain }\end{array}$} & basic cond. & -0.21 & $-0.59 * *$ & -0.19 & 0.28 \\
\hline & & success cond. & $-0.60 * *$ & -0.13 & -0.24 & -0.16 \\
\hline & \multirow{2}{*}{$\begin{array}{l}\text { post-test } \\
\text { pain }\end{array}$} & besic cond. & 0.00 & -0.18 & -0.20 & 0.16 \\
\hline & & success . cond & $-0.46 *$ & -0.19 & -0.39 & 0.28 \\
\hline & \multirow{2}{*}{$\begin{array}{l}\text { exertion } \\
\text { level }\end{array}$} & basic cond. & 0.24 & 0.36 & 0.00 & 0.40 \\
\hline & & guccess cond & -0.05 & $0.45 *$ & 0.33 & 0.27 \\
\hline \multirow{2}{*}{$\begin{array}{l}\text { Control } \\
\text { group }\end{array}$} & \multirow{2}{*}{$\begin{array}{l}\text { exertion } \\
\text { level }\end{array}$} & basic cond. & -0.02 & -0.22 & 0.24 & -0.04 \\
\hline & & success cond. & 0.01 & 0.04 & 0.13 & -0.11 \\
\hline
\end{tabular}

* $p<0.05$

** $p<0.01$

Experiment II: The adequate feedback condition, compared to the basic condition.

As in experiment I changes in dependent measures were analyaed by a 2 (basic vs. edequate feedback condition) $\times 2$ (groups) analysis of variance for repeated measures (ANOVA). This analysis ghowed gignificant group effects for respiratory quotient ( $F=4.71 ; p=0.03)$, lactate $(F=804 ; p=0.007)$ and heart rate $(F=3.98 ; p=0.05)$. Condition effects were significant for subjective exertion $(F=11.13 ; p=0.002)$, and heart frequency $(F=20.0 ; p<0.001)$. T-tests were used to compare performances within both groups in the basic and adequate feedback conditions. They show (see Table II) thet the significant condition effecto from the analysis of variance (ANOVA) were found for the CLBP group as well as for the control group.

In both conditions the CLBP group has subjective post-test exertion 
Levels equal to the control group at objectively different levels of per formance.

For CLBP patients the treadmill test was not associated with significantly increased aubjective pain. Pain increase (or decrease) - posttest pein minus pre-test pain - did not significantly influence treading time:

$r$ (apain-time, basic condition) $\quad=0.02$ (ns)

r (a pain-time, adequate feedback condition) $=0.32$ (ns)

Subjective and objective variables were also correleted for experiment II. The results are summarized in Table 5 .

Table 5. Correlation-matrix between subjective and objective variables in the basic and adequate feedback condition

\begin{tabular}{|c|c|c|c|c|c|c|}
\hline & & & & & \\
\hline & & & heart rate & lactate & time & resp.q. \\
\hline \multirow{6}{*}{$\begin{array}{l}\text { CLBP } \\
\text { group }\end{array}$} & \multirow{2}{*}{$\begin{array}{l}\text { pre-test } \\
\text { pain }\end{array}$} & basic cond. & -0.04 & 0.07 & -0.05 & 0.00 \\
\hline & & adeq.f.cond. & 0.41 & 0.09 & 0.40 & 0.14 \\
\hline & \multirow{2}{*}{$\begin{array}{l}\text { post-test } \\
\text { pain }\end{array}$} & basic cond. & -0.09 & -0.23 & 0.00 & $-0.51 *$ \\
\hline & & adeq.f . cond & 0.18 & 0.09 & 0.20 & 0.15 \\
\hline & \multirow{2}{*}{$\begin{array}{l}\text { exertion } \\
\text { level }\end{array}$} & basic cond. & -0.11 & 0.16 & 0.12 & -0.03 \\
\hline & & adeq. $f$.cond. & 0.10 & $0.45^{*}$ & 0.243 & 0.16 \\
\hline \multirow{2}{*}{$\begin{array}{l}\text { Control } \\
\text { group }\end{array}$} & \multirow{2}{*}{$\begin{array}{l}\text { exertion } \\
\text { level }\end{array}$} & baslic cond. & $0.50^{*}$ & $0.55 *$ & 0.561 & 0.37 \\
\hline & & adeq.f.cond. & $0.53 *$ & $0.54 *$ & 0.41 & $0.45^{*}$ \\
\hline
\end{tabular}

* $p<0.05$

In this experiment it seems that neither pre-test pain nor post-test pain correlates significantly with the objective performance variables. However, while there is no significant correlation between subjective exertion level and objective performance variables within the CLBP-group, this correlation is clear and positive within the contral group. 


\section{Discussion}

The purpose of this research was to investigate the persistence behavior of CLBP patients under standardized conditions in which the expectation pattern was manipulated experimentally. Conclusions drawn from earlier research concerning the persistence behevior of CLBP petients in a failure condition, were used as hypotheses to investigate the persistence behavior of CLBP patients in the same treadmill setting in which a success condition and an adequate feedback condition were manipulated. The results will be discussed on the basis of these hypotheses.

Hypothesis 1. CLBP patients perform more poorly on the treadmill-test as measured by total treading time and physiological measures compared to a healthy control group.

Although the differences are not large, Table II and the ANOVA show that especially on the physiological measures the CLBP group achieves somewhat less. That these differences are smaller than those found in the study in which the fallure condition was used may be the result of different patient selection procedures. In the failure condition investigetion the CLBP patients were asked to participate during thell visit to the orthopedic specialist in the hospltal. In this study they were recruited by an announcement in a local newspaper.

Hypothesis 2. The treadmi1-test, although back-stressing, is not associated with pain increase.

In the study of CLBP behavior under fallure conditions (15) it was shown that differences in achievement between the CLBP group and the contral group could not be explained by an increase of pain in the CLBP group. It was ghown that reports of an increase of pain within the CLBP group should be viewed more as attribute of the failure experience than as the result of the back-stressing capacities of the treadmill-test. This means that in the present investigation in which no failure experience was manipulated, no Bignificant increase in pain was expected for any of the conditions. This Indeed appeared to be the case. These findings therefore strengthen the theory relating to the attribution function of pain in a failure experience which was men- 
thoned earlier. Furthermore, it appears that the treadmill test does not result in subjective increase of pain and cannot be used as an explenation for the differences in the performance measures between the CLBP group and the control group.

Hypotheais. 3. The persistence behavior of CLBP patients in backstressing situations is determined more by pre-test pain levels than by post-test pain levelo.

In the failure condition study it was concluded thet the physicallyimposing persistence behavior of CLBP patients under failure conditions is not regulated by the pain that is produced by it, but by the preceding pain. As mentioned earlier correlations between -0.67 and -0.74 were found between physiological perforinance measures and pretest pain level. This may not be concluded, however, on the basis of the study of the success and adequate feedback condution. In the success-condition pre-test pain correlates only with heart rate; in the adequate feedback condition no significant correlations can be found. On the other hand, however, it seems that neither the level of pain at the moment the test was stopped nor the increase of pain during the treadmill-test are related to the achievement measures. The interpretation of this data is unclear. It could be hypothesized that CLBP patients as a result of their physical limitations are prone to give up quickly when they enticipate failure, decision which is influenced by the degree of pain present beforehand. In conditions where this anticipation is present to a lesser degree or where the CLBP patient does not experience failure, his performance behavior will be more like that of heal thy subjects.

As a general conclusion it can be stated that the giving-up or persistence behavior of CLBP patients in back-atressing performance situations is certainly not a clear function of the subjective pain experience. On the one hand, back-stresing does not automatically mean more back pain. In general this is not the case. On the other hand, expectations, perticularly negative expectations, seem to influence the performance ultinately delivered. The promising cognitive-behavioral approach is relevant here $(6-9)$. 
Hypothesis 4. CLBP patients do not adequately observe proprioceptive fatigue signals.

This statement was based on the results of the failure condition study. It was found that in the control group subjects who stop relatively early generally report a lower level of tiredness than aubjects who continue for longer time. This correlation was also found between subjective exertion on the one hand and heart rate, lactate and respiratory quotient on the other. $R$ varied between 0.45 and 0.50 , which is quite similar to the correlation between the physiological measures. For CLBP patients this more or less obvious relation was not found. It was therefore concluded that because CLBP patients who were not at all tired reported that they were severely tired as well as not tired at 811, the CLBP patients' perception of tiredness was disturbed. Mareover, it was shown in the failure condition study that the presentation of - false - external information to the CLBP group as well as to the control group constitutes a noise factor for the adequate perception of tiredness.

In both experiments done in this study it appears that the CLBP group does not give an adequate estimate of their own physiological exertion in any of the conditions investigated. In experiment I (the basic and suiccess condition) this seems to be a somewhat unexplainable artifact, since there is also no correlation between subjective and objective exertion variables in the control group. In experiment II, however, (the basic and adequate feedback condition) findings are again clearer: correlations within the control group are systematic and significant, varying between 0.45 and 0.55 . Besides, presentiation of adequate feedback and information adds no noibe-effect, compared to the basic condition. In this experiment, also shown in Table IV, the CLBP group beheves differently. According to hypothesis 4 , within the CLBP group, objective perfarmence variables and gubjective exhaustion are independent variables.

This means that CLBP patients when deciding to end a physical exertion da not rely on their subjective feeling of tiredness. It was stated before that they also do not use the absolute pain level or the increase of pain as a reference. This is a confirmation and expansion of the 'adagium of Fordyce' (13): "pain behawiors may be little, if at all, related to inferences about underlying noxious stimulation"; or 
In other words: what a CLBP patient does is one thing, what he reports about his pein and exertion is another thing.

\section{Hypothesis 5.}

CLBP patients are inclined to overrate their actual individual effort. As can be seen in Table II, in both experiments and all conditions post-test exertion levels of the CLBP group and the control group do not differ. However, objective performance variables are systematically higher for the control group than for the CLBP group. This leads to the conclusion that CLBP patients have a generalized tendency to subjectively overrate their actul efforts.

This research leads to the conclusion that most of the findings from earlier research can be confirmed, but that theoretically fewer new points of view energe than in the failure condition research mentioned before. In this connection it is doubtful whether the success manipulation, for example, has been experienced as such. This was only put in relative terms; meeting the reference time requirement meant perfarming better than the avarage of a back pain group. This can, however, mean very little to the CLBP patients since no information was given obout the reference time of healthy subjects. This holds for the adequate feedback condition as well. The failure condition is much clearer: fallure with respect to the CLBP norm time would mean a certain failure with reapect to the norm of, the control group. Fram a therapeutlo point of view further situdy of the back pain behavlor of patients who are offered real success experiences seens relevant, particularly for the group of serious and chronic LBP patients who are in a treatment setting where the avoidance of unnecessary fallure experiences is the basis for treatment. Reference can be made to Fordyce who in an almost Iidentical treadmill setting produced very significant improvenent in performance by repeating the test several times and offering adequate feedback (13).

The study clearly shows that the CLBP graup is very heterogeneous, consisting of CLBP patients who function very well and those who function very poorly. Both groups experience many success and many failures in their daily lives that are related to their physical capacities. This is reflected in the treadmill-study. A comparigon 
between subgroups of CLBP patients with very good and very poor treadmill-test performances could refine the conclusions of this situdy. In this way a clearer description of disabled CLBP patients could be provided. 


\section{References}

1. Vâllfors B. Acute, subacute and chronic low back pain: Clinical symptoms, absenteeism and working environment. Scandinavian Journal of Rehabilitation Medicine 1985; supplement no.11.

2. Nachemson A.L. Low back pein. Its etiology and treatment. Clinic. Med. 1971; $78: 18-24$.

3. Flor H., Turk D.C. Etiological theories and treatments for chronic back pain. I. Somatic models and interventions. Pain 1984; 19: 105-121.

4. Melzack R. The Puzzle of pain, Penguin, Hammondsworth, 1973.

5. Sternbach R.A. Fundementals of psychological methods in chronic pain. In: Bonica J.J. et al. (eds.) Advances in pain research and therapy, vol.5. Raven Press, New York, 1983.

6. Turk D.C., Melichenbaum D., Cenest M. Pain and behaviorel medicine, a cognitive - behavioral perspective. Guilford Press, New York and Landon, 1983.

7. Turk D.C., Flor H. Etiological theories and treatments for chronic back pain. II. Paychological models and interventions. Pain $1984 ; 19: 209-233$.

8. Tan $5-Y$. Cognitive and cognitive-behavioral methods for pain control: a selective review. Pain 1982; 12:201-228.

9. Turner J.A., Chapman C.R. Psychological interventions for chronic pain: a critical review. II Dperant conditioning, hypnosis, and cognitive-behavioral therapy. Pain 1982; 12:23-46.

10. Fordyce W.E. Behavioral methods for chranic pain and illness. Moaby, St. Louis, 1976.

11. Fordyce W.E., Fowler R.S*, Lehmann J.F., Delateur B.J., Sand P.L., Trieschmenn R.B. Operant conditioning in the treatment of chronic pain. Arch. Phys. Med. Rehabil. 1973; 54:399-408.

12. Fordyce W.E. Behavioral conditioning concepts in chronic pain. In: Bonica J.J. et al. (eds.) Advances in pain research and therapy, vol.5. Raven Press, New York, 1983.

13. Fordyce H.E., Robers A.H., Sternbech R.A. The behavioral management of chronic pain: a respanse to critics. Pain 1985; 22: $113-125$. 
14. Schmidt A.J.M. Cognitive factors in the performance level of chronic low back pain petients. J. Psychosom. Res. 1985; 29:183-189.

15. Schmidt A.J.M. Performance level of chronic low back pain patients in different treadmill-test conditions. J. Psychosom. Res. 1985; 29:639-645.

16. Luteyn F., Starren J., Van Dijk H. Nederlandse persoonlijkheidsvragenlijst. Swets \& Zeitlinger B.V., Amsterdam, 1974.

17. Hermans H.J.M. Handleiding bij de Prestatie Mativatie Iest (PMT). Swets \& Zeitlinger B.V., Amsterdam, 1968.

18. Carlsson A.M. Assessment of chronic pain. I. Aspects of the reliability and validity of the visual analogue scale. Pain 1983; 16: 87-101.

19. Price D.D., McGrath P.A., Raffii A., Buckingham B. The validation of visual analogue scales as ratio scale measures for chronic and experimental pain. Pain 1983: 17:45-56.

\section{Acknowledgements}

The author acknowledges the valuable criticisms of J. Bremer and the assistance of R. Gierlings, M. de Heus, J. van Houtem, I. van Noppen and the staff of the sport-laboratory of the Univeraity of Limburg, particularly $P$. Geurten, H. Kuipers and F. Verstappen. 
$-78-$ 


\section{GENERAL IZATIONS}

In the preceding articles the persistence behavior of CLBP patients was studied in standardized, back-stressing conditions. The absence of advance information, i.e. feedback during the test procedure, was always the basic condition. These results were compared with the results from repeated measures in other experimental conditions in which the information and feedback offered were manipulated in such a way that the influence of expectations on the performance level could be determined.

In anticipation to the general discussion, it can now be stated that the persistence behavior of CLBP patients in all the conditions inverstigated is worse than that of the contral group. It could not be demonstrated, however, that this lower level of performance was a direct result of the back-stressing, and therefore assumed pain provoking, character of the treadmill test.

If it appears that the poorer persistence behavior of CLBP patients is not dependent on reported increase in back pain, the following assumptions are warranted:

1. In back-stressing circumstances CLBP patients are more cautious than is necessary because of an unfounded fear of increasing their pain.

2. Even in other than back-stressing performance situations, their persistence behavior is prabably not optimal. This last hypothesia is important with respect to the consequences for all kinds of activities in the daily life of CLBP patients.

In the studies discussed in the following articles this last hypothesis was further investigated in two performance directed testa. In the first atudy the persistence behavior of CLBP petients was invasigated in an acute, experimental pain situation, the cold-pressor test, which is not considered as back pain relevant.

In the second study the persistence behavior of CLBP patients was investigated in a perfomance situation, a psychomotor reaction time test, which is not considered to be in any way pain relevant. The design of both studies was based as much as possible on the proce- 
dure applied in the basic condition of the treadmill test:

- performance tagk that gradually increases in difficulty,

- no information or feedlback which could be used as a frame of reference, and therefore provide the subjects with information about how well or how poorly they performed at that moment,

- the moment at which the cotivity stopped was completely left to the subjects,

- perbistence behavior was chosen as the most important dependent variable. 
9.1.

\title{
PERSISTENCE BEHAVIOR OF CHRONIC LOW BACK PAIN PATIENTS IN AN ACUTE PAIN SITUATION
}

\author{
ANton $\mathbb{I}$. M. Schmid ${ }^{*}$ and ANne-MInke E. F. Brands \\ (Received 15 August 1985; accepted in rewised form 29 October 1985)
}

\begin{abstract}
The test behavior of 24 chronic low back pain patients was compared with the behavioi of

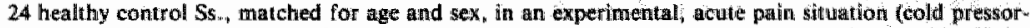
test). Chronic low back pain patienis showed poorer persistence behavior and feported mon pain. Thus, elements of typical chronic low back pain behavior were also present in an acute pain situation. These findings are discussed within the framework of stimulus-generalization theory. In addition the effect of different coping strategies on pain tolerance was reconfirmed. The chronic low back pain group and the contral group did not cope differently.
\end{abstract}

\section{INTRODUCTION}

IN THE literature on pain research the distinction between acute pain and the chronic pain syndrome is emphasized. Acute pain is considered to be "as symptom which occurs as an automatic or reflex response to an afferent stimulus produced by some pathogenic factor" [1]. With acute pain the onset is recent and is related to tissue damage. Acute pain is gemerally considered to be a sensory phenomenon $[2-4]$.

To understand the chronic benign pain syndrome a multidimensional approach is necessary, in which not only the pain-antecedent but also the pain-consequent factors can be studied [5-7]. Chronic benign pain is not considered to be the result of tissue-damage. On the contrary: "most striking is the lack of the typical response pattern associated with acute pain. Physiological changes indicating autonomic nervous system actiwity are not present" [8]. In contrast to acute pain, chronic pain, for which 6 months is often set as the lower limit, appears to be related to personality variables, although this personality image shows little coherence. Chronic, non-organic pain was linked to anxiety, neturoticism, introversion, depression and low self-esteem $[9,10]$. Specific MMPI profiles were also described [11].

With regard to treatment possibilities, acute and chronic pain situations are also totally different. While somatic treatment is frequently successful with acute pain, this approach often fails with chronic benign pain. Hartman ef al. [12] state that 'recent estimates suggest that no more then $50 \%$ of chrontic pain patients obtain adequate amelioration of pain as a function of purely somatogenic treatment'. These figures compare favourably with similar evaluations of chronic low back pain (CLBP) patients [13]. Hartman concludes that, among other things, "lack of efficacy of the traditional medical treatment approaches has forced many patierits into a 'low back loser' career with changing physictans, growing medical records, disability, depression and overutilization of the health care system without appropriate relief" [13]. Bionica further notes "the lack of organized teaching and the

- Requests for reprints: Dr. A. J. M. Schmidi, Depl. of Medical Psychology, Universily of Liraberg P.O. Box 616,6200 MD Mastrichn, The Netherlands. 
lack of appreciation of the difference between acute and chronic pain causes physicians to apply the same therapeutic modalities as are used in treating acute pain to the management of patients with chronic pain; this invariably ends in drug toxicity and drug dependence 14 ]. This fundamental distinction, in the diagnostic as well as the therapeutic field, between acute and chronic pain does not, however, make the question of their interaction less important or interesting. This interaction can occur when chronic pain patients are confronted with an acute pain situation. There are two psychological theories which suggest that chronic pain patients will behave differently in an acute pain situation than non-chronic pain patients. These two theories, which in fact lead to opposite hypotheses, can be designated as the stimulus generalization theory [15] and the adaptation level theory [16]. According to the principle of stimulus generalization, a particular response which is at first linked to only one specific stimulus will after some time generalize to other stimuli which resemble the original stimulus [15]. From this hypothesis can be deriwed that chronic pain patients will react with chronic pain behaviour not only in situations that can be regarded as ones which would elicit chronic pain (e.g. physical exertion for CLBP patients), but also in acute pain situations. This hypothesis can be operationalized by stating that CLBP patients when given an acute, experimental pain stimulus will react with poorer persistence behavior than a control group. On the other hand, the adaptation level theory states that 'pain patients would evaluate experimental pain within the context of their previous experiences with pain. The model predicts that pain patients should have higher pain thresholds than controls because of extensive prewious experience with pain' [16]. This theory thus predicts that when given an acute experimental pain stimulus, a CLBP group will exhibit better persistence behavior than a control group.

The primary abjective of this research was to test both conflicting hypotheses in a controlled setting. The cold-pressor test was chosen as the acute, experimental pain stimulus. This method was selected because of the relatively simple and therefore easy to standardize procedure, and on the basis of good experiences which are mentioned in the pain research literature $[17,28]$. This literature also indicates that cognitive coping strategies (e.g. "attention focusing' $v . s$. 'distraction') influence the maximum pain tolerance $[18-20,22-25,27,29-32]$. For this reason cognitive variables were included in this study.

\section{METHODS}

\section{Subjects}

Forty-eght male subjects participated in the cold-pressor-test. The 24 CLBP patients were setected from a larger sample of CLBP patiens who participated in earlier research. Selection ariteria included: low back palif for at least 3 yr

sontatic find ings not corresponding with severity of complatints: no major pathological findings and adequare back fienctions in an orihopaedic examination.

Excluded were pathents with evident somatic fandings: ankglosing spondylattis, cancer and spinal infections as well as referted pain from the trirary tract of inestine and pelwic organs $[34\}$.

The CLBP patienis were dinically diagnosed as having low back pain, a degenerative back-complaint, spondylosis, spondyatrthosis or chronic myalgia. The condition for partitipation in the test was the presence of constart chrotit: pain, which possibly waried in intensity. The 24 control subjects were recruited from the general population of Maastricht and were matched for age before being seen. Subjects received a shor medical questionmaire. Exclusion criteria-ialso for the ClBP parients-included Raynaud phenomenon, carpal tunnel syndrome, exacerbating infecton, blood pressurt hagher than $170-100$ and cartiovagcular disorders. All normall subjects and CLBP puticnts were paid wolunters. 
Apparatus

Ice water was chosen as the pain stimulus, replicatung the cold pressor hest procedure of Bliz and Dinnerstein [25]. The subject's non dominan hand was immersed in a plastie container $(8 \times 8 \times 16$ inchy of tee water which was maintained at $1^{*} \pm 1^{\circ} \mathrm{C}$ by occasionally adding ice. The temperature was measured prior tho each trial.

\section{Procedure}

All subjects were rested in a singte blind design by a female experimenter. Upon entering the laboratory ${ }_{n}$ the subjects learned about the prowedurc, were asked to remove jewelry on the non dominant hand and sit in a straight back chair with arms. The following instructions were pregented wotly:

"When I signal, without mowing the fingers, place your open hand in the cold water up to the wrist."

Keep your hand in the ice water for as tong as you can, Say 'stop' when you reach your maximum pain tolerance. Then immediately take your hand out of the cold wation "(instruction parapthrased).

When subjects signaled that they had reached their tolerance, the experimenter stopped the timer which had been started ty the inmersion signal. Time was measured in seconds; the preset limit for immersion being 5 min. After subjects look their hands out of the water, the experimenter megsured pain intensity on a-100 Vusual A ralogute Scale. Then subjects were asked to sit quielly and relax without moving their painful hand. The following instructions were presented orally: "Say "stop" when the pain sensations in your hand disappear. Mild tingling and warm seristations may last but are not painful'. When subjects signaled that the pair sensations were gone, the experimenter stepped the timer again, measuring the pain extinction time.

In addition ${ }_{n}$ subjects were informed that the cold pressor test had been completed and were asked about the cognitive coping strategy employed most during immersion, for example:

"focusing on pain sensations" vs "distraction"

maxumum ws non-maximum motivation to persist during immersion.

The whole experimental session lasted approx. $20 \mathrm{~min}$.

\section{Measures:}

The following information was watatated from the CLBP patients:

Prewlest measurew.

somatic screening (questionnaire)

pain-anamnesis

assessment about situations provoking and dimmishung low back pain

self-esteen questionnaire

pre-test low back pain lewel on a 0-100 Visual Analogue Stalle.

Test mieasures:

pain tolerance time

pain intensily (WAS)

pain extinction time.

Post-hesr mearsiarens.

questionnaire containing 2 force choice questions about coping strategies

post-test low back pain level (VAS).

The same information with the exception of the low back pain specific measures was obutined from the control group.

\section{RESULTS}

In both groups the average age was 43 and the range was $27-56$. Subjects in the CLBP group had back complaints averaging $14 \mathrm{yr}$, with a lower limit of $3 \mathrm{yr}$ and an upper limit of $27 \mathrm{yr}$. Situations or circumstances that elicit or aggravate back pain are generally described in terms of physical exertion (e.g. bending, lifting), colld or bad weather and a lack of movement (e.g. sitting in the same position for a long time). Situations or circumstances that decrease back pain mainly inwolve movement, warmth, good weather and especially rest ( $2 / 3$ of the CLBP patients). The lack of coherence is striking: physical exertion and rest can both increase and decrease the back pain (see Table I). The reinforcing role of bed(rest) is likewise 
striking. Chronic back pain behavior is thus primarily characterized by the avoidance of exertion.

\begin{tabular}{|c|c|c|c|}
\hline Incretises back pain & & Decreases back pain & \\
\hline $\begin{array}{l}\text { Physical exertions (bending, } \\
\text { lifting, walking standing) }\end{array}$ & $29 \times$ & Rest & $16 x$ \\
\hline Lying, situmg, driwing a car & $11 x$ & Movement/sports & $7 \times$ \\
\hline Weat wer thangesircoli & $9 x$ & Cood weather warmth: & $6 x$ \\
\hline Psychological tensions & $4 x$ & Alternative medicine & $2 \times$ \\
\hline Other & $3 x$ & & \\
\hline
\end{tabular}

The difference in cold-pressor test behavior between the CLBP group and the control group is presented in Figs. 1 and 2 . The frequency distribution (in strata of $20^{i t}$ ) of the maximum pain tolerance time for the control group and the CLBP group is given in Fig. 1. The Mann-Whitney U rest for two independent samples (corrected for tied scores) showed a significant difference between both groups $\left(U=130, N_{1}=N_{2}=24\right.$, $p<0.01$, two-tailed); the CLBP group performing less well.

The frequency distribution (in strata of 20") of the pain-extinction time for the control group and the CLBP group is given in Fig. 2. The Mann-Whitney U test for two independent samples (corrected for tied scores) showed a significant difference between both groups $\left(U=182, N_{11}=N_{2}=24, p<0.05\right.$, two-tailed); the CLBP group showing a shorter extinction time.

This shorter extinction time is more related to pain tolerance time $(r=0.52$, $p<0.01)$ than to max. pain $(r=0.09, \mathrm{NS})$. The mean pain intensity level for the CLBP group was 70 (sD 18), for the control group this was 54 (sD 24), meaning that the CLBP patients reported more intense pain at the end of the hand-immersion period $(t=2.35, \mathrm{df}=46, p<0.05)$.

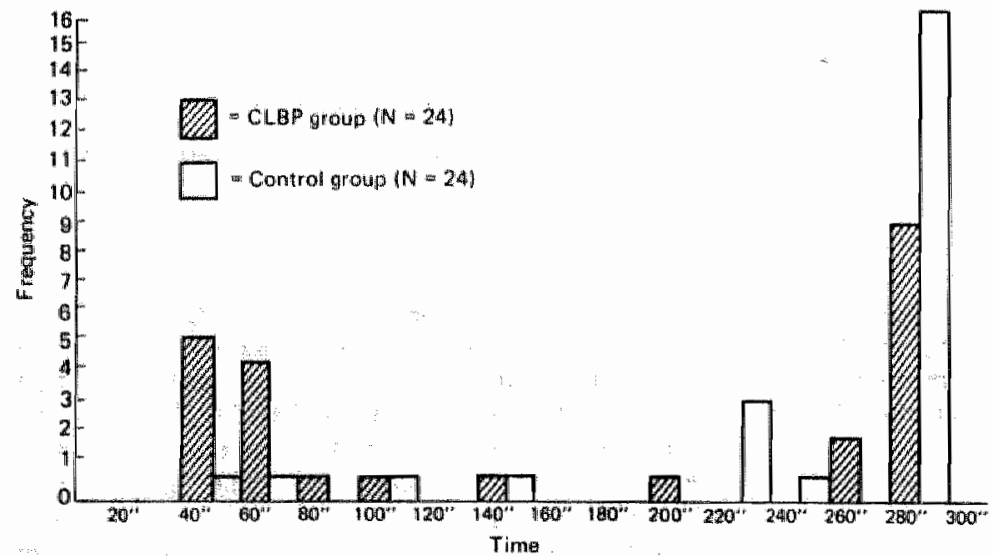

From. 1. Frequency distribution of maximum pd in tolerance time of CLBP patients and control subjects on the cold pressor test. 


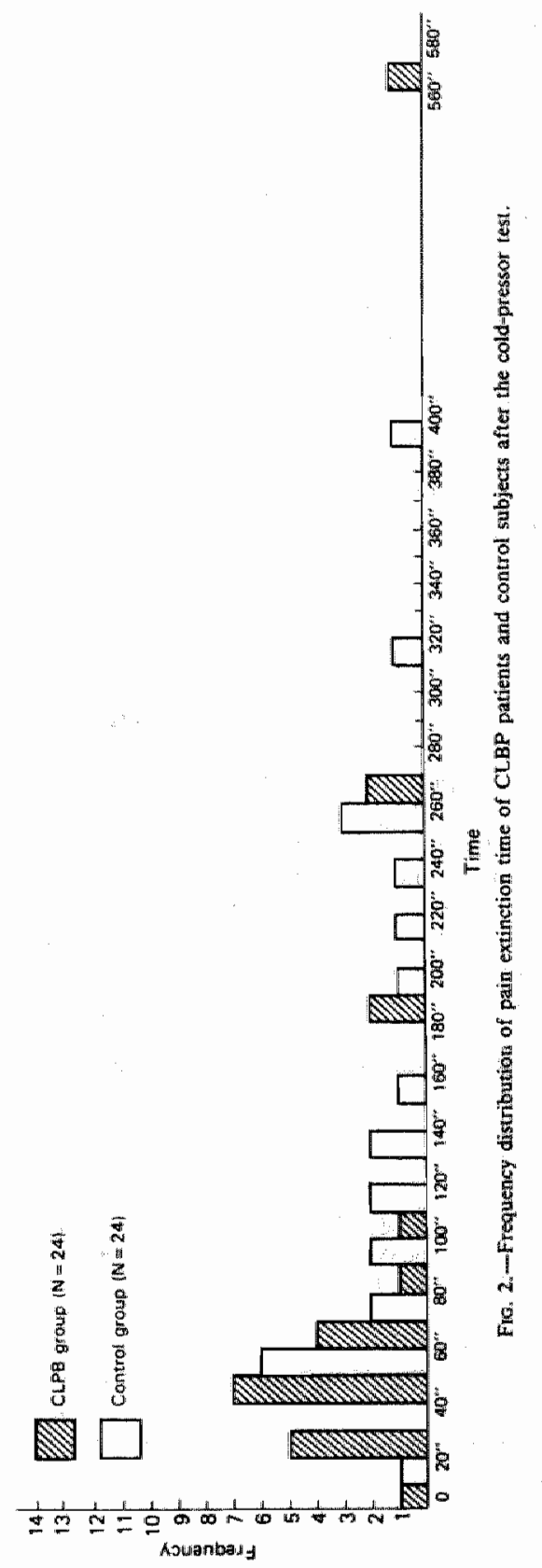


A clear effect of reported coping style on maximum pain tolerance time could be shown: "focusing on pain sensations" resulted in poorer pain tolerance time, compared with 'distraction' (Mann-Whitmey $U=208, N_{1}=22, N_{2}=26, p<0.05$ ). A lower pain volerance time was also found with the group that in retrospect reported a nonmaximum motivation to persist, compared with the maximum motiwated group (Mann-Whitney $U=190, N_{1}=17, N_{2}=31, p<0.05$ ). However, no difference was found in coping strategy between the CLBP group and the control-group:

$x^{2}$ (focusing vs distraction) $\quad=0.34 \mathrm{df}=1$; NS.

$x^{2}$ (max. vs nom max. motivation) $=0.09 \mathrm{df}=1$; NS.

Therefore differences in test behavior between both groups could not be attributed to a difference in coping style,

No relations could be found between duration of low back pain (in months) and pain tolerance time $(r=0.20$, NS) or pain intensity level $(r=0.04, \mathrm{NS})$.

For the CLBP group the cold pressor test did not significantly influence reported low back pain intensity as measured by comparing pre- and post-test low back pain level. The Sign test showed $11(+), 4(0)$ and $9(-), N S_{;} \bar{X}$ pre-test pain level $=40$; $\widetilde{X}$ post-test pain level $=40$.

\section{DISCUSSION}

The results show that some aspects of chronic low back pain behavior are also present in an experimental, acute pain situation. These aspects are a poorer persistence behawior ${ }_{\text {, }}$ combined with the subjective report of more intense pain. At first these findings appear to contradict the research of Cohen et al. [16] who found higher heat pain thresholds for a CLBP group than for a control group. He explains this increased threshold with the adaptation theory. However, it is important to realize that Cohen was specifically interested in pain perception thresholds, while this study dealt with maximum pain tolerance and avoidance or coping behavior. Secondly, Cohen only used subjective reports (VAS) as a basis for his conclusion, while this study, and also many others $[1,4,33]$, show that there can be a wery considerable discrepancy between verbal pain report and observable pain behavior with CLBP patients. Therefore, observation of the persistence behavior of CLBP patients in an acute pain situation gives more support to the stimulus generalization theory than to the adaptation theory. Newertheless, there is no contradiction between both studies: a higher pain perception threshold can be associated with a lower maximum pain tolerance, thereby narrowing the perceived intensity of a broad range of pain stimuli.

Stimulus generalization theory seems to be the theory of choice for the explanation of the influence of chromic pain in an acute pain situation. The converse influence of the acute pain stimulus on the post-test low back pain level could not be demonstrated.

The fact that CLBP patients react with chronic pain behavior in an acute pain situation does not logically mean that this type of behawior is the result of chronicity. Theoretically it is also possible that poorer persistence behavior combined with the report of more intense pain in an acute pain situation is a risk factor in the etiology of chronic pain. If this is the case, it can be hypothesized that 
the disturbed acute pain behavior of CLBP patients is independent of the duration of the low back pain. This hypothesis cannot be adequately tested with our group of CLBP patients. It is true that no relation was found berween these 2 variables, but CLBP patients with complaints for a duration of less than $3 \mathrm{yr}$ were not ineluded in this study. To test this etiological hypothesis a longtitudinal study is necessary. The shorter pain tolerance time of the CLBP group compared with the control group fits well with the reported shorter extinction rime. This can be explained physiologically. However, reports of pain intensity at the end of the immersion period are disproportionately high. In other words, CLBP patients estimate the pain as more intense compared with non CLBP patients. This may heighten the reinforcing value of poor persistance behavior with these patients.

It is important to notice that both the experimental and the control group were controlled for cognitive coping style, the most relevant coping styles being "focusing" vs. 'distraction' and 'maximum' vs. 'non-maximum motivation'. Although the effect of these strategies on maximum pain tolerance time was clear and in accordance with the results of other research, differences between both groups could not be attributed to their differential use of these coping styles.

The major characteristic of this research is the introduction of a new, acute pain situation to chronic pain patients. The question which can be asked is which learning processes and behavior changes will occur on repeated measures with relatively short. interwals. In non-CLBP patients training and habituation effects will probably occur, resulting in an increase of persistence behavior.

However, for CLBP patients it can be hypothesized that according to stimulus and response generalization phenomena, with repeated tests more and more aspects of chronic pain behavior will determine the acute pain response, thereby leading to a decrease of persistence behavior. This would give insight into the psychological etiollogy of chronic low back pain.

Acknowledgements-The authors acknowjedge the assistance of R. Gierlings, J. van Howtem, I. van Noppen and $G$. van Wunnik.

\section{REIERENCES}

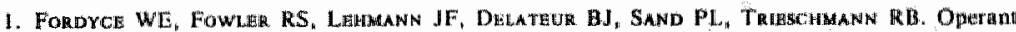
conditioning in the treatment of chronis ptin. Arch Phys Med Rehathil 1973; 54:399-408.

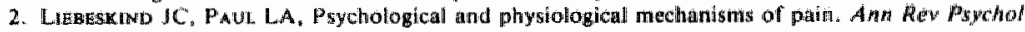
1977: 28: 41-60.

3. ANDERsan LP. REHM LP. The relationship betwern strategics of coping and perception of pain in: three chronic pain groups. I Clin Psychor 1984; 40; 1170-1177.

4. Fordyce WE, Steger JC. Chronic Pain. In Behavioural Medicine: Theory and Practice (Edited by

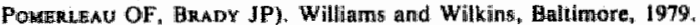

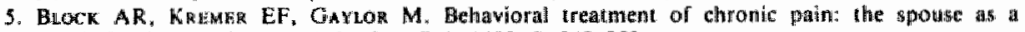
discriminative tue for pain behawior. Pain 1980; 9: 243-252.

6. TURmex IA. CHAPman CR. Psychological interventions for chronic main: a crinkal review, $I$. Relaxak on training and biofeedback. Paim 1982; 12: 1-21.

7. TURener JA, Chapman CR. Psychological interventions for chronic pain: a critical review, I1. Operant condicioning, hypnosis and cognitiwe-thehawioral therapy. Pain 1982: 12; 23-46.

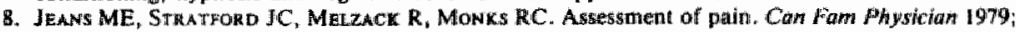
$25: 159-162$.

9. El ton D, Stanley GV, Blumeows GD. Self-esteem and chronic pain. J Psychosom Res 1978; 22: 25-30. 


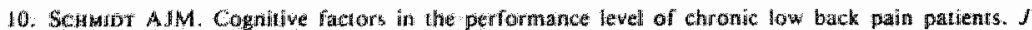
Pingehosom: Re; $1985 ; 29: 183-189$

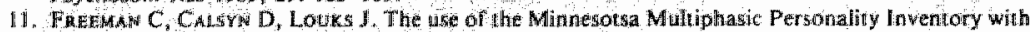
low back pain paitients. J Clin Psychol 1976: 32: 294-298.

12. HastMAH LM AIs

13. FLo HI TuR DC Etiological ineories and lleatmients for chronic back pain. I Sormatic models and

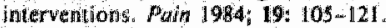

14. Bomen II. Uitutled. Tritugle 1981:20:1-6:

15. Fonovice WE. Wehawtoral conditioning comcepts int chronic pain. In Aldwances in Pain Research and

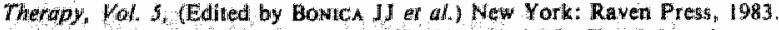

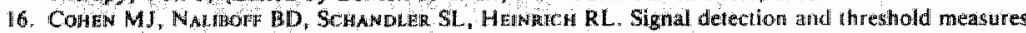
to loud tones and radiant heat in chironte low back pain patients and cohot controls. Pain 1983: 16: $245-252$

17. TAN $\mathrm{S}_{-} \mathrm{Y}$. Cognitive and cognitsvebehavioral methods for pain control: a selective review. Pain $1982 ; 12 ; 201-228$.

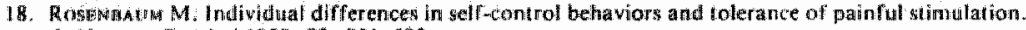
J. Abnorm Princhal 1980; 89: $351-590$.

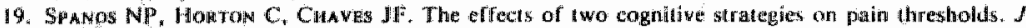
Abnorm Psycthol 1975; 84: 677-681.

20. KMNFE FH, SEIONER ML. Self-control: factors enthancing toleriance of noxious stimulation. I Person Soc Prychol 1973; $25: 381-389$.

21. Dowino I. Autonomic measures and behavioral indices of pain sensitivity. Fat 1983; 16: 193-200.

22. JaRzmo ME. Cognitive strateglies in the control of pain tolerance. I Behov Therap Exper Psychiat 1978:9:239-244.

23. BHERs TM, KaroLY P. Cognitive strategies, expectancy and coping style in the control of pain. $J$ Consult Clin PSycholl 1979: 47: 179-180.

24. MCCAUI, KD, HAUGTVEDT C. Attention, distraction and cold-preissor pain. I Person Sac Prychol 1982; 43: 154-162:

25. Burtz B, DINNERstenN AJ. Role of attentional focus in pain perception: manipulation of response to noxious stimulation by instructions. $J$ Abmorm Psychol $1971 ; 77 ; 42-45$.

26. GRIMM L, KANYBA FH. Tolerance of aversiye stimulation. Behay Therap 1976; 7: 593-601.

27. Kanfar FH, GoLofoot DA. Selfmeontrol and tolerance of noxious stimulation. Psychol Repiorts $1966 ; 18: 79-85$.

28. Hines EA. Technic of the cold pressor thest. Proc. Siaff Metening Mayo Clinic, 22 March 1939, pp. $185-187$.

29. Chaves JF, BARBER TX. Cognitiwe strattegies, experimenter modeling, and expectations in the attenuation of pain. I Abnorm Pspchol 1974; 83: 356-363.

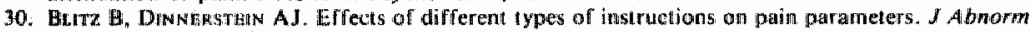
Psychal 1968: 73: 270-280.

31. Spanos MP, Mr:NH:II. C, GWYN MI. STram HI. Effects of suggestion and distraction on reported pain in subjects high and low on hypnotic susceptibility. $J$ Abnorm Psychol 1984; 93: 277-284.

32. FARTHING GW, VENTURINO M, Brown SW. Suggestion and distraction in the control of pain: vest of two hypotheses. I Abinom Psychol 1984; 93: 266-276.

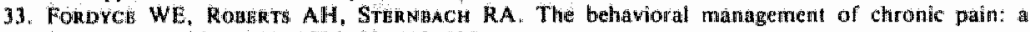
response 10 critics. Pain 1985: 22: 113-125.

34. AWDenson MAD. Low back pain-cause and prevention of long term handican (a critical review). Int Rehab Med 1981: 3: 89-93. 


\title{
9.2. PERSISTENCE BEHAVIOR OF CHRONIC LON BACK PAIN PATIENTS IN A NON PAIN ELICITING TEST SITUATION
}

\author{
A. J.M. Sohmidt \\ M.A. de Heus
}

\section{Abstract}

Chronic low back pain patients display poor performance behavior in back-stressing performance situations. The stimulus generalization hypothesis states that in the course of a patient's medical history this type of pain behavior is generalized from very specific stimuli to more general situations. In order to investigate the scope of the stimulus generalization hypothesis, the persistence behavior of 53 CLBP patients and a control group $(N=50)$ in a non-back-pain-relevant performance test was studied. The performance of the two groups did not differ. Within the back pain group there was a clear negative relationship between the pre-test pain level and persistence behavior during the test. The results are discussed in connection with earlier research in which the relationship between persistence behavior in back-stressing performance situations and pre-test pain levels was also demonstrated.

\section{Introduction}

One of the most fruitful theories about the chronic benign pain ayndrome was developed by fordyce $(7,8,9)$. He applied the principle of operant conditioning to the occurrence of pain behavior. Pain behavior was operationalized es verbal and non-verbal expression of pain, medication consumption, pain related health care utilization, lowering of activity levels, etc. (10). All these cases are concerned with observable and quantifiable behavior. Applying the principle of operant learning, Fordyce stated that the consequences of chronic pain behavior have a greater effect on it than antecedent stimuli. Several studies show this relationship in experimental as well as therapeutic settings $(3,4,6,16)$. 
However, even in the chronic pein stage 1 it is useful to continue aaking about the importance of antecedent stimuli: which stimuli elicit or intensify the chronic pain behavior?

Both the literature and clinical observation indicate the type of stimuli that elicit or intensify pain behavior in CLBP patients. In general, these are phyaical exertions that place a strain on the back such as lifting, walking stairs, bending, etc. In these situations pein behevior is poor performance behavior. The poorer performance of CLBP patients compared to a control group on a standardized backstresaing treadmill test was ahown by Schmidt (14). It could not be demonstrated, however, that this difference in perfornance was related to an increase of back pain in the CLBP group. These findings indicate the influence of avoidance learning and the presence of stimulus generalizetion. Hereby, CLBP patients exhibit poor performance behavior in gtimulus aituations which less and less resemble the original pain stimulus. The scope of the stimulus generalization hypothesis for CLBP patients: can be inveatigated by studying their performance behavior in a test situation that is not considered to be back pain eliciting. In this experiment a gtandardized reaction time test was used which required the subjects, under a continuous visual feedback condition, to react to auditory stimuli, regularly decreasing the reaction time required. Persistence behavior as a dependent variable was studied.

\section{Methods}

Sub jects

50 Male CLBP patients and 53 healthy control 59 . participated in the test. Two patients were referred by their family physician, half were referred by the orthopaedic and neurologic clinics of the medical centre. The other half responded to an announcement in a local newsproper.

Selection criteria included:

- age between 24 and 56

- Low back pain for et least 6 months

- somatic findings not corresponding with severity of compleints: no 
major pathological findings and adequate back functions in an orthopeedic examination.

All Ss. were volunteers. The CLBP patients were clinically diagnosed as having low back pain, a degenerative back-complaint, spondylosis, spondylar thosis or chronic myalgia.

of the original 59 CLBP patients, one patient could not discriminate between high and low tones, which made it impossible to administer the test.

The deviant test behavior of eight patients and the report that followed suggested that they did not understand the instructions. Thus the number of CLBP patients who completed the test protocol was 50.

60 Male control ss. were recruited by letter from the general population of Maastricht and were matched for age before being seen. The response rate was about $10 \%$. Ss. received a short medical examination to exclude chronic pain or medical disease. In this group it appeared that seven subjects, given their deviant test behavior and the report that followed, did not understand the instructions. Thus the number of subjects who completed the protocal was 53 .

\section{Apparatus}

A random high/low tone generator (500 and 1600 herz) was used for the reaction time test. The subjects were instructed to press buttion on the left side of the panel as fast as posaible at the sound of the low tone. When the high tone was heard, a button on the right side had to be pressed. When a response was too slow or inoorrect, Immediate fredback was given by means of a red signal; a green signal was given to indicate a correct response. The required reaction time could be adjusted in steps of $50 \mathrm{milligeconds.} \mathrm{This} \mathrm{took} \mathrm{place} \mathrm{outside} \mathrm{the} \mathrm{sub-}$ ject"s field of vision. High and low tones were produced randomly, with an average frequency of 29 tones per minute and a range of $26-32$ tones per minute. 
Procedure

The subjects were given the following instructions:

"You are participating in reaction-time test. You will hear bath high and low tones. If you hear a low tone, press the button on the left as quilckly as possible; if you hear a high tone, press the botton on the right as soon as possible. After pressing a button always move your finger to the neutral button in the middle. If you respond correctly and quickly, a green bulb will light up immediately after you have pressed one of the two buttons; if you do not respond correctly or your reaction is too slow, a red bulb will light up. In the beginning the teat will not be difficult, but you will notice that it becomes more difficult. If you think the test is becoming too difficult and it does not make sense to continue, say "stop" "instruction paraphrased).

Before the actual measurement took place the subjects were given the opportunity to practice for a short time with tones that required a reaction time of 900 msec.

The experimental measurement started with a required maximum reaction time of $600 \mathrm{msec}$. For the first two minutes. The time was reduced by 50 msec. every two minutes to a minimum of $300 \mathrm{msec}$. Inability to respond within the required reaction time resulted in a red signal* After a maximum of 30 minutes the test was stopped by the person administering the test. No werbal feedback or encouragement was given during the test. The registration apparatus was set up outside the subjecta" field of vision so no information aside from the feedback given by the red and green signal lights was available.

Measures

The following information was obtained from the CLBP patients:

- pre-test measures - sometic screening (questionnaire)

- pain-enamnesis, especially duration of the complaints, extent of feeling handicapped

- self-esteem questionnaire

- pre-test pain level (only with a sub-group, $N=19)$. 
- post-test measures - time

- percentage of correct responses

- number of incorrect responses + missings (1.e. all responses which resulted in a red signal as feedback)

- number of successive incorrect responses after the last correct answer until giving up. This variable is considered to be the operationelizetion of persiatence behavior.

The following information was obtained from the control group:

- pre-test measures - somatic screening (questlonnaire)

- gelf-egteem questionnaire

- post-test measures - see CLBP patients

\section{Results}

Biagraphical and psychological data for the CLBP group and the control group were compared. The results are summarized in Table 1. T-tests were used to indicate significant differences between the groups.

Table 1. Some biagraphical and paychological variables of the CLBP patients and the control group

\begin{tabular}{|c|c|c|c|c|c|}
\hline \multirow[b]{2}{*}{ Variables } & \multicolumn{2}{|c|}{$\begin{array}{l}\text { CLBP patients } \\
N=50\end{array}$} & \multicolumn{2}{|c|}{ Control group } & $\mathrm{p}$ \\
\hline & $\bar{x}$ & s.d. & $\bar{x}$ & s.d. & \\
\hline $\begin{array}{l}\text { biographical } \\
\text { - age (yra.) } \\
\text { - duration of the } \\
\text { complaints }\end{array}$ & $\begin{array}{l}41.3 \\
9.4\end{array}$ & 10.2 & $\begin{array}{l}40.9 \\
--\end{array}$ & $\begin{array}{l}10.3 \\
-\end{array}$ & n.t. \\
\hline $\begin{array}{l}\text { psychological } \\
\text { - extent of } \\
\text { feeling } \\
\text { handicapped } \\
\text { - self-esteem }\end{array}$ & $\begin{array}{l}49.8 \\
42.6\end{array}$ & $\begin{array}{l}28.9 \\
13.1\end{array}$ & 51.0 & 8.1 & $<0.01$ \\
\hline
\end{tabular}


The average duration of the chronic back complaints was 9.4 years (a.d. 7.7), varying from six months to thirty years. The results of the reaction time test for both groups are presented in Table 2 .

Table 2. Results of CLBP patients and the control group on the reaction time test

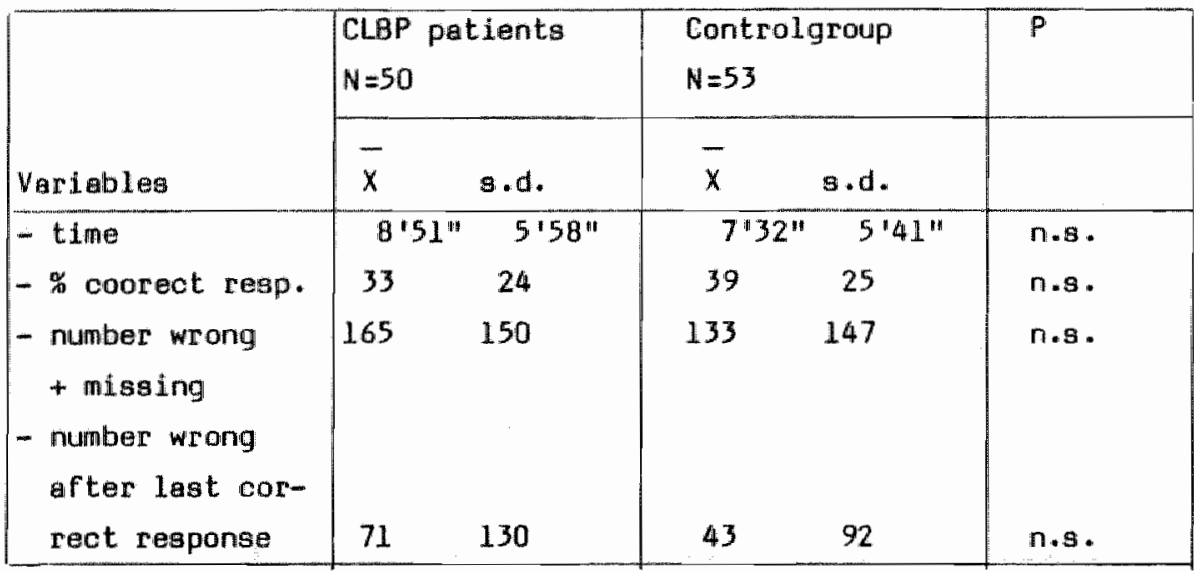

Striking in this table is the very large spresd of the responses. The test behawior of both groups did not differ. In the last group of CLBP patients $(N=19)$ the pre-test pain level was measured using the Visual Analogue Scale technique $(1,5,11,12,13)$.

Correlationg (Pearson corr. coeff) between the pre-test pain levels and the results on the reaction time test were negative and significant.

$r($ pre-test pain - time $)=-0.63(\rho<0.01)$

$r($ pre-test pain - persistence behavior $)=-0.54(p<0.01)$.

For the back pain group the length of the complaints did not appear to influence the performance as a whole, although it appeared to influence the more specific persistence behevior in a positive direction. $r$ (duration of the complaints - time) $=0.18$ (n.s.)

$r$ (duration of the complaints - persistence behavior) $=0.44(p<0.01)$. Finally for the combined group $(N=103)$ it appears that the quality of the self-concept is not related to performance. 
$r($ self-concept - time $)=-0.06(n .5 *)$

$r($ self-concept - persistence behavior) $=-0.14(\mathrm{n.s.})$.

\section{Discussion}

The finding that CLBP patients have a low self-concept, compared to a matched control group, confirmed the results of previous research with CLBP patients (2). Moreover, it appears that the quality of the selfconcept does not influence performance on the specific task in this study.

The hypothesis that CLBP patients would react with poor persistence behavior in non-back-stressing performance situations mas not confirmed. CLBP patients did not stop the protocol faster. Specific persistence behavior (=succesive number of errors tolerated after the last correct response) is, in comparison to the control group, stronger rather than weaker, although the great heterogenity in the answer patterns of both groups makes it impossible to speak of significance. Nonetheless, within the CLBP group this persistence behavior seems to be related positively to the duration of the complainta. There is no obwious explanation for this. If there was a relationship between the duration of the back complaints of CLBP patients and the results on a performance test, a negative correlation would, according to the stimulus generalization hypothesis, be more likely.

The finding that the performence level and the persigtence behavior of the CLBP group are clearly related to the pre-test pain level $(r=-0.63$ and $r=-0.54$ ) seems important. In earlier research 5 chmidt (15) demonstrated that the poorer performance of CLBP patients compered to a matched control group, under back stressing treadmill test conditions, was strongly related to the pre-test pain level and was only alightly related to the pain or exertion levels which were reported at the moment that the CLBP pratients stopped the treadmil1 test.

If therefore appears that CLBP patients have generalized tendency to react not to the actual situation and the proprioceptive or nonproprioceptive feedback signals avallable in that situation, but to an evaluation of the initial situation especially with respect to the seriousness of the back pain. 
This conclusion suggests a cognitive approach to the phenomenon of chronic low back pain: poor performance as a response is not elicited by specific stinuli, but by the expectations the stimuli evoke. 
References

1. Aitken, R.C.B., Measurement of feellings using visual analogue scales. Proc. roy. soc. ned., vol.62, (1969) 989-993.

2. Armentrout, D.P., The impact of chronic pain on the self-concept. Journal of clinical psychology, vol.35, (1979) 517-521.

3. Block, A.R., Kremer, E.F., Gaylor, M., Behavioral treatment of chronic pain: the spouse as a discriminative cue for pain behavior. Pain, 9, (1980) 243-252.

4. Cairns, D. and Pasino, J.A., Comparison of verbal reiriforcenent and feedback in the operant treatment of diability due to chronic low back pain. Behavior therapy, 8, (1977) 621-630.

5. Carlson, A.H., Assessment of chronic pain I. Aspects of the reliability and validity of the visual analogue scale. Pain, 16, (1983) 87-101.

6. Flor, H. and Turk, D.C., Etiological theories and treatments for chronic back pain. II Psychological models and interventions. Pain, 19, (1984) 209-233.

7. Fordyce, W.E. and Steger, J.C., Chronic Pain. In: 0.F. Pomerleau and J.P. Brady (eds.): Behavioral Medicine: theory and practice. Williams and Wilkins, Baltimore, (1979).

8. Fordyce, W.E., Behavioral conditioning concepts in chronic pain.

In: J.J. Bonica et al. (edg.): Advances in Pain Research and Therapy, vol.5, Raven Press, New York, (1983).

9. Fordyce, W.E., Fowler, R.5., Lehmann, J.F., Delateur, B.J., Sand, P.L. and Trieschmenn, R.B., Operant conditioning in the treatment of chronic pain. Arch. Phys. Med. Rehabil. vol.54, (1973) 399-408.

10. Fordyce, W.E., Lansky, D., Calsyn, D.A., Shelton, J.L., Stolov, W.E. and Rock, D.L., Pain Measurement and Pain Behawior. Pain, 18, (1984) 53-69.

11. Huskisson, E.C., Measurement of pain. The Lancet, (1974) 11271131.

12. Ohnhaus, E.E., Adler, R., Methodological problems in the measurement of pain: a comparison between the verbal rating scale and the visual analogue scale. Pain, $1,(1975) 379-384$. 
13. Price, D.D., MeGrath, P.A., Rafii, A., Buckinghan, B., The validation of visual analogue scales as ratio scale measures for chronic and experimental pain. Pain, 17, (1983) 45-56.

14. Schildt, A.J.M., Cognitive factors in the performance level of chronic low beck pain patients. Journal of psychosometic Research, vol.29, (1985) 183-189.

15. Schmidt, A.J.M., Performance level of chronic low back pain patients in different treadmill test conditions. Journel of psychosomatic research, vol.29, (1985) 639-645.

16. Turner, J.A. and Chapman, C.R., Psychological interventions for chronic pain: a critical review. II operant conditioning, hypnosis and cognitive-behavioral therapy. Pain, 12, (1982) 23-46.

\section{Acknowledgements}

The authors acknowledge the masistance of R. Gierlings, J. van Houtem and I. van Noppen. 


\section{GENERAL CONCLUSIONS}

The foregoing studies repeatedly point out that the persistence behavior of CLBP patients under back-stressing conditions is at a lower level than that of control groups of non-back pain patients. Whether under no-feedback canditions, time-feedback conditions, success conditions, failure conditions, or adequate feedback conditions with the treadinill test, this difference in performance level shows up. The difference found even seems to generalize to performance situations which involve enduring a pain stimulus increasing in intensity for as long as possible, but in which there is no strain on the back. Obviously a general nociception is the stimulus for the poorer performance behavior.

These findings contradict the conclusion of Fordyce (1985), discussed in Chapter 5, who found no differences in performance behavior between CLBP patients and control persons under exertion conditions. The conclusion, however, that pain sensations are the cause of the repeatedly measured poorer persistence behavior of CLBP patients cannot be drawn. On the contrary, one of the most consistent findings of the foregoing studies is that in back-taxing stress tests no demonstrable increase of back pain was reported.

It also appeared that the intensity of the reported pain levels at the moment that the CLBP patients stopped the test was not related to the physical performance. For CLBP patienta as a group it can therefore be stated that intense back strain can colncide with an inorease and decrease of pain and that a slight physical exertion can alao colncide with pain increase as well as pain decrease. Or, stated more simply: for CLBP patients back strain is not related to aubjective back pain report.

Fordyce (1981) also found indications that cast doubt on the generally used principle with respect to chronic pain patients: "the more I do, the more I hurt" and "the more I protect or limit myself, the less I hurt." In physiotherapeutic exercise situations, in which the pain patient himself must decide when to stop the exercise, he found a significant negative correlation between performance behavior and pain behavior. In view of the lack of relationship between aubjective pain 
report and objectively deteminable pain behavior noted earlier, this finding is not contrary to the conclusion in the previous paragraph. The findings from our own research and that of Fordyce undermine the general statement that CLBP patients are pure physically handicapped people who, as a result of their pain, have to be satisfied with a lower level of functioning.

If the pain is not the mast influential factor with respect to the disturbed persistence behevior of CLBP patients, which apparent factors are?

The following indications, which emerge from research, each need further empirical aupport.

1. A more general fector is created by the negative self-image that CLBP patient have of themselves. This negative self-image includes:

- having the idea that athers can do all kinds of things better,

- having the idea that they cannot do many things well,

- being insecure about themselves,

- having a tendency to consider themselves as failures.

Even if a specific performance-decreasing effect of a negative appreciation of their own capablilities has not been demonstrated for CLBP patients in the foregoing studies, within the framework of social psychological research the activity of this mechanism thes been directly observed (Andrews et al., 1978; Fisher, 1974; Ryckmen et al., 1972).

The findinge with the Performance Motivation Test (PMT) used in this study are in accord with the above. The high F-scores of the CLBP patienta indlcate a negative cognitive attitude especially in unclear performance situations. With respect to the impact of self-concept on performance behavior, reference can also be made to a study by Mettee (1971). He found confirmation of the following proposition:

"In the chronic failure's eyes, suddenly performing well may mean an Increase in both internal and external demends that he continues to perform at a similar level in the future. Consequently, the failure may reject success because he does not care to assume the responsibility for maintaining such high levels of performance." Earlier Aronsion et al. (1962) demonstrated thet rejection of unexpected success is a real phenomenon. They explained this by using 
the general cognitive consistency principle, "which in egsenoe states that individuals will avoid unexpected or incongruent outcomes in order to maintain a consistent (negativel) conception of themselves. In this view, unexpected success is feared and would be rejected because of its inconsistency per se."

Applied to CLBP patients these social psychological findings mean that these patients will tend to reject or avoid unexpected success experiences with respect to performance behavior:

a. because of the psychological incongruency that is raised by the discrepancy between success experience and the stable negative self-image.

b. because of the negative consequences of accepting success. The lower level of activity and lower persistence behavior level of CLBP patients is then considered a consequence of avoiding success experiences. One can speak of rejection of success experiences when attributing these successes to chance or luck instead of to their own behavior possibilities. With avoldence as well as rejection, the low self-image can remain untouched. Further research on the actual existence as well as an the role of these assumed mechaniams is indicated.

Finally, the relationship between negative self-image and persistence behavior can be demonstrated indirectly by studying the relationship between positive self-talk and an increase in motoric performance. Weinberg at al. (1980) denonstrated this relationship in an experimental setting with healthy athletea. The dependent variables were muscular strength, power and endurance, especially with respect to $\operatorname{leg}$ muscle exercise.

It can be concluded that the non-optimal performance behavior of CLBP patients is also brought about by more general, negative, psychological influence, which can be attributed to a negative self-cancept. In this personality cheracteristic, one of the basic symptoms of depression can be recognized (APA, 1980).

2. On the treadmill tests under failure conditions, as well as in the study where the persistence behavior of CLBP petients on a psychomotor task was studied, it became obvious that pre-test back pain 
Levelo are systematically related to persistence behavior. This is to say: CLBP patients who indicate in advance that they have a great ded of trouble with their backs, will then perform less wo 11, while CLBP patienta who indicate in advance that they do not have much pain in their back, will perform better. In view of the fact that it was also demonstrated that in back stressing conditions, the lower persistence behavior of CLBP patients is not related to pain increase or a high pain level, there are indications that CLBP patients in situations they experience as back taxing give up faster, more so because they were in advance, in connection with the extent of the back pain then present, already implicity inclined to do that. This specific, negative expectation pattern seems, in view of the findings with the psychomotor test, also to generalize to non-back pain relevant performance situations.

These findings correspond with socilal psychological research on the role of the attributional interpretations of the expectancy of the extent of success. Weiner et al. (1976) found that expectations with respect to success or failure in a performance situation were directly related to "the stability of the perceived cause of prior positive (or negativel) outcome(s)." For CLBP patients, with their lang lasting pain complaints and pain behavior, this means that in performance situations one can speak of negative expectations, which also have a negative influence on the performance behavior that follows it (Feather et a1., 1967; Andrews et al., 1978).

Conclusions :

- In performance situations the persistence behavior of CLBP pa-

tients is also determined by the level of back pain present a priori.

- In back pain relevant performance situations this expresses itself in a lower performance level with more pain reported in advance; the performance level of CLBP petients is also generally lower in these situations.

- In non-back pain relevant performance situations, this expresses itself in a lower performance level with more pein reported in advance; the performance level of CLBP patients is generally not lower in these situations. 
On the basis of these conclusions it may be hypothesized that with CLBP general expectation pattern based on pain relevance and self concept is responsible for the average level of performance and that specific expectations (a priori pain level) is (more) responsible for individual fluctuations around this average.

3. An alternative explanation of the poorer persistence behavior of CLBP patients is, in theory, the use of less efficient pain coping techniques by this group, compared with non-CLBP petients. In the literature on acute pain, however, no indications of this are found. The coping techniques studied most, e.g. 'focussing' versus 'distraction" (Blitz et al., 1971) do not appear to be used differently by the CLBP group and the control group in our own research. These also appear to be no differences in a priori dedication or motivation.

4. As a further explanation of the differences in persistence behavior between CLBP-patients and controls, a difference in pain experience can be assumed. The hypothesis could then be that CLBP patients experience a standardized pain stimulus as more painful than nonpain patients do and therefore give up faster in pain situations. The cold-pressor test study does indeed give indications in that direction. It was found that compared with healthy persons atandardized pain stimulus increasing in intensity could not be endured as long by CLBP patients, while the intenstty of the maximum pain stimulus endured on a visual analogue scale was higher. Thua a lower pain tolerance ls coupled with more intensive pain experience. This supports the claim that an equal amount of pain w11 still produce clear differences in pain intensity reported. As a consequence of having to deal with pain for a long time, CLBP patients in an experimental pain situation seem to be sensitized to pain sooner than habituated to it. An alternative hypothesis could be that the heightened pain intensity experience of the CLBP patients which was observed is not so much a consequence of the CLLBP syndrome expressing itself as a form of pain behavior, but that this greater sensitivity to pain stimuli is an already present rigk factor for the development of CLBP. Only further study can provide a solution to this dilemme. 
5. Finelly, 1t should be stated that there are no indications that the differences found in persistence behavior on the exertion test between CLBP patients and control subjects are a consequence of obvious differences in physical condition between the two groups. With identical objective taxation levels, the physiological meagures, which can be considered an indication of exertion, i.e. exhaugtion levels, do not differ.

It is already known from sport medicine particularly that the maximum performence level of healthy people is determined not only by physical cepabilities or limitations, but also by motivational factors (Morgan et a1., 1983). The extent to which one is willing to tolerate feelings of tiredness or exhaustion lao determines the performance. So two factors are important:

- the objective determination of tiredness, i.e. exhaustion,

- the subjective processing of these signals.

Again, as was assumed before with expectation patterns, a two factor theory can be proposed. In this theory the factor fatigue, which is dilectly related to physical condition, especially for the group of CLBP patients and control subjects investigated, is a more or less constant factor. This more general factor will in principle set the linits with respect to the maximum performance level. Fluctuations around this level would, according to this two factor theory, be ascribed to the second factor, subjective processing of these stress sensations.

This theoretical perspective can be applied to the research results that were found. It was said earlier that there were no prior indications that the differences found between the CLBP patients and control group were the effect of demonstrable differences in physical condition. In other words: the factor exertion influences performance only to the extent that there is a disturbance in the subjective interpretation, 1.e. processing of these signals.

The research repeatedly undergcores the fact that the relationship between subjective fatigue report and objective tiredness is different for CLBP patients.

This relates to the intuitive assumption that healthy people report higher levels of tiredness for a higher degree of physiolagical tired- 
ness, 1.e. exhaustion. This observation was made in the first article on the treadmill test and was replicated in the study related to the combined basic and adequate feedback condition experiment. It is striking that the less external noise in the form of confusing and incorrect information and feedback there was, the clearer the relationship between physiological tirednesa and the subjective perception of it shows.

The findings for the CLBP group form a contrast. Considering the bagic condition measures in the different experiments, there appears to be no aingle aystematic relationship between objective and subjective tiredness. In other words, the conclusion drawn at the beginning of this chapter with reapect to the relationship between pain and physical taxation also holds with respect to the relationship between subjective report of fatigue and objective tiredness. It can be atated that for CBLP patients as a group intense physiological exertion can invalve a report of slight as well as intense tiredness and that minor exertion can also involve great fluctuations in the degree of tiredness reported. For CLBP patients the tiredness report says nothing about physiological tiredness, i.e. exhaustion of the body.

There is a second point worth noting in regard to the exertion report. In all the treadinil tests and in all the conditions investigated, the physiological exhaustion measures were higher for the non-back pain group than for the CLBP group. This means that the control group becomes more exhausted physialogically than the CLBP group. Even 9o, the CLBP group constantly reported the same tiredness levels as the control group. This gives reason to assume that CLBP patients tend to overestimate their physiological tiredness or to underestimate their physical capabilities.

The conclusions above are related to the contribution of some psychological - mostly cognitive - factors to the poorer persistence behavLor of CLBP patients in performance-situations.

In general, the increase of pain did not play an important pert. There was one exception: there are indications of a report of an increase in pain in those situations in which fallure experiences occur. It may be concluded that these statements about increage of pain have more to do with the specificity of this failure condition than with the back- 


\section{DIAGNOSTIC AND THERAPEUTIC CONSEQUENCES}

The primary goal of the foregoing stuidy was to gain more insight into the possible role of several psychological factors with respect to the persistence behavior of CLBP patients. As such the study makes a contribution to the development of medical-psychological theory. Insight into these complaint-sustaining factors is requisite for the development of therapies specifically for CLBP. Although not directly related to the primary objectives of this study, the implicationg for the therapeutic situation of some theoretical developments from the research findings are indicated.

As already noted in Chapter 1 , the treatment of CLBP is not very successful when all aspects of the complex phenomenon chronic pain are not dealt with. Reducing CLBP to an organic pathological syndrome, while the relationship between somatic findings and CLBP complaint has in general been insufficiently demonstrated w11, in a therapeutic situation, often result in failure and frustration for the person who gives the treatment as well as the CLBP patient.

Two recent Scandinevian studies support this proposition. In a study by Lindequist et al. (1984) a consecutive series of 56 patients who visited general practitioner over a 3 month period complaining of acute low back pain localized to the lumbo-sacral region were randomly assigned to either a treatment group or a contral group. Moreover, according to the erguments presented in section 2.1 . wing the 3 month criterion in this case means thet one can speak of a CLBP group. In both groups obvious somatic explanations of the pain (infections, tumore, fractures) were also excluded. The tretiment group received a largely somatically-oriented treatment: posture advice, instruction about the function and anatomy of the spine, with emphasis on preventing strain on the back and a physiotherapeutic training program on an outpatient basis. After 6 weeks, if necessary, supplementary treatment: with physiotherapy, corset, etc. was provided. The period of sickleave was individually decided upon at each visit. The control group did not receive direct advice, physiotherapy or inatruction. The only advice that was given was to avold straining the back and to use painkillers when needed ( 1 ; see Fordyce's criticism of the principle: "let 
pein be your guide"). In sumary "young' CLBP group without organic defecto recelved a largely sonatically-oriented treatment. After approximately one year all the patients were re-examined. The results were disappointing: "No significant differences could be demonstrated either concerning the initial duration of symptoms and slck-leave or the number of recurrences and their duration during the observation year."

The second study was published by Mellin et al. (1984). She evaluated treatinent results (pre-treatment ws. post-treatment) of a group of CLBP patients who were treated clinically (rehabilitation centre) or as outpatients. The treatment consisted of heat and electrotherapy, massage, back exereises, physical exercises and pain-informetion and advice program. Here too the treatment program for the CLBP group was predominantly sometically-oriented. The results of this study were likewise disappointing. The slight effects of the treatment noted at the end of the treatment period could not be observed for either the in-patient or out-patient group in a follow-up done one year later. This applies to the dependent variables physical measurements of spinal function and a back-pain index besed on the replies to questionnaires.

Thus, although the ffect of a one-sided somatic treatment is disappointing, it must be concluded that, given the complexity of the phenomenon chronic pain, little can be expected from a one-sided paychological or psychiatric treatment. A recent study by Bassett et a1. (1985) 1llustrates this. In this study chronic pain patients were referred for psychotherapy by a pein clinic. Two kinds of treatment were employed: six fortnightly half-hour sessions of supportive psychotherapy or 12 weekly one-hour sessions of dynamic psychotherapy. The following pre- and post-test measures were compared: the Illness Behavior Questionnalire, depression questionneire and the Spielberger State-Trait Anxiety Inventory. Rating scales were obtained for the overall opinion of their state of well-being, pain intensity and current level of activity. Therapy-related improvements could not be demonstrated on any of the dependent variables. Participation in therapy and attendance was a significant problem, because most patients found the idea of "talking" treatment for chronic pain difficult to accept. 
The therapy-outcome studies discussed above illustrate the necessity of multidisciplinarity in the trestment of CLBP. When judging the treatment results of CLBP patients, at least three dimensions should be considered:

1. The subjective intensity dimension. This refers to the patient's report of the severity of the pain complaints and should include pain intensity measures, reports about the frequency and duration of pain or pain-free periods and those measures which use scaling techniques whereby the patients indicate the effect of a treatment on the pain. So, a characteristic of this dimension is that subjective pain is somehow registered or evaluated.

2. The pain attitude dimension. This refers to the patient's attitude towards CLBP notied by the person who is giving the treatment. This dimension includes general self-image, a priori expectations in back-stressing situations, fear of the complaints becoming worse with exertion or change, insight into CLBP and maintaining factors, the presence or absence of a depressive, fatalistic or apathetic basic attitude, internal or external locus of control with respect to pain, the willingness to see CLBP not only as the cause of dysfunction, but also as the effect, the extent to which pain is placed or kept in the center of daily 1 ife and the extent of cognitive fixation on CLBP, in other words, the extent of thinking about pain and always talking and complaining about it.

3. The pain behavior dimension. This has to do with those apecific forms of overt, recordable and quantifiable behavior in which CLBP patients differ from non-pain patients, such as the use of medicines (pain-killers, tranquillizers, sleeping pills), complaint behavior, frequency of visits to the doctor, level of activity, physical/motoric performance and avoidance behavior, among others.

The foregoing studies show that there is no simple linear relationship among these three dimensions. A certain pain attitude can coincide with a certain pain behavior, while pain behavior and pain report on an individual level have to be considered as independent dimensions. This means that changes in one dimension do not necessarily imply changes in the two other dimensions. 
While, on the one hand, the interrelations between subjective intensity - the pain attitude - and the pain behavior dimension are not linear, there is, on the other hand, a connection between the nature of the treatment used and the rating dimension used.

Treatments which attempt to bring about changes within the subjective intensity dimensilon (zpain decrease) are of a somatic nature: physiotherapy, advice regarding exercise, biofeedback training, prescribing rest or other aids, pharmacological treatments, operations, etc. Conversely, these treatments also use pain report as a dependent variable. Other evaluation instruments, e.g. satisfaction with the treatment, have to be considered as not relevant with respect to the objective of this treatment.

- The treatments directed at decreasing observable pain behavior are besed on operant principles and are directed at increasing the level of activity and decreasing dependence on medicines. Therefore, in the eveluation of these treatments, obserwation scales or scoring lists which operationalize pain behavior will be used. Pain intensity measures are not relevant in this case, because the decrease of pain is not an objective and pain intensity reports also do not have a direct relation to pain behavior. Sometimes operant programs seem to have somatic nature in the sense that in operant treatments exercise, training and instructions can also occur. The dependent variables used are different, however, because the objective of the more somatic treatment is to decrease pain, while in the operant programs the inorease of activity itself is the objective.

- The treatments which are dicected at a change in pain attitude can be summarized under the heading cognitive treatments. The objective of these cognitive treatiments is to teach the patient a more rational and less neurotic way of thinking about pain, using the appropriate psychotherapeutic treatment methods. These forms of therapy have, at least until now, been the most difficult to evaluate. Basically, it has to do with attitude measures, which are often quantified by questionnaires. More generally, one can think of depression or self-concept registrations; more specifically, one can think of the measurement of changes in pain cogritions, locus of control with respect to pain and expectations with respect to their 
own coping possibilities. Ruestionnaires of this type have not been developed yet.

The above has important diagnostic and therapeutic consequences. It is of course possible to direct the treatment at one of the dimensions mentioned above, but then lasting results cannot be expected, because the other two dimensions do not change autonatically. The treatment of CLBP can be called successful only if:

a. the patient complains less about pain, and

b. no longer exhibits pain behavior, and

c. has a more adequate and rational pain attitude.

Regarding the assessment of CLBP, the dete with respect to the CLBPdimensions has to be interrelated. This has less to do with pain behavior measures, laboratory results, information from psychological studies or subjective reports separately, than with the interpretation of their interrelations such as the relationship between pain behavior and physical taxation, between pain report and exertion and between self imege and pain behavior. In principle, the treadmill-setting used In this study provides an excellent opportunity to determine the interrelationship of the behavioral, physiological and subjective dimensions of CLBP. This study shows that it is definitely possible in this standardized setting to set up a number of frames of reference which are relevant for CLBP diagnosis.

One can think of the following operationslizations, in which the results of non-pain patients can be used as the healthy norm:

1. persistence time under standardized back stressing conditions

2. subjective pain increase under standardized back stressing conditions such as used in $\mathbb{1}$

3. relationship between maximum level of pain and performance (aee 1)

4. relationship between pre-teat level of pain and performance (see 1 )

5. physical condition

6. the importance of physical condition and performance

7. the extent of the discrepancy between objective exertion and subjective exertion report

8. physical exertion, 1 -e. fatigue threshold (whether or not related to pain levell). 
Using these diagrostic deterninations, interactions are clearly expressed: wth the presentation of a relevant pain-provoking stimulus (the treadmill test), somatic aspects can be evaluated (e.g., physical condition), subjective information can be collected (e.g., intensity measures) and pain behavior can be observed (e.g., poor persistence behavior) simultaneously. Because this collection of information will show a large spread among individual CLBP patients and will on the group level overlap with the norm group of nan-backpain patients, by using the treadmill test, a CLBP profile with respect to the variables described can in principle be rather well constructed on an individual level. By comparing this individual profile with the norm results of the CLBP group or the non-pain group as a whole, even therapy objectives can be operationalized.

These operationalizations are limited, however, to the setting of feasible treatment objectives with respect to the performance on the treadmill test of CLBP patients. However, increasing the persistence behavior of CLBP patienta in backstressing situations has to be considered as a crucial CLBP treatment objective.

The foregoing studies with respect to generalizing CLBP behevior to acute pain situations and non-pain relevant performance situations are still of such an explarative nature that it would be premature to use them in a clinical setting, especially to use them for estimating the degree of generalization of CLBP behavior. More cesearch is needed before this can be done. 
SUMMARY

In this study a number of research papers on the persistence behavior of chronic low back pain (CLBP) patients in back-stressing as well as non-back-stressing performance situations are described. The primary consideration on which the design of these experimental studiles was beused, is that CLBP is such a complex phenomenon that a linear relationship between back pain intensity and physical stress or persistence behavior was not expected. It was assumed that certain aspects of typical CLBP behavior in back-stressing performance situmtions especially poorer persistence behavior, i.e. giving-up behavior would generalize to non-back taxing performance situations, so that, in these latter situations CLBP patients would also function less well. In order to put these specific questions in more general psychological frame of reference, the studies in the five articles are preceded by some introductory chapters in which the most important: aspects of CLBP are discussed on the basis of the available professional literature. These articles are followed by two integrating chapters.

In chapter 1 some basic concepts are discussed. The CLBP syndrame is described and the causes of it. (or rather the lack of adequate explanatory causes) are presented. The distinction between acute and chronic pain is discussed; particular attention is paid to concomitant. physical reactions, the relationship with tasue damage and the importance of personality factors. These various aspects are dealt. with more thoroughly in later chapters.

In chepter 2 some epidemiological aspects of CLBP are discussed. Studies on the history of low back pain complaints indicatie that acute LBP attacks lead to an average sick leave of 18-20 work days; after an absence of eight, weeks due to illnegs, there is a $10 \%$ ahance the LBP patient will become a chronic pain patient when the six months crit.erion is used. On the basis of this, it is recommended that this chronicity criterion be lowered from 6 to 2 months.

Also in this chapter the role of risk factors for the development of CLBP is discussed. In the literature, prolonged (hervy) physical 
activity, whether work-related or not, is not considered a sufficient: explanation for the development of CLBP. The epidemiolagical studies hew provided 1ittle evidence of psychological risk factors. Moreover, the nature of this research does not allow conclusions to be drawn about the direction of $a$ possible causal relationship between, for instance CLBP and depression.

Chapter 3 discusses the contribution of psychology as an empirical science to a better understanding of the CLBP phenomenon. The most: important themes eppear to be the psychodiagnostics of the CLBP patients, as well as the development of a psychological theory of chronic pain and the psychological treatment methads derived fron it. Specific personality variables of CLBP patients have been described many times; in this connection the Minnesota Multiphasic Personelity Inventory (MMPI) has been used frequentlly. The picture that emerges is not very homogeneous. More recent. research hes been directed at: predicting the operation results on CLBP patilents on the basis of extensive psychodiagnostic research. Very positive outcomes have been claimed, especially in the American literature; the status of this research in clinical decision-making procedures, however, is still unclear and methodologically uncertain.

The development of empirical psychological theory concerning CLBP is mainly based on the operant and cognitive paradigm. The operant point. of view atates that behavior - including CLBP behavior - that is reinforced positively will increase in frequency. Acute pain behevior will under these circunstances develop into chronic pain behavior, while chronic pain behavior already present will not be extinguished. The usefulnegs of the operant. theory has been demonstrated in many studies, especially the numerous therapy evaluation studies in which the therapeutic application of the operant principle in the treatment. of CLBP patients is central. Reports indicate that such treatment has been particularly ffective in increasing the level of activity and decreasing dependence on medication.

The cognitive point of view with respect to chronic pain states that. cognitions (attitudes, beliefs, expectations) of CLBP patients concerning their behavioral possibilities determine their emotional and 
behavioral reactions to certain situations. Because emotional variables, especially fear, influence the pein experience, it is also assumed that cognitive modifications influence the pain experience itself. In this chapter this interaction is discussed extensively with reference to four kinds of studies:

L. studies on the influence of advance imformation on a subsequent experimenter pain stimulus.

2. studies on the influence of advance information on a subsequent. painful medical operation.

3. studies on the influence of several coping styles on a subsequent. experimental pain stimulus.

4. studies on the influence of several coping styles on clinical pain. In the literature, the significant, relations are most clearly between the use of certain pain-coping techniques and an increase of pain perception or pain tolerance threshold in experimental situations (studies of type 3 ).

In chapter 4 the literature review is summarized and the gaps in speciffic, psychological knowledge concerning CLBP are indicated.

Chapter 5 introduces the general question from which the studies that. follow are derived. If, eccording to the operant principle, CLBP behavior, especially poor persistence behevior, in situations experienced as backpain taxing is maintained by positive reinforcement. from the enviromment of the patient, then the removal of this feedbeck must lead to the disappearance of this CLBP behavior. If, in addition, CLBP behavior is also directed by cognitions (expectations), then experimental manipulation of these expectations must. lead to another behavior in back-stressing situations. In several studies ettemptsa were made to operationalize these questions in experimental research.

Chapter 6 describes the basic experiment. In this experiment CLBP patients performed a standardized, stress increasing treadmill exercise without possible feedback conditions present. Compared to a control group, the poor performance scores of the CLBP group did not. seem to be related to pain increase or maximum pain level during the 
test. Physiological fatigue levels were not correctly appraised by CLBP patients. Psychometic variables systematically appeared to be less favourable for CLBP patients.

Chepter 7 also describes the basic experiment, in which advance information was presented, which led to CLBP patients not succeeding in reaching the reference values offered. In this threatening failure candition, the control subjects made an extra effort; CLBP patients did nat. It. could be demanstrated that the significant increase in pain reported during the exertion was not related to back-stress, but. t.o the failure condition. Also in contrast to the control group, the pre-test pain variables were more related to the performance of the CLBP patients than the test pain variables.

Chepter $\theta$ also describes the treadnill test, but now in expected success or adequate feedback conditions. Adding these conditions led to the confirmation of earlier findings, but did not result in specific new findings.

In chapter 9 the next two articles are introduced. If the persistence behavior of CLBP patients in objective back stressing performance situations is at a lower level than that of non-CLBP patients, but. this is not caused by increasing pain levels, it can be assumed that. giving up quickly has become a characteristic of CLBP patients and has ala generalized to other performance situations. To investigate this hypothesis the persistence behavior of CLBP patients was also studied in a non-back-taxing, acute pain situation (chapter 9.1) and in a nonpain-relevant perfornance situation (chapter 9.2).

In chapter 9.1 it was demonstratted that CLBP patients, compared to a control group, endure an acute pein stimulus less longer and experience it as more painful. The differences in performance between the CLBP group and a control group do not seem to be related to differences in coping style. 
In chapter 9.2 it is demonstrated that the performance behavior of CLBP patients, compared to a control group, was adequate on a psychomotoric task (reaction time test). No indications were found for faster giving-up behavior, $\mathbb{1}$.e. a lower tolerance for failure for the CLBP group. Yet back pain within the CLBP group influenced the individual performance levels: more back pain in advance led to a poorer performance on this non-pain relevant task.

In chapter 10 the foregoing results are summarized, resulting in a scheme in which the interrelationships of pasitive and negative, i.e. performance increasing and performance decreasing, psychological influences on the persistence behavior of CLBP patients are pregented.

Finally, in chapter 11 , the implications of the research findings for the assessment. and therapy of CLBP are discussed. 
$-118-$ 


\section{SAMEN VATT ING}

In deze studie worden een aantel onderzoeken beschreven met betrekking tot. het wolhoudgedrag van chronische lage rugpijn (CLBP) patienten in rugbelastende, zowel als niet-rugbelastende prestatiesituaties. Een uitgangspunt bij de opzet van deze experimentele studies was dat CLBP een dermate gecompliceerd fenomeen is, dat zeker geen linealre relatie tussen rugpijnintensiteit en fysieke belasting of volhoudgedrag werd verwacht. Ten aanzien van de niet-rugbelastende prestatiesituaties werd verondersteld dat bepaalde aspecten van het typische CLBP-gedrag - m.n. een slechter volhoudgedrag c.q. een sneller opgeefgedrag zouden $z i j n$ gegeneraliseerd van rugbelastende naar niet-rugbelastende prestat.ie-situaties, zodat ook in deze laatatgenoende situaties CLBPpattienten minder goed zouden functioneren.

Teneinde deze specifieke vraggtellingen te plaatsen in een meer algemeen psychologisch referentiekader, worden de in 5 artikelen beschreven studies voorafgegaan door enkele inleidende hoofdstukken maarin op de belangrijkste aspecten van CLBP wordt ingegaan aan de hand van de beschikbare vakliteratuur. Bovendien worden de genoende artikelen gevolgd door twee integrerende hoofdstukken.

In hoofdstuk 1 worden enkele basisbegrippen besproken. Het syndroom van CLBP wordt omschreven en de oorzaken ervan (beter gezegd: het. gebrek aan voldoende verklarende oorzaken ervan) worden wearglegeven. Tevens wordt het, onderscheid tussen acute en chronische pijn behandeld, m.n. wat betreft begeleidende lichanelijke reacties, de relatie met. weefselbeschadiging en het belang van persoonlijkheidsfactoren. Deze verschillende aspecten komen in latere hoofdstukken diepgaander aan de orde.

In hoofdstuk 2 worden enkele epidemiologiache aspecten van CLBP besproken. Met name studies over het beloop van lage rugklachten makan duidelijk dat acute LBP aanvallen leiden tot een gemidideld ziekteverzuim wan gemiddeld 18-20 werkdagen, terwijl bij aen ziekteverzuin van 8 weken er een 10\% kans bestat dat de betreffende LBP-patient en chronische pijnpatient wordt, wanneer hiervoor als criterium de onder- 
grens van 6 maanden wordt. gesteld. Mede op grond hierwan wordt bepleit on dit chroniciteitscriterium te verlagen van 6 naar 2 meanden.

In dit hoofdstuk wordt. tevens ingegaan op de rol van risicofactoren bij het ontataan van CLBP. Langdurige (zware) lichamelijke activiteiten, al of niet in relatie tot arbeid, wordt in de literatuur zeker niet gezien als een afdoende verklaring voor het ontstakn van CLBP. Psychologische risicofactoren zijn in epidemiologische studies nauwelijks aangetoond. De aard van dit onderzoek laat overigens ook geen conclusies toe over de richting van een mogelijke causaliteitsrelatie b.v. tussen CLAP en depressie.

Hoofdstuk 3 behandelt de bijdrage van de psychologie als empirische wetenschep tot een beter begrip van het fenomeen van de CLBP. De belangrijkste thema"s blijken vooral te zijn: de psychodiagnostiek van de CLBP-patient, alsmede de psychologlische theorievorming van chronische pijn met de daarvan afgeleide psychologische behandelingsmethoden.

Specifieke persoonlijkheidavariabelen van CLBP-patienten zijn veelvuldig beschreven, waarbij met name de Minnesota Multiphasic Personality Inventory (MMPI) valk wordt gebruikt. Toch is het beeld wat near voren komt, weinig homogeen. Recenter onderzoek richt zỉch meer op die voorspelbaarheid van operatie-resultaten bij LBP-patienten aan de hand van uitgebreid psychodiagnostisch onderzoek. Hierbij worden, m.n. in de Amerikeanse literatuur, zeer positieve resultaten geclaimed; de status van dit onderzoek blj klinische besluitvormingsprocedures is echter nog onduidelijk en methodologisch nog onzeker.

De empirisch-psychologische theorievorming m.b.t. CLBP gaet vooral uit. ven het operante en het cognitieve paradigma. Het operante uitgangspunt atelt dat gedrag - dus ook CLBP-gedrag - dat positief wordt bekrachtigd, in frequentie zal toenemen. Acuut pijngedrag zal onder deze onstandigheden uitgroeien tot chronisch pijngedragy terwijl reeds aenwezig chronisch pijngedrag niet zal uitdoven.

De brulkbaarheid van de operante theorie werd in vele onderzoeken aangetoond. In het bijzonder kan hier worden gerefereerd aan de talloze therapie-evaluatie onderzoeken, waarbij de therapeutische toepassing van het operante uitgangspunt. in de behandeling van CLBP patienten 
centraal stabt. Zeer goede behandelingsresultaten worden $\mathrm{m} . \mathrm{n}$. vermeld wat betreft verhoging van het activiteitemiveau en afname van medicatie-afhankel i jkheid.

Het cognitieve uitgengspunt bij chronische pijn stelt dat cognities (attitudes, avertuigingen, verwachtingen) van CLBP-patienten ten aanzien van hun handelingsmogelijkheden sterk bepalend zijn voor huin emotionele en gedragsmatige reacties in bepaalde situaties. Aangezlen emotionele variabelen $(\mathrm{m} \cdot \mathrm{n}$. angst) de pijnervaring beinvioeden, wordt: ervan uitgegaen dat cognitieve modificaties van invloed zijn op de pijnervaring zelf. In dit hoofdstuk wordt op deze interactic vitgebreid ingegaan, aan de hand van een viertal soorten studies:

1. studies naar de invloed van voorafgaande informatie op een subsequente experimentele pijnprikkel,

2. studies naar de invloed van voorafgaande informatie op een subsequente pijnlijk klinische ingreep,

3. studies naar de invloed van diverse coping-stijlen op een aubsequente experimentele pijnprikkel,

4. studies near de invloed ven diverse coping-stijlen bij klinische pijn.

In de literatuur komen het duidelijkst de significante relaties naar voren tussen het hanteren van bepaalde cognit.ieve coping-technieken en een toename van pijnperceptie- of pijntolerantiedrempels in experimentele situaties (m.a.W. studies van het type 3 ).

In hoofdstuk 4 wordt, het literatuuroverzlicht samengevat en worden de grote lacunes in specifieke, psychologiache kennis m.b.t. CLBP ananegeven.

Hoofdstuk 5 leidt. de algemene vraagstelling in wasuit de erop volgende onderzoeken zijn afgeleid. Indien, volgens het operante principe, ClBP-gedrag, met. name slecht volhoudgedrag, in als rugpijnbelastend ervaren situaties in stand wordt. gehouden door positieve bekrachtiging uit de omgeving van de patient, zal het wegnemen van deze feedback moeten leiden tot het verdwijnen van dit CLBP-gedrag. Als daarenboven CLBP-gedrag ook nog wordt geatuurd door cognities (verwachtingen), dan zal experimentele manipulatie van deze verwachtingen moeten leiden tot. 
een ander gedray in rugbelastende situaties. In de diverse studies werd getracht on deze vraagstellingen in experimenteel onderzoek te operationallseren.

Hoofdstuk 6 beschrifft het basale experiment. Hierin voerden de CLBP patienten een gestandaardiseerde, in belasting toenemende loopbandoefening uit in afwezigheid van mogelijke feedback-condities. De, vergelaken met een controlegroep, slechtere prestatie-scores van de CLBPgroep bleken niet gerelateerd aen pijntoename of maximaal pijnniveau tijdens die test. Fysiologische vermoeidheidaniveau's werden door CLBPpatienter niet goed ingeschat. Psychometrische gegevens bleken voor CLBP-patienten systemetisch ongunstiger uit te wallen.

Hoofdstuk 7 beschrijft eweneens het basale experiment, waarbij echter voorafgaande infarmat.le werd verschaft, die ertoe leidde dat de CLAP petienten er niet. in slabgden aangeboden referentie-waerden te biereiken. In deze dreigende faalconditie spanden de controlepersonen zich extra in; CLBP-patienten niet. Aangetoond kon worden dat de gerapporteerde significante pijntoename tijdens de inspanning niet gerelateerd was aan de rugbelasting, marr aan de faalconditie. Eveneens in tegengtelling tot de controlegroep waren bij CLBP-patienten pre-test variabelen meer aan de geleverde prestatie gerelateerd dan test-variabelen.

Hoofdstuk 8 beschrijft eveneens de loopbandproef onder voorziene succes of adequate feedback-condities. Toevoeging van deze condities leidde tot bevestiging van eerdere, matr niet tot specifieke, nieuwe bevindingen.

In hoofdstuk 9 worden de beide volgende artikelen geintroduceerd. Indien het volhoudgedrag van CLBP-patienten in objectief rugbelastende prestatie-situaties wel op een lager niveau staat dan dat van nietCLBP-patienten, doch niet wordt veroorzaakt door toenemende pijnniveau's, kan worden verondersteld dat snel opgeefgedrag een kenmerk is (geworden) van CLBP-patienten dat: zich ook naar andere prestatiesituaties heeft gegeneraliseerd. Om dit te onderzoeken werd het volhoudgedrag van CLBP-patienten ook bestudeerd in een niet-rugbelastende, 
acute pijnsituatie (hoofdstuk 9.1) en in een niet-pijnrelevante prestatiesituatie (hoofdstuk 9.2).

In hoofdstuk 9.1. wordt aangetoond dat. CLBP-patienten, vergeleken met: een controlegroep, een acute pijnprikkel (in dit geval d.m.v. de coldpressor test) minder lang verdragen en bovendien als pijnlijker ervaren. De verschillen in prestatie tussen CLBP-groep en controlegroep blijken niet samen t.e hangen met, verschillen in coping-stijl.

In hoofdstuk 9.2. wordt aangetoond dat het prestatiegedrag van CLBPpatienten, vergeleken met een controlegroep, adequat. was op een psychomotorische taak (reactietijden-test). Er werden geen aanwijzingen gevonden voor een sneller opgeefgedrag, $c . q$. een lagere faaltalerantie voor de CLBP-groep. Toch beïnloedde de rugpijn binnen de CLBP-groep het individuele prestatieniveau: meer rugpijn van te varen leidde tot. een slechtere prestatie op deze niet-pijnrelevante taak.

In hoofdstuk 10 worden de gegevens uit het voorafgaande samengevat, resulterend in een scheme warin zoveel mogelijk de positieve en negetieve, dat. wil zeggen prestatieverhagende en prestatieverlagende psychologische invloeden op het volhoudgedrag van CLBP-patienten worden weergegeven in hun onderlinge verband.

In hoafdstuk 11, tenslotte, wordt in discussievorm beaproken welke consequenties de onderzoeksbevindingen kunnen hebben voor de diugnostilek en theraple wan CLBP. 
$-124-$ 


\section{REF ERENCES}

Aitken, R.C.B. Measurement, of feelings using Visual Analogue 5cales. Proc. Roy. Soc. Med., 1969; 62:989-993.

American Psychiatric Association. Diagnostic and Statistical Manual of Mental Disorders. Washington D.C., 1980.

Anderson, G.B.J. Epidemiological Aspects of low-back pain. Industry Spine, 1981; 6:53-60.

Anderson, J.A.D. Low back pain - cause and prevention of long term handicap (a critical review). Internetional Rehabilitation Medicine, 1981; 3:89-93.

Anderson, L.P. \& Rehm, L.P. The relationship between strategies of coping and perception of pain in three chronic pain groups. Journal of Clinical Psychology, 1984; 5:1170-1177.

Anderson, T.P., Colle, T.M., Gullickson, G., Hutgens, A. \& Roberts, A.H. Behavior modification of chronic pain: a treatment progran by a multidisciplinary team. Clinical Orthopaedy, 1977, 129:96-100.

Andrew, J.M. Recovery from surgery, with and without preparatory instruction, for three coping styles. Journal of Personallity and Social Psychology, 1970; 3:223-226.

Andrews, G.R. \& Debus, R.L. Persistence end causal perception of failure: modifying cognitive attributions. Journal of Educational Psychology, 1978; 2:154-166.

Appels, A. \& Mulder, P. Type A behavior and myocardial infarction. A 9.5 year follow-up of a small cohort. International Journal of Cerdiology, 1985; 8:465-470.

Armentrout, D.P. The impact of chronic pein on the gelf-concept. Journal of Clinical Psychology, 1979; 3:517-521.

Aronson, E. * Carlsmith, J.M. Performance expectancy as a determinant. of actual performance. Journal of Abnormal and Social Paychology, $1962 ; 65: 178-182$.

Auerbach, S.M., Kendall, P.C., Cutt.ler, H.F. \& Levitt, R. Anxiaty, 1 ocus of control, type of preparatory information, and adjustment to dental surgery. Journal of Consulting and Clinical Psychology, $1976 ; 5: 809-81.8$. 
Avia, M.D. Kanfer, F.H. Coping with aversive stimulation: the effects of training in elf-management. context. Cognitive Therapy Research, 1980; 1:73-81.

Beecher, H.K. Relationship of significance of wound to pain experienced. Journal of American Medical Association, 1956; 161:1609-1613. Beers, T.M. \& Karoly, P. Cognitive strategies, expectancy and coping style in the contral of pain. Journal of Consulting and Clinical Paychology, 1979; 1:179-180.

Benn, R.T. \& Hood, P.H.M. Pain in the back - an attempt to estimate the size of the problem. Rheumatological Rehabilitation, 1975; $14: 121-128$.

Blitz, B. \& Dinnerstein, A.J. Effects of different types of instructions on pain parameters. Journal of Abnormal Psychology, 1968; 3: $276-280$.

Blitz, B. \& Dinnerstein, A.J. Role of attentional focus in poin perception: manipulation of response to noxious stimulation by instructions. Journal of Abnormel Psychology, 1971; 1:42-45.

Block, A.R., Kremer, E.F. \& Gaylor, M. Behavioral treatment of chronic pain: the spouse as a discriminative cue for pain behavior. Pa in, 1980; $9: 243-252$.

Blumer, D. \& Heilbronn, M. The pain-prone disorder: a clinical and psychological profile. Psychosomatics, 1981; 5:395-402.

Blumetti, A.E., Modesti, L.M. Psychological predicturs of success or fallure of surgical intervention for intractible back pain. In: J.J. Bonica \& D. Albe-Fessard (eds.). Advances in pain research and therapy, 1976; 1:323-325, Raven Press, New York.

Boby, M.J. \& Davidson, P.O. The effects of vicarious and cognitive rehearsal on pain tolerance. Journal of Psychosomatic Research, $1971 ; 15: 329-335$.

Bonica, J.J. Untitled. In: Triengle, 1981; 20:1-6.

Bouchons, A.J. Recent developments in the classification of pain. Psychosomatics, 1985; 8:637-645.

Bouchons, A.J., Litman, R.E. \& Baer, L. Denial in the depressive and pain-prone disorders of chronic pain. In: Fields, H.L., Dubner, R., Cervero, F. (eds.): Advances in pain research and therapy. Proceedings of the Fourth World Congress on Pain, 1984. New York, Raven Press, 1985. 
Brown, T., Neniah, J.C. Barr, J.5. \& Berry, H. Psychologic faetors in low back pain. New England Journal of Medicine, 1954, 4:123-128.

Cailliet, R. (Ed). Low back pain symdrome. F.A. Davis Company, Philadelphia, 1981 .

Cairns, D. Pasino, J.A. Comparison of verbal reinforcement and feedback in the operant treatment of disability due to chronic low back pain. Behavior Therepy, 1977; 8:621-630.

Cairns, D., Thomas, L., Mooney, V. \& Blair Pace, J. A comprehensive treatment approach to chronic low back pain. Pain, 1976; 2: 301308.

Carlsson, A.H. Assessment of chronic pain I. Aspects of the reliability and validity of the visual analogue scale. Pain, 1983; 16:87-101.

Carlsson, A.H. Assessment of chronic pain. II. Problems in the selection of relevent questionnaire items for classification of pain and evaluation and prediction of therapestic effects. Pain, 1984; 19:173-184:

Carron, H., De Good, D.E. \& Tait, R. A comparison of low back pain patients in the United States and New Zealand: psychosocial and economic factors affecting severity of disability. Pain, 1985, 21:77-89.

Cautela, J.R. The use of covert conditioning in modifying pain behavior. Journal of Behavioral Therapy and Experimental Psychiatry, $1977 ; 8: 45-52$.

Chapnean, C.R., Sola, A.E. \& Bonica, J.J. Illness behavior and depression compared in pain center and private practice patienta. Pain, 1979, $6: 1-7$.

Chaves, J.F. \& Barber, T.X. Cognitive strategies, experimenter modeling, and expectations in the attenuation of pain. Jourinal of Abnormal Psychology, 1974; 4: 356-363.

Cohen, F. \& Lazarus, R.S. Active coping processes, coping dispositions and recovery from surgery. Psychosomatic Medicine, 1973; 5: 375389.

Cahen, M.J., Naliboff, B.D., Schandler, S.L. \& Helnrich, R.L. Signal detection and threshold measures to loud tones and redient heat. In chronic low back pain patients and cohort controls. Pain, 1983; $16: 245-252$. 
Collingwood, T.R. The effects of physical training upon behavior and aelf attitudes. Journal of Clinical Psychalogy, 1972; 28:583-585.

Craig, K.D., Beat, H. \& Reith, G. Social deteminanto of reports af pain in the absence of painful stimulation. Canadian Journal of Behavioral Science/Review Canadian Science Comp., 1974; 2:169-177.

Davidson, P.O. (ed.) The behavioral management of anxiety, depression and pain. Brunner, Mezel, New York, 1976.

Dowling, $J$. Autonomic meesures and behavioral indices of pain sensitivity* Pain, 1983; 16:193-200.

Duckro, P.N., Margolis, R. \& Tait, R. Psychological assessment in chronic pain. Journal of Clinical Psychology, 1985, 4:499-504.

Elton, D., Stanley, G.V. \& Burrows, G.D. Self-esteen and chronic pain. Journal of Psychosamatic Research, 1978; 22:25-30.

Engel, G.L. "Paychogenic" pain and the pain-prone patient. American Journal of Medicine, 1959; 26:899-918.

Farthing, G.W., Venturino, M. * Brown, 5.W. Suggestion and distraction in the control of pain: test of two hypotheses. Journal of Abnormal Psychollogy, 1984; 3:266-276.

Feather, N.T. \& Saville, M.R. Effects of amount of prior success and failure on expectations of success and subsequent. task performance. Journal of Personal and Social Psychology, 1967; 5, 2:226-232.

Fischer, R.I. Cognitive appraisal: an examination. Journal of Psychology, $1974 ; 88: 147-152$.

Flor, H. \& Turk, D.C. Etiological theories and treatments for chronic back pain. I. Somatic models and interwentions. Pain, 1984; 19: $105-121$.

Fordyce, W.E., Fowler, R.S., Lehmann, J.F., Delateur, B.J., Sand, P.L. \& Trieschmann, R.B. Operant conditioning in the treatment of chromic pain. Archives of Physical Medicine and Rehabilitation, 1973; 54:399-408.

Fordyce, W.E. (Ed). Behavioral methods for chronic pain and illness. The CV Mosby Company, St. Louis, 1976.

Fordyce, W.E. \& Steger, J.C. Chronic Pain. In: D.F. Pomerleau and J.P. Brady [eds.]: Behavioral Medicine: theory and practice. Williams and Wilkins, Balt timore, 1979. 
Fordyce, W.E. Environmental factors in the genesis of low back pain. In: J. Bonica, J. Liebeskind, D. Albe-Fessard (eds.). Advances in Pain Research and Therapy, 1979, 3:659-666, Raven Press, New York. Fordyce, W.E., McMahon, R., Rainwater, G., Jackins, S., Questad, K., Murphy, T. \& Delatyeur, B. Pain complaint - exercise performance relationship in chronic pein. Pain, 1981; 10:311-321.

Fordyce, W.E., Shelton, J. \& Dundore, D. The modificetion of avoidence learning in pain beheviors. Journal of Behavioral Medicine, 1982; 5: $405-414$.

Fordyce, W.E. Behavioral conditioning concepts in chronic pain. I $n$ : J.J. Bonica et al. (eds.): Advances in Pain Research and Therapy, 5, Raven Press, New York, 1983.

Fordyce, W.E., Lansky, D., Calsyn, D.A., Shelton, J.L., StoLow, W.E. \& Rock, D.L. Pain Measurement. and Pain Behavior. Pain, 1984; 18:5369.

Fardyce, W.E., Roberta, A.H. \& Sternbach, R.A. The behavioral management of chronic pain: a response to critics. Pain, 1985; 22:113125.

Freeman, C., Calsyn, D. \& Louks, J. The use of the Minnesota Multiphasic Personality Inventory with low back pain patients. Journal of Clinical Psychology, 1976; 2:294-298.

Garron, D.C., Leavitt, F. Demographic and affective covariates of pain. Paychomatic Medicine, 1979; 7:525-534.

Cottlieb, H., Strite, L.C., Koller, R., Madorsky, A., Hockersmith, V., Kleeman, M. * Wagner, Journal of Comprehenaive rehabilitetion of patients having chronic low back pain. Archives of Physical Rehabilitation, 1977; 58 : $101-108$.

Grimm, L. \& Kanfer, F.H. Tolerance of eversive stimulation. Behavior Therapy, 1976; 7:593-601.

Groenman, N.H. De rugpijnpatient bij de klinisch psycholoog. In: Kingma, M.J. \& Dokter, H.J. (Eds.): Rugpi.jn. Bohn, Scheltema en Holkema, Utrecht, 1985.

Groenman, N.H. Chronische pijnklachten. Tijdschrift voor Psychiatrie, $1985 ; 10: 710-717$.

Haanen, H.C.M. Een epldemiologisch onderzoek naar lage rugpijn (an epidemiological survey on law back pain). Dissertation, Rat,terdam, 1984 . 
Halfens, R.J.G. Locus of control. Beheersorientatie in relatie tot. zlekte- en gezondheidsgedrag. Proefschrift, Masstricht, 1985.

Hanvik, L.J. MMPI profillea in patients with low beck pain. Journal of Consultant. Psychology, 1951; 15:350-353.

Hartman, L.M. \& Alnsworth, K.D. Self regulation of chronic pain. Canadian Journal of Psychiatry, 1980; 25:38-43.

Haynes, S.A., Feinleb, M. * Kannel, W. The relationship of psychosocial factors to coronary heart disease in the Framingham Study. American Journel of Publical Health, 1980; 111:37-57.

Hemborg, B., Moritz, U., Hamberg, J. Intra-abdominal pressure and trunk muscle activity during lifting. III. Effect of abdominal muscle training in chronic low back pain patients. Scandinavian Journal of Rehabilitation Medicine, 1985; 17:15-24.

Hermans, H.J.M. Handleiding bij de Prestatie Motivatie Test (PMT). Swets en Zeitlinger, Amsterdam, 1968.

Hilgerd, E.R. The alleviation of pain by hypnosis. Pain, 1975; 1:213231.

Hines, E.A. Technic of the cold pressor test. Proc. staff Meet, Mayo Clinic, 1939, March; 22:185-187.

Holroyd, K.A., Andrasik, F. \& Westbrook, T. Cognitive control of tension headache. Cognitive Therapy Research, 1977; 2:121-133. Horan, J.J., Hackett, G., Buchanan, J.D., Stone, C.J. \& Demchik-5tone, D. Coping with pain: component analysis of stress inoculation. Cognitive Therapy Regearch, 1978; 3:211-221.

Hult, L. Cervical, dorsal and lumbal spinal syndromes. Acta Orthopaedice Scandinavica, $1954 ; 17: 5-100$.

Huskisson, E.C. Measurement of pain. The Lancet, 1974, November, 9: $1127-1131$.

Jaremko, M.E. Cognitive strategies in the control of pain talerance.

J. Behav. Ther. and Exp. Psychiot., 1978; 9:239-244.

Jeans, M.E., Stratford, J.C., Melzack, R. Monks, R.C. Assessment of Pain. Can. Fam. Physician, 1979; 25:159-162.

Johneon, J.E. Effects of accurate expectations about sensations on the sensory and distress components of pain. J. Pers. Soc. Psychol., $1973 ; 27: 261-275$. 
Johnson, J.E., Leventhal, H. Effects of accurate expectations and behavioral instructions on reactions during a noxious medical examination. Journal of Personality and Social Psychology, 1974; 5: $710-718$.

Joyce, C.R.B., Zutshi, D.W., Hrubes, V. \& Mason, R.M. Compariaon of fixed interval and visual analogue sceles for rating chronic pain. Jourral unknown, 1975.

Kanfer, F.H. \& Goldfoat, D.A. Self-contral and tolerance of noxious stimulation. Psychological Reports, 1966; 18:79-85.

Kanfer, F.H. \& Seidner, M.L. Self-control: factors enhancing tolerance of noxious stimulation. Journal of Personality and Social Psychom logy, 1973; 3: 381-389.

Krishnen, K.R.R., France, R.D. \& Houpt, J.L. Chronic low back pain and depression. Psychosometics, 1985; 4:299-302.

Lankhorst., G.J., Stadt. v.d. R.J. \& Korst v.d. J.K. The natural history of idiopathic low back pain. Scandinavian Journal of Rehabilitation Medicine, 1985; 17:1-4.

Latimer, P.R. External contingency management for chronic pain: critical review of the evidence. American Journal of Psychiatry, 1982; 10: $1308-1312$.

Leavitt, F., Garron, D.C., Whistler, W.W. \& Sheinkop, M.B. Affective and sensory dimensions of back pain. Pain, 1978, 4:273-281.

Leavitt, F., Garron, D.C. Validity of back pain classification scale for detecting psychological disturbance as meesured by the MMPL. Journal of Clinicel Psychology, 1980; 1:186-189.

Lefebvre, M.F. Cognitive distortion and cognitive errors in depressed paychiatric and low back paln patienta. Journal of Consulting and Clinical Psychology, 1981; 4:517-525.

Liebeskind, J.C. \& Paul, L.A. Paychological and physiological mechanisins of pein. Annual Review of Paychology, 1977; 28:41-60.

Linden, A.J. v.d. Over de warde van röntgenonderzoek bij lage rugpijn. Tijidschrift voor Sociale Geneeskunde, 1978; 56:838-841.

Lindequist, S., Lundberg, B., Wikmark, R., Bergstad, B., Loöf, G. \& ottermark, A. Information and regime at low back pain. Scandinavian Journal of Rehabilitetion Medicine, 1984; 16:113-116. 
Lloyd, G.G., Wolkind, S.N., Greenwood, R. \& Harris, D.J. A psychietric etudy of patients with persistent. Low back pain. Rheumatological Rehabilltation, 1979; 18: 30-34.

Luteijn, F. Starren J. \& van Dijk, H* Nederlandse Persoonlijkheidsvragenlijst. Swets \& Zeitlinger B.V. Ansterdam, 1974.

Meruta, T., Swanson, D.W. Swenson, W.M. Pain as a psychiatric sympton: comparison between low back pain and depression. Psychosomatlcs, $1976,17: 123-127$.

Maruta, T., Swanson, D.W., Swenson, W.M. Chronic Pain: which patients may a pain management program help? Pain, 1979; 7:321-329.

Merzillier, J.5. Cognitive therapy and behavioral practlice. Behavior Research and Therapy, 1980; 18:249-258.

McCaughan: Stability/instability and chenge of expectancy, a test for cognitive determinants of psychomotor performance. Perceptual and Motor Skills, 1978; 46:219-225.

McCaul, K.D. \& Haugtvedt, C. Attention, distraction and cold-pressor pain. Journal of Personality and Social Psychology, 1982; 43, 1: 154-162.

McCreary, C., Turner, 3. \& Dawson, E. Differences between functional versus organic low back pain patients. Pain, 1977; 4:73-78.

McCreary, C., Turner, J. \& Dawson, E. Principal dimensions of the pain experience and psychological disturbance in chronic low back pain patients. Pain, 1981; 11:85-92.

McCreary, C. Locus of control, repression-sensitization and psychological disorder in chronic pain patients. Journal of Clinical Psychology, 1984; 4:897-901.

MoGill, C.M. Industrial back problems. Journal of Dccupational Medicine, $1968 ; 4: 174-178$.

Meichenbaum, D. \& Turk, D.C. The cognitive-behavioral management of anxiety, anger and pain. In: P.O. Davidson (Ed.): The behavioral management of anxiety, depression and pain. Brunner-Mazel, New York, 1976.

Meichenbaum, D.H. Cognitive behavior modification. Plenum, New York, 1977. 
Melling, G., Järvikoski, A. \& Verkaselo, M. Treatment of patients with chronic low back pain. Comparuson between rehabilitation centre and outpatient care. Scandinavian Journal of Rehabilitation Medicine, $1984 ; 16: 77-84$.

Melzack, R. \& Wall, P.D. Pain mechanisms: A theory. Science, 1965; 150: $971-979$.

Melzack, R. The Puzzle of pain, Penguin, Hammondsworth, 1973.

Mettee, D.R. Rejection of unexpected success as a function of the negative consequences of accepting success. Journal of Personelity and Social Psychology, 1971; 3:332-341.

Morgan, W.P., Horatman, D.H., Cymermen, A. \& Stokes, J. Facilitation of physical performance by means of a cognitive strategy. Cognitive Therapy Research, 1983; 3:251-264.

Murray, J.B. Psychological aspects of low back pain. Psychaloglical reports, 1982; 50:343-351.

Nachemson, A.L. Low back pain. Its etiology and treatment. Clinioical Medicine, 1971; 78:18-24.

Nachemson, A.L. Towards a better understanding of low back pain: A review of the mechanics of the lumbar disc. Rheumatologic Rehabi1itation, 1975; 14: 129-143.

Nachemson, A.L. A critical look at the treatment for low back pain. Scandinavian Journal of Rehabilitation Medicine, 1979; 11:143-149. Naliboff, B.D., Cohen, M.J. \& Yellen, A.N. Does the MMPI differentiate chronic illness from chronic pain? Pain, 1982; 13:333-341.

Neufeld, R.W.J. \& Davidson, P.O. The effects of vicarious and oognitive rehearsal on pain tolerance. Journal of Paychosomatio Research, 1971; 15:329-335.

Newman, R.I., Painter, J.R. \& Seres, J.L. A therapeutic milieu for chronic pain patients. Journal of Human Stress, 1978, june, 8-12.

Ohnhaus, E.E. \& Adler, R. Methodological problems in the measurement of pain: a comparison between the verbal rating scale and the visual analogue scale. Pain, 1975; 1:379-384.

Oostidam, E.M.M. Voorspelbaerheld van het operatie-resultaat bij patienten met lage rugpijn. Academisoh proefschrift, Rotterdam, 1982. 
Pichŏt, P., Perse, J., Lebeaux, 14.0., Duresu, J.L., Perez, C.L. \& Ryckewart, A. La personnalité des sujets presentant des douleurs dorales fonctionnelles valeur de $L^{\prime}$ inventiare multiphasique de personal du Mimnesota (MMPI). Revue Psychol. Appl., 1972; 22: 145-172.

Pilowski, I. Dimensions of hypochondriasis. Britiah Journal of Psychiatry, 1967, 113:89-93.

Pilowski, I* \& Spence, N.D. 11 lness behavior syndromes associated with intractible pain. Pain, 1976; 2:61-71.

Pangratz, J. Leitsymptom: Wirbelsgulenschmerzen. Eine psychosomatische 5tudie. Zeitschrift Psychosomatische Medizin, 1980; 26:12-39.

Price, D.D., McGrath, P.A., Rafii, A. \& Buckingham, B. The validation of viauel anelogue scales as ratio scale measures for chronic and experimental pain. Pain, 1983; 17:45-56.

Prieto, E.J., Hopson, L., Bradley, L.A., Byrne, M., Geisingerk, Midax, D. * Marchisello, P. The language of low back pain: factor structure of the MoGill Pain Questionnaire. Pain, 1980; 8:11-19.

Reading, A.E. A comparison of pain rating scales. Journal of Psychosomatic Research, 1980; 24:119-124.

Riemer, B.5. Influence of causal beliefs on the affect and expectancy. J. Person. Soc. Psychol., 1975; 6:1163-1167.

Roberts, A.H. \& Reinhardt, L. The behevioral managenent of chronic pain: long-term follow-up with comparison groups. Pain, 1980; 8: $151-162$.

Rosenbeum, M. Individuel differences in self-control behaviors and tolerance of painful stimulation. Journal of Abnormal Psychology, $1980 ; 4: 581-590$.

Rasenstiel, A.K. \& Keefe, F.J. The use of coping strategies in chronic low back pain patients: relationship ro patient characteristics and current adjustment. Pain, 1983; 17:33-44.

Rotter, J.B. Generallzed expectancies for internal versus external control of reinfarcement. Psychological Monographes, 1966, 1.

Rybatein-Blinchik, E. Effects of different cognitive strategies on chronic pain experience. Journal of Behavior Medicine, 1979; 1: 93-100. 
Rybstein-Blinchik, E., Grzesiak R.C. Reinterpretative cognitive strategies in chranic pain management. Archives of Physical and Medical Rehabilitation, 1979; 60:609-612.

Ryckman, R.M., Rodda, W.C. Confidence maintenance and performance as a function of chronic self-esteem and initial task experience. The Psychological Record, 1972; 22:241-247.

Schmidt, A.J.M. Cognitive factors in the performance level of chronic low back pain patients. Journal of Psychosonatic Research, 1985; 2:183-18.9.

5chmidt, A.J.M. Performance level of chronic low back pain patients in different treadmill test conditions. Journal of Psychosomatic Research, 1985; 29:639-645.

Schmidt, A.J.M., Brands, A.E.F. Persilstence behevior of chronic low beck pain patients in an acute pain situation. Journel of Psychosomatic Research 1986; 3:339-346.

Seres, J.L. \& Newmen, R.I. Results of treatment of chronio low back pain at the Portland Pain Center. Journal of Neurosurgery, 1976; 45: $32-36$

Skevington, S.M. Chronic pain and depression: universal or personel helplessness? Pain, 1983; 15:309-317.

Skevington, 5.M. Activities as indices of illness behaviour in chronic pain. Pain, 1983; 15:295-307.

Skinner, B.F. The behavior of organiams. Appleton-Century-Crofts, New York, 1938.

Skinner, B.F. Science and human behavior. McMillan, New York, 1953.

Spanos N., Hortion C. \& Chaves J.F. The effects of two cognitive atrategies on pain threshold. Journal of Abnormal Psychology, 1975; $6: 677-681$.

Spanos N.P., MCNeil C., Giwynn M.I. \& Staln H.I. Effects of suggestion and distraction on reported pain in subjects high and low on hypnotic susceptibility. Journal of Abnormal Psychology, 1984; 3: $277-284$.

Staub, E. \& Kellet.t, D. Increasing pain tolerance by information about. aversive stimuli. Journal of Personality and Social Pgychology, $1972 ; 2: 198-203$. 
Sternbach, R.A. \& Rusk, T.N. Alternatives to the pain career. Psychotherapy: Theory, Research and Practice, 1973; 10:321-324.

Sternbach, R.A., Wolf, 5.R., Murphy, R.W. \& Akeson, W.H. Traits of pain patlents: the Low back "loser". Psychosomatics, 1973, 14:226229.

Sternbach, R.A. Pain patients, Traits and Treatment. Academic Press, New York, 1974.

Sternbach, R.A. \& Timmermans G. Personality changes associated with reduction of pain. Pain, 1975; 1:177-181.

Sterribach, R.A. Fundamentals of psychological methods in chronic pain. In: Bonice J.J. et. al. (eda.) Advances in pain research and therapy, 5, Raven Press, New York, 1983.

Swanson, D.W., Swenson, W.M., Maruta, T. \& McPhee, M.C. Program for managing chronic pain I. Program deacription and characteristics of patients, Mayo Clinic Proceedings, 1976; 51:401-408.

Swanson, D.W., Floreen, A.C. \& Swenson, W.M. Program for managing chronic pain II. Short-term results, Mayo Clinic proceedings, $1976 ; 51 ; 409-411$.

Swanson, D.W., Maruta, T. \& Swenson, W.M. Results of behavior modification in the treatment of chronic pain. Psychosomatic Medicine, 1979; 1:55-61.

Swenson, W.M. Psychological correlates of medical illiness. Psychosomatics, 1981 ; $22: 384-391$.

Tan, S.Y. Cognitive and cognitive-behavioral methods for pain contral: a selective review. Pain; 1982; 12:201-228.

Toomey, T.C., Gover, V.F. \& Jones, B.N. Spatial distribution of pain: a descriptive characteristic of chronic pain. Pain, 1983; 17:289300 .

Turk, D.C. Coping with pain: a review of cognitive control techniques. In: Feuergtein: Psychological appraoaches to pain control, 1982.

Turk, D.C., Meichenbaum, D. \& Genest, M. Pain and behavioral medicine. A cognitive behavioral perspective. Guilford Press, New York, 1983.

Turk, D.C. \& Flor, H. Etiological theories and treatments for chronic back pain. II. Psychollogical models and interventions. Pain, 1984; 19: 209-233. 
Turner, J.A., \& Chapman, C.R. Psychological interventions for chronic pain: a critical review. I. Relaxation training and biofeedback. Pain, 1982; 12:1-21.

Turner, J.A. \& Chapman, C.R. Psychological interventions for chronic pain: a critical review. II. Operant conditioning, hypnosis and cognitive-behawioral therapy. Pain, 1982; 12:23-46.

Valkenburg, H.A. \& Haanen, H.C.M. The epidemiology of low back pain. In: White, A.A. \& Gordon, S.L. (eds.): Symposium on idiopathic low back pain. St. Louis: Cy Mosby Co, 1982; 9-22.

Vailfors, B. Acute, subacute and chronic low back pain: Cilnical symptoms, absenteeism and working environment. Scand. J. Rehab. Med., 1985; supplement. no.11.

Verkes, R.J. \& Megchelen van, P.J. Nek- en rugpijn bij gevoelens van agressie en ormacht. Huisarts en Wetenschap, 1985; 25:331-334.

Wall, P.P. On the Relation of Injury to Pain. Pain, 1979, 6:253:264.

Walsh, T.D. \& Leber, B. Meesurement of chronic pain: Visual Analog Scales and McGill Melzack Pain Questionnaire Compared. From: Advances in Pain Research and Therapy, 5, ed. by John J. Bonica et. al., Raven Press, New York, 1983.

Heinberg, R.S., Gould, D. \& Jackson, A. Cognition and motor performance: effect of psyching-up strategies on three motor tasks. Cognitive therapy and research, 1980; $2: 239-245$.

Weiner, B., Nierenberg, R. \& Goldstein, M. Social learning (locus of control) vs attributional (causal stebility) interpretations of expectancy of success. Journal of Personality, 1976; 44:52-68.

Weiner, B. Achievement Motivation and Attribution theory. General Learning Press, Morriston N.J., 1974.

White, B. \& Sanders, S. Differential effects on pain and mood in chronic pain patients with time - versus pain - contingent medication delivery. Behavior Therapy, 1985; 16:28-35.

Woodforde, J.M. \& Merskey, H. Some relationships between subjective measures of pain. Journal of Psychosomatic Research, 1972; 16: $173-178$.

Zimberdo, P.G., Cohen, A.R., Weisenberg, M., Dworkin, L. \& Fireston, I. Control of pain motivation by cognitive dissonance. Soience, $1966,151: 217-219$. 
$-138-$ 
DANKWOORD

Een belangrijk thema van dit. proefschrift gaat over volhouden en doorzetten. Het is niet alleen voor de hand liggend, maar ook julst dat dit onderwerp eveneens een grote rol heeft gespeeld bij de totstandkoming ervan. Chronische pijn boeit mij al vele jaren als bron van studie en interesse, maar pas sinds enige jaren werd mijn behoefte om zelf wetenschappelijk onderzoek te gaan doen, steeds groter. Voor het groeien van deze interesse - een onomikeerbear proces - ben ik anderen erkentelijk.

Allereerst mijn promotor, prof. dr. J. Bremer. Beste Joost, darik zij jouw valhoud-gedrag heb je tenslotte gedaen gekregen, dat: mijn aanwankelijke weerzin tegen vele zaken die te maken hebben met status en diplona's in dit opzicht is ongebogen tot een nag lang niet afgerond stuk wetenschappelijk onderzoek, waar ik volkomen achter sta en warvan de neerslag, in de vorm van deze promotie, mij veel voldoening geeft. Uiteraard bedank ik je ook voor de aandecht die je als promotor hebt besteed aen het doornemen en bespreken van het manuscript.

Wat dit laatgte betreft, bedank ik ook de referenten, prof: dr. A. van der Linden, prof. dr. L. Menges en prof. dr. R. Reneman, die Leder vanuit zeer uiteen lopende vakgebieden - eigen aan het onderwerp ohronische pijn - het manuscript voorzagen van commentear.

Een grote, inhoudelijke stimulans ging uit van het deelproject "Experimentele Paychopathologie:. De voortreffelijke organigatie ervan Joor dr. M. Beekers en daarnaat de stimularende inbreng van met name dr. M. van den Hout hebben angetwijfeld een positieve invloed gehad op mijn motivatie tot dit onderzoek.

Bij de uitvaering van de studiea zijn anderen behulpzeam, belangrijk, respectievelijk onmisbaer geweest. In de leatste categorie behoort ongetwijfeld mevr. R. Gierlings. Beste Riet, de wijze warap jij in de afgelopen jaren aan het onderzoek hebt gewerkt, gaf mij het prettige gevoel datt ik veel zaken, die met voorbereiding en uitvoering te maken hadden, rustig - zelfs beter - aan jou kon overlaten. Door jouw grote neuwkeurigheid en voortreffelijke organisatie verliep het onderzoek zelf magenoeg vlekkeloos. Ik wil je hiervoor heel hartelijk bedanken. Een groot gedeelte van de onderzoeken vand plat.s in het laboratorium voor inspanningsfyaiologie. Ik bedank dr. F. Veratappen, dr. H. Kul- 
pers en dr. H. Keizer voor hun bereidheid en inspanningen om in hun aportlab een plaats in te ruimen voor psychologisch onderzoek, hetgeen ook van hen de nodige aanpassing vergde. P. Geurten bedank ik in het bijzonder voor zijn deskundige voorbereiding en advisering bij de protocollen, die daardoor gteeds weer zonder storingen konden worden gedraaid. Voor zover de onderzoeken verliepen in het gedragswetenschappelijk laboratorium, wil ik hiervoor ook G. van Wunnik bedanken.

Dok anderen droegen hun ateentje bij aan het goede verloop van de experimenten. Ik denk dan aan $\mathrm{S}$. Wijnen en de capaciteitsgroep Huisartsgeneeskunde voor de medische begeleiding van de experimenten en aan de capaciteitsgroepen Orthopaedie en Neurologie, die zorgden voor een aantal chronische lage rugpijnpatienten.

Alle proefpergonen - rugpijin en niet rugpijnpetienten - bedank ik voor hun deelname aan het onderzoek, warin ze zich belangeloos - maar in naam van de wetenschap! - behoorlijk moesten afpeigeren.

De beide co-auteurs, drs. A. Brands en drs. M. de Heus-van Putten, bleken bereid om zich enige tijd geheel wrijwillig bezig the houden met chroniache pijjnklachten. AnneMieke en Margreet, als mede-uitvoerders van deel-onderzoeken werden jullie getrakteerd op piekbelestingen en werken in de avonduren. Voor jullie volhoudgedrag hierbij mijn erkentelijkheid.

Voor de deskundige en efficiente ondersteuning bij de verwerking var de onderzoekresultaten bewees J. van Houtem (in hoeveel praefschriften is hij intussen al bedankt?) wederom zijn zeer gewardeerde diensten. De typografie berustte bij I. van Noppen in snelle en vaardige handen. Beste Isel, je hebt stapels schrijfsel verwerkt tot dit boekwerkje en dat in een fabelachtig tempo en met een voorbeeldige instelling. Bedanikt voor de fijne samenwerking.

Vormgeving-adviezen werden verstrekt door 5. Sweerus, terwij1 B. Meerstad de druk verzorgde. De vertaling werd verzorgd door mevr. M. Sanders.

Tenslotte: het ontwerp van de omslag werd gemaakt door mijn vrouw Hannie, die dearmee voor $\mathrm{mij}$ het proefschrift en voor hasrzelf een nieuw perspectief opent.

\section{A.J.M. Sohmidt.}

November 1986 


\section{CURR ICULUM VITAE}

De schrijver van dit proefschrift werd geboren op 24 oktober 1946 te Den Haag. Hij behaalde het HBS-b diploma in 1965 aan het. St. Jans college aldaar. In 1967 begon hij met zijn universitaire studie aan de subfaculteit psychologie van de Rijksuniversitteit Leiden. Het doctoraal examen werd gehaald in 1973 met als hoofdvak klinische psychologie en als bijuak psychiatrie.

Sinds 1974 is hij als wetenschappelijk medewerker verbonden arin de capaciteitsgroep Medische Psychologie van de Rijksuniversiteit. Limburg (Prof. dr. J.J.C.B. Bremer). 